\title{
REACTION MECHANISMS
}
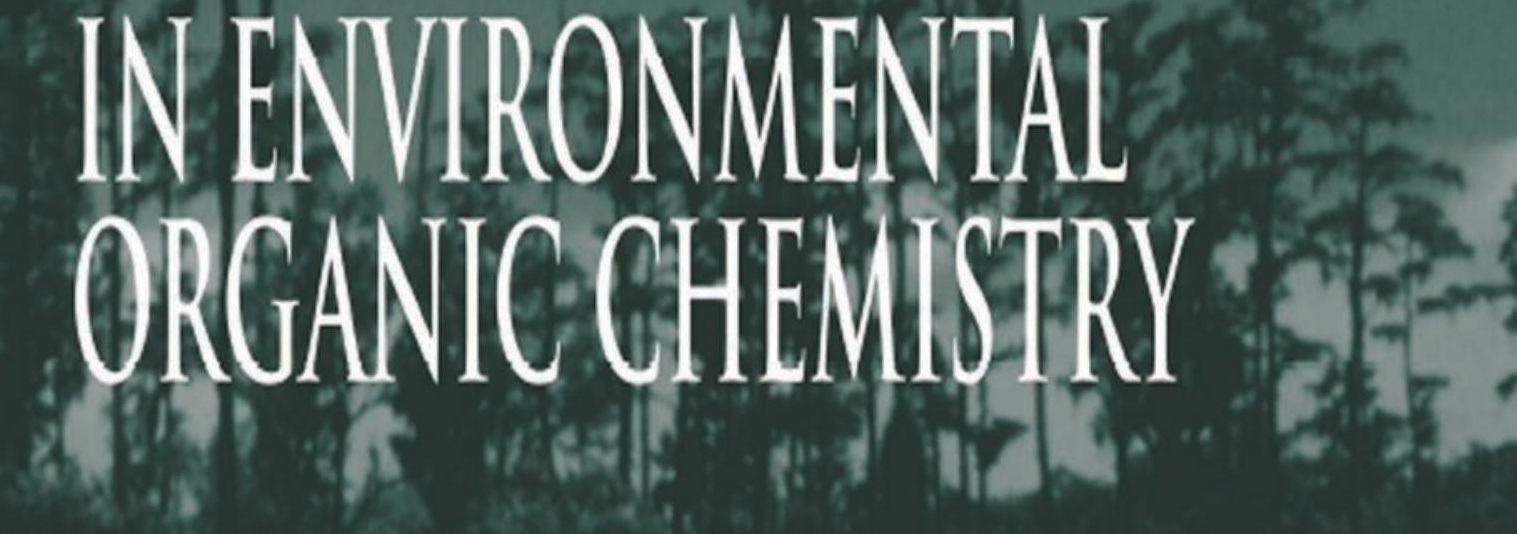

\section{Richard A. Larson}

Eric J. Weber

1) LEWIS PUBLISHERS 

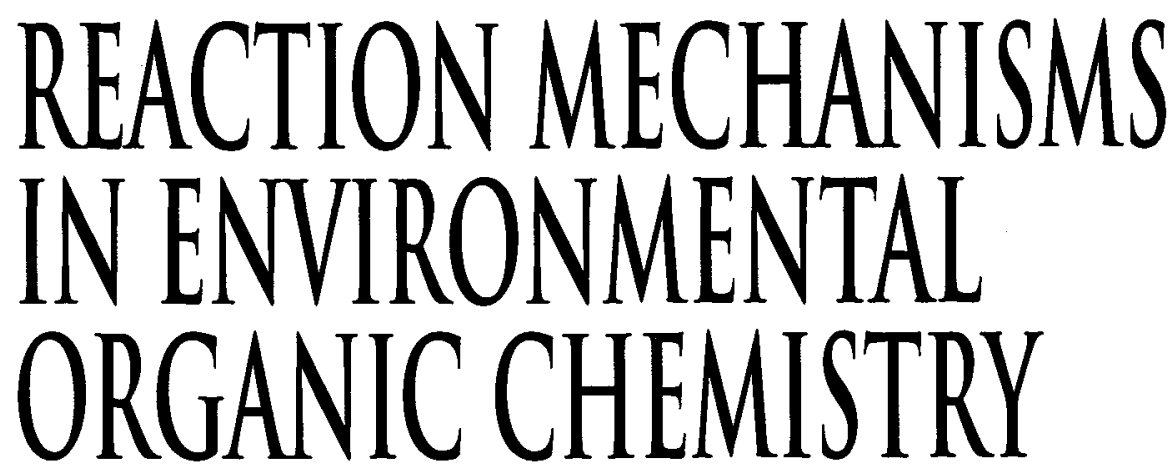

Richard A. Larson

Eric J. Weber

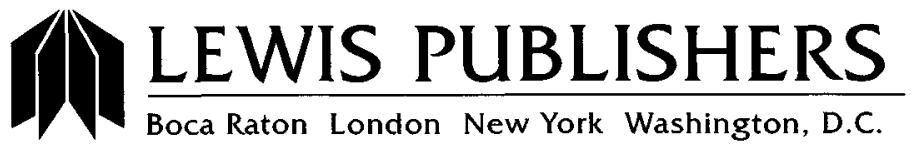




\section{Library of Congress Cataloging-in-Publication Data}

\section{Larson, Richard A.}

Reaction mechanisms in environmental organic chemistry / Richard A. Larson and Eric J. Weber p. $\mathrm{cm}$.

Includes bibliographical references and index.

ISBN 0-87371-258-7

1. Organic compounds - Environmental aspects. 2. Environmental chemistry. 3. Chemical reactions. I. Weber, Eric J. II. Title.

TD196.073L37 1994

$628.5-\mathrm{dc} 20$

$93-1622$

This book contains information obtained from authentic and highly regarded sources. Reprinted material is quoted with permission, and sources are indicated. A wide variety of references are listed. Reasonable efforts have been made to publish reliable data and information, but the author and the publisher cannot assume responsibility for the validity of all materials or for the consequences of their use.

Neither this book nor any part may be reproduced or transmitted in any form or by any means, electronic or mechanical, including photocopying, microfilming, and recording, or by any information storage or retrieval system, without prior permission in writing from the publisher.

The consent of CRC Press LLC does not extend to copying for general distribution, for promotion, for creating new works, or for resale. Specific permission must be obtained in writing from CRC Press LLC for such copying.

Direct all inquiries to CRC Press LLC, 2000 N.W. Corporate Blvd., Boca Raton, Florida 33431.

Trademark Notice: Product or corporate names may be trademarks or registered trademarks, and are used only for identification and explanation, without intent to infringe.

Visit the CRC Press Web site at www.crepress.com

(1) 1994 by CRC Press LLC

Lewis Publishers is an imprint of CRC Press LLC

No claim to original U.S. Government works

International Standard Book Number 0-87371-258-7

Library of Congress Card Number 93-1622 
RAL:

To the memory of James Wright

1928-1980

Poet, educator, sage

Morir com'esso, ma morir segundo te.

EJW:

To my wife, Jodi, and children, Joel and Sarah, for their love, support and patience during the writing of this book, and to my chemistry mentors, Dr. Christopher J. Dalton at Bowling Green State University and Dr. Scott E. Denmark at the University of Illinois, who provided me with a fundamental education in organic chemistry. 
$\because$ Taylor \& Francis

Taylor \& Francis Group

http://taylorandfrancis.com 


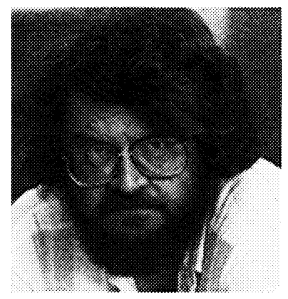

Richard A. Larson (BA, Chemistry, University of Minnesota, 1963: PhD, Organic Chemistry, University of Illinois, 1968) has had extensive research experience over the past $20+$ years in the area of environmental chemistry. He has been author or coauthor of well over 100 papers, presentations, and reports in this period, including over 70 peer-reviewed manuscripts. In addition, he is the author, coauthor, or editor of three books.

After postdoctoral appointments at Cambridge University and the University of Texas, Dr. Larson worked for several years at the Academy of Natural Sciences of Philadelphia. Since 1979, when he joined the faculty of the Institute for Environmental Studies at the University of Illinois, Dr. Larson has held a joint appointment in the University's Department of Civil Engineering. During the academic year 1985-1986, he studied free radical reactions in water as a National Research Council senior fellow in collaboration with Dr. Richard Zepp at the U.S. Environmental Protection Agency research laboratory in Athens, Georgia.

Dr. Larson has worked principally in the specific research areas of environmental photochemistry (kinetics, mechanisms, and products of light-induced reactions of environmental significance), disinfectant chemistry (ozone, chlorine, and chlorine dioxide and their reactions with organic compounds), and natural product chemistry. He is especially interested in the reactions of polar organic compounds of potential environmental health significance. 


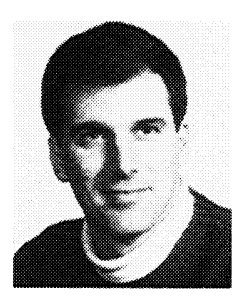

Eric J. Weber (BS, Chemistry, Bowling Green State University, 1980; PhD, Organic Chemistry, University of Illinois, 1985) received his initial training in synthetic and physical organic chemistry. During his $\mathrm{PhD}$ program he developed an interest in environmental chemistry after taking a course from his current coauthor, Dr. Richard Larson, focusing on the fate of organic chemicals in aquatic ecosystems. Upon completion of his PhD, Dr. Weber furthered his training in environmental chemistry as a Research Associate with the National Research Council at the U.S. Environmental Protection Agency research laboratory in Athens, Georgia. In 1986, he joined the staff at the Athens laboratory as a Research Chemist. Dr. Weber's research has focused on transformation pathways of organic chemicals at the sediment-water interface with a primary emphasis on the identification of reaction products. He has also developed an interest in elucidating the reaction mechanisms by which organic chemicals form covalent bonds with natural organic matter. 
Environmental organic chemistry is a rapidly expanding subject and one that allows many perspectives. Environmental chemistry historically grew out of analytical chemistry and the ability of analytical chemists to detect very low concentrations of pollutants, especially chlorinated organic compounds, in complex matrices such as soils, atmospheric particles, and animal tissues. The discovery that such pollutants are transported throughout the world, and that some are highly persistent in the environment, led to increasing interest in the fates of such compounds in nature.

The physical and chemical factors that govern the transport of organic compounds in the environment have been intensely studied. Thanks to the work of Sam Karickhoff, Donald Mackay, Cary Chiou, Louis Thibodeaux, and many others, we now have a group of sophisticated modeling tools with which to investigate the movement of organic materials within and between various environmental compartments - air, water, soils and sediments, and biota. Organic reactions that transform particular chemicals into by-products, however, have received less attention. There are several reasons for this. First of all, most investigations of organic chemical reactions have been performed in the absence of water. Rigorous procedures for the exclusion of moisture, and often, oxygen from reaction mixtures are commonplace in the organic laboratory. Secondly, organic reactions can be extremely complex. Even in purified solvents using carefully controlled conditions, many products can be formed whose identification may tax the ingenuity of the investigator. Finally, in many environmental situations, readily identified organic compounds are present only in extremely small concentrations in the presence of a complex matrix. In order to study the fate of pollutants under these conditions, early practitioners of environmental organic chemistry found it difficult enough merely to determine the rates of disappearance of their substrates, let alone to determine the mechanisms and products of the reasons that they were undergoing.

Recent years have seen an expansion of interest in studying organic reactions under environmental conditions. Many studies have shown that the environmental alteration products of some organic molecules are much more hazardous than their precursors; for example, treatment of natural waters with chlorine causes potentially 
toxic or mutagenic organochlorine compounds to be formed. Moreover, a general curiosity about how the global environment functions has led to a desire for intellectual re-examinations of fundamental scientific issues, such as the carbon cycle and the effects of human activities on it. To acquire this fundamental knowledge, it is necessary that we understand the forces that drive these global processes. As a consequence, many scientists throughout the world are turning their attention to investigating some well-known chemical reactions in detail, with an eye to being able to use the knowledge gained to predict the fates of unknown synthetic chemicals that may be released in significant concentrations in the future.

It is the purpose of this book to assist this process by giving an overview of the environment, of the principal organic chemical species in it, and of the processes and reactions that tend to transform these species. The organization of the book features, first, an introductory chapter that lays out the three principal environmental compartments - air, water, and solid phases - and surveys the conditions found in each of them that tend to promote chemical reactions. The remainder of the book is a survey of the principal types of organic reactions that may occur under environmental conditions, with discussions of the particular structural features of organic molecules that may make them more or less susceptible to each type of reaction. Chapter 2 deals with hydrolyses and nucleophilic reactions, with many examples chosen from the literatures of pesticide chemistry, industrial chemistry, and physical organic chemistry. Chapter 3 covers reduction, a process that until recently has been neglected from an environmental perspective, but one that is being shown to be an increasingly important route for converting many compounds once thought to be "persistent" to products. Oxidation, the subject of Chapter 4, takes place in a range of environments from the upper atmosphere to the surfaces of sediments, and encompasses a plethora of oxidizing agents, from transient free radicals with lifetimes of microseconds to mundane minerals such as iron oxide. In Chapter 5, disinfection is addressed; these reactions and their projects are the subjects of public debate in virtually every community where water treatment is practiced. Sunlightinduced reactions are covered in Chapter 6 , on photochemistry. These reactions are also sure to come under increasing scrutiny, as the world tries to adjust to life under a different regime of solar energy, featuring higher levels of short, energetic UV-B wavelengths. Finally, Chapter 7 introduces a few other reactions that do not fit under the previous categories, but nevertheless could be significant for the fates of many classes of compounds.

The production of this book has been the outcome of many hours of discussions over the years. The two coauthors have learned a great deal from each other as well as from our many colleagues, students, and friends. An incomplete list of the most important people to whom we owe debts of gratitude would include Mike Barcelona, Michael Elovitz, Bruce Faust, Chad Jafvert, Karen Marley, Gary Peyton, Frank Scully, Alan Stone, Paul Tratnyek, Lee Wolfe, Ollie Zafiriou, and Richard Zepp. Invaluable help with the manuscript was provided by Jean Clarke, Tori Corkery, Jennifer Nevius, and Heather Walsh. Finally, special thanks are due to the students of Environmental Studies 351 at the University of Illinois, who have provided indispensable suggestions about the subject matter of this book over the years. 


\section{CONTENTS}

\section{Chapter}

1: ORGANIC CHEMICALS IN THE ENVIRONMENT $\ldots \ldots \ldots \ldots \ldots \ldots \ldots 1$

Environmental Fates of Organic Chemicals .................. 1

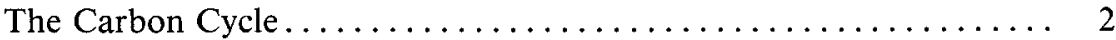

Translocation of Organic Chemicals ................ 7

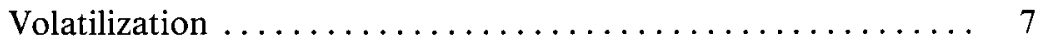

Transport Within the Aqueous Phase .............. 9

Partition into Solid Phases . . . . . . . . . . . . . . . 10

Transformation of Organic Compounds ................. 14

Reaction Mechanisms ....................... 14

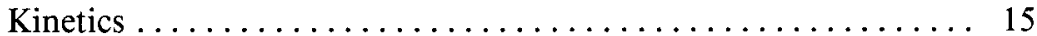

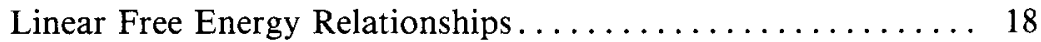

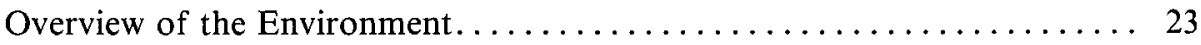

The Troposphere and the Stratosphere $\ldots \ldots \ldots \ldots \ldots \ldots \ldots \ldots \ldots 23$

The Thermal Structure of the Atmosphere ........... 24

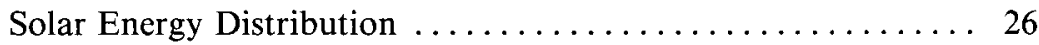

Chemical Constituents and Their Reactions ............. 28

Natural Waters ... . . . . . . . . . . . . . . . . . . . . . . . . 36

Water as Solvent and Reactant ................ 37

Marine Waters and Estuaries................... 41

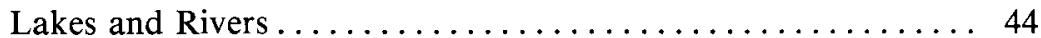

The Air-Water Interface: The Surface Microlayer . . . . . . . . 46

Groundwater ........................ 51

Organic Matter in Aquatic Environments ............ 52

Solid Phases............................... 60

Soil Structure ....................... 60

Aquatic Sediments........................... 63

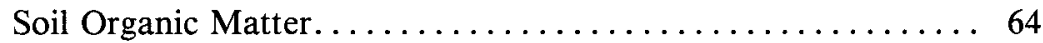

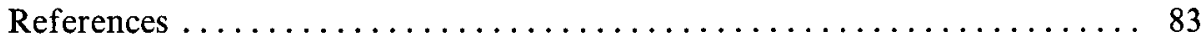




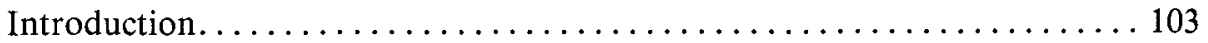

Hydrolysis Kinetics................................. 105

Specific Acid and Base Catalysis ........................... 105

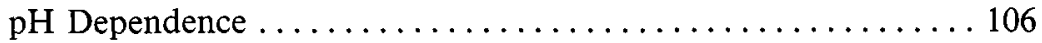

Hydrolysis Reaction Mechanisms........................ 107

Nucleophilic Substitution............................. 107

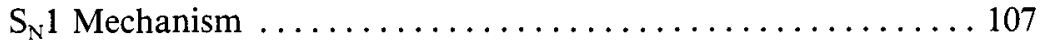

$\mathrm{S}_{\mathrm{N}} 2$ Mechanism ................................... 108

Functional Group Transformation by Nucleophilic Substitution

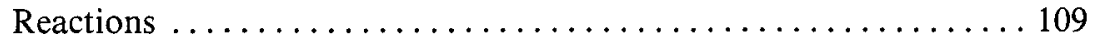

Halogenated Aliphatics........................... 109

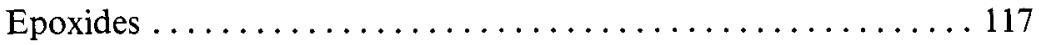

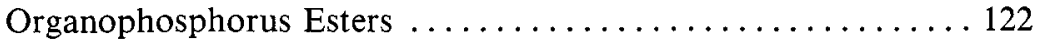

Nucleophilic Acyl Substitution ....................... 124

Addition-Elimination Mechanism................... 124

Functional Group Transformation by Nucleophilic Acyl

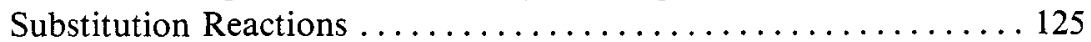

Carboxylic Acid Derivatives ......................... 125

Carbonic Acid Derivatives........................ 132

Other Nucleophilic Substitution Reactions................... 136

Reactions with Naturally Occurring Nucleophiles ............ 136

Nucleophilic Reactivity........................ 137

Reactions of Sulfur-Based Nucleophiles with Halogenated Aliphatics. 140

Neighboring Group Participation (Intramolecular Nucleophilic

Displacement) .............................. 143

Catalysis of Hydrolytic Reactions in Natural Aquatic Ecosystems ....... 145

General Acid and Base Catalysis . . . . . . . . . . . . . . . . . 146

Metal Ion Catalysis............................... 147

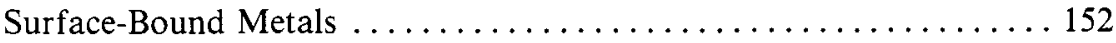

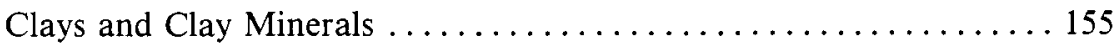

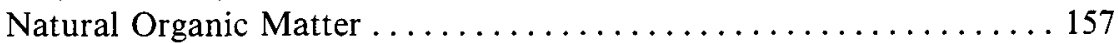

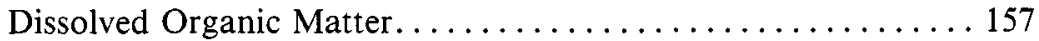

Soil and Sediment-Associated Organic Matter .......... 158

References ....................................... 160

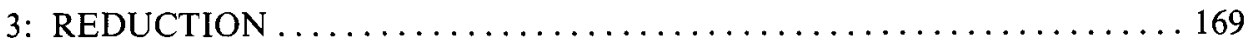

Introduction. ...................................... 169

Reductive Transformation Pathways........................ 171

Reductive Dehalogenation.......................... 171

Halogenated Aliphatics........................... 174

Halogenated Aromatics ....................... 178 
Nitroaromatic Reduction .......................... 181

Polynitro Aromatics ......................... 182

Regioselectivity............................ 186

Aromatic Azo Reduction ............................ 187

N-Nitrosoamine Reduction ........................ 190

Sulfoxide Reduction ............................. 193

Quinone Reduction................................ 194

Reductive Dealkylation ........................... 196

Reduction Kinetics ................................. 198

One-Electron Transfer Scheme ...................... 198

Structure Reactivity Relationships for Reductive Transformations ... 199

Electron-Mediated Reductions . . . . . . . . . . . . . . . . 201

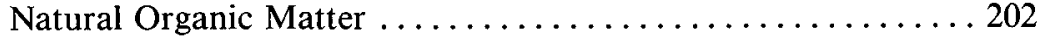

Mineral Systems............................ 202

Microbial-Mediated Reductions ................... 205

Effects of Sorption on Reduction Kinetics ................ 205

References .................................... 208

4: ENVIRONMENTAL OXIDATIONS $\ldots \ldots \ldots \ldots \ldots \ldots \ldots \ldots \ldots \ldots \ldots \ldots \ldots \ldots$

Molecular Oxygen.................................... 218

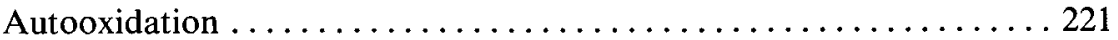

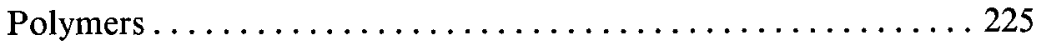

Petroleum ................................226

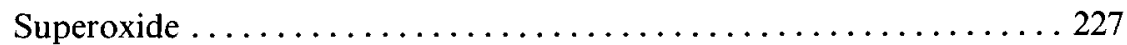

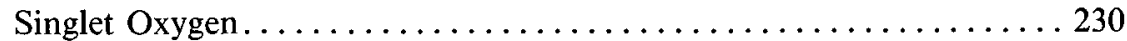

Ozone and Related Compounds: Photochemical Smog .......... 234

Hydrogen Peroxide and Its Decay Products ................... 239

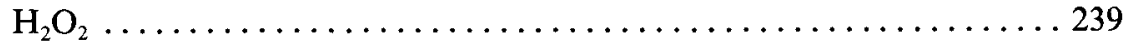

Hydroxyl Radical ............................. 240

Formation............................... 240

Reactions with Organic Compounds ................ 242

Daughter Radicals: Bromide, Carbonate, etc. ........... 246

Peroxy Radicals................................ 247

Alkoxy and Phenoxy Radicals ....................... 250

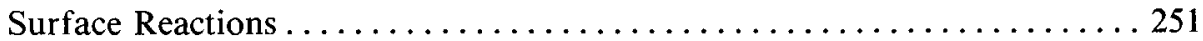

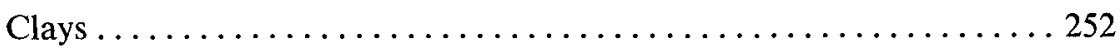

Silicon Oxides ................................ 253

Aluminum Oxides ............................... 254

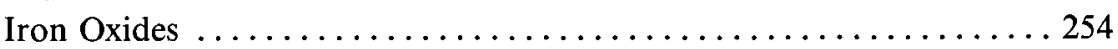

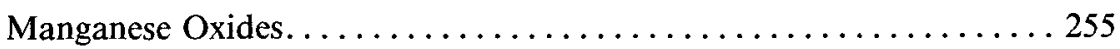

Thermal Oxidations .................................. 257

Combustion and Incineration ....................... 257

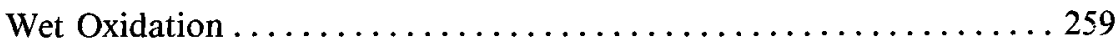

References ...................................... 261 


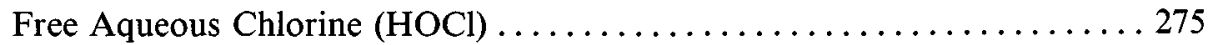

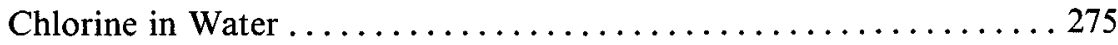

Oxidation Reactions ................................ 277

Substitution and Addition Reactions.................... 279

Phenols ................................... 279

Phenolic Acids ................................ 283

Aromatic Hydrocarbons....................... 284

Enolizable Carbonyl Compounds: the Haloform Reaction ........ 286

Alkenes ...................................... 294

Humic Polymers and Natural Waters ................ 296

Other Polymers .............................. 298

Combined Aqueous Chlorine (Chloramines) ................... 301

Formation of Chloramines ........................ 301

Formation and Reactions of Chloramines ................ 302

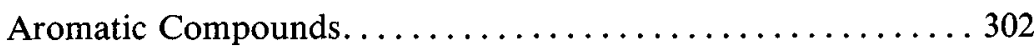

Aliphatic Compounds......................... 303

Amino Sugars. ............................... 305

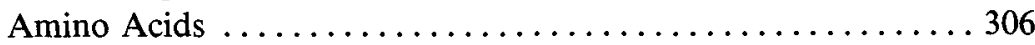

Heterocyclic Nitrogen Compounds . ................... 310

Ozone ............................................. 313

Ozone in Water ................................... 314

Decomposition Mechanisms of Aqueous Ozone ........... 314

Reactions of Ozone............................... 315

Kinetics .................................... 315

Hydrocarbons............................... 315

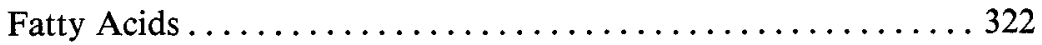

Phenols ................................... 322

Nitrogen Compounds ......................... 325

Humic Materials: Natural Waters................... 328

Advanced Oxidation: Wastewater Treatment ............ 329

Chlorine Dioxide................................... 332

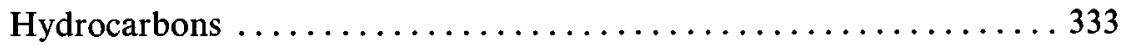

Phenols ........................................ 334

Amines ........................................ 336

Other Compounds................................. 337

Surface Reactions of Disinfectants ........................ 338

References ...................................... 341 


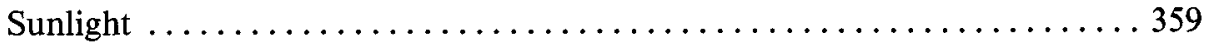

Chromophores and Excited States .................... 362

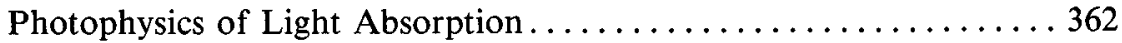

Singlet and Triplet States . . . . . . . . . . . . . . 362

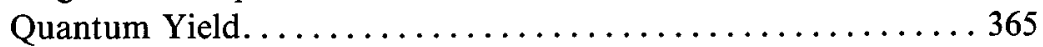

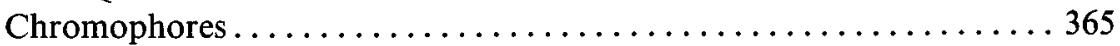

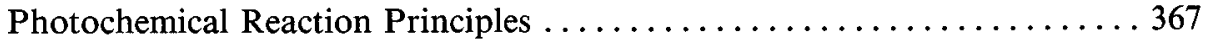

Direct Photolysis . . . . . . . . . . . . . . . . . . 367

Sensitized Photolysis. . . . . . . . . . . . . . . . . . 368

Radical-Producing Photochemical Reactions ............. 368

Kinetics .................................. 369

Atmospheric Photochemistry . . . . . . . . . . . . . . . . 370

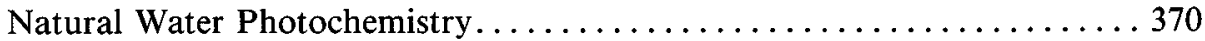

Inorganic Chromophores ..................... 371

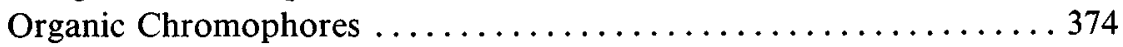

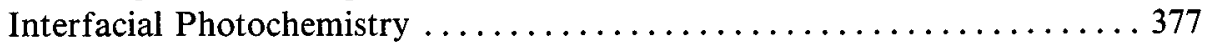

The Air-Water Interface. . . . . . . . . . . . . . . . . . 377

Natural Surface Films.................... 377

Oil Spills ............................ 378

Solid-Water and Solid-Air Interfaces. . . . . . . . . . . . 380

Soils and Mineral Boundaries . . . . . . . . . . . . . 380

Surfaces of Organisms . . . . . . . . . . . . . . . 383

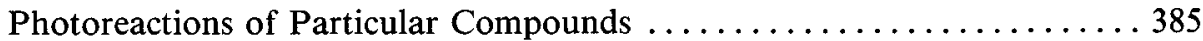

Natural Organic Matter . . . . . . . . . . . . . . . . . . . 385

Aromatic Hydrocarbons . . . . . . . . . . . . . . . 386

Halogenated Hydrocarbons. . . . . . . . . . . . . . . . 388

Carbonyl Compounds ........................ 392

Phenols . . . . . ........................... 396

Anilines. . . . . . . . . . . . . . . . . . . . . . . . . . . . . . 400

Nitro Compounds .......................... 401

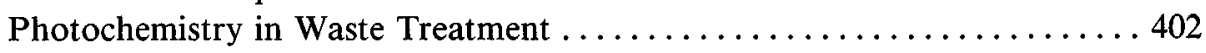

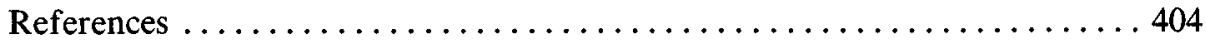

7: MOLECULAR REACTIONS: THE DIELS-ALDER AND

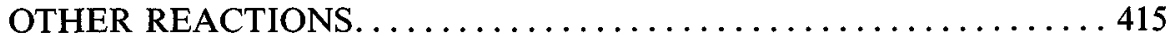

Surface and Aqueous Catalysis of the Diels-Alder Reaction. . . . . . . 415

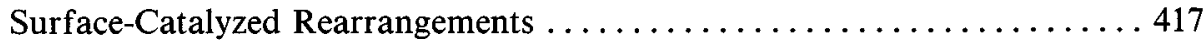

References ............................... 418

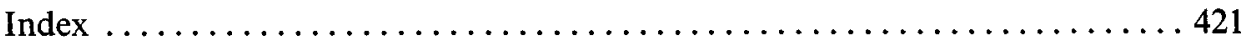


If the Lord Almighty had consulted me before embarking upon the Creation, I should have recommended something simpler. - ALPHONSO X OF CASTILE ("THE WISE")

Strange events permit themselves the luxury of occurring. - "CHARLIE CHAN" (CREATED BY EARL DERR BIGGERS)

The map appears to us more real than the land.

-D. H. LAWRENCE

Organic chemistry just now is enough to drive one mad. It gives the impression of a primeval, tropical forest full of the most remarkable things, a monstrous and boundless thicket, with no way of escape, into which one may well dread to enter.

$$
\text { -FRIEDRICH WÖHLER (1845) }
$$

There is something fascinating about science. One gets such wholesale return of conjecture out of such a trifling investment of fact.

Reality may avoid the obligation to be interesting, but hypotheses may not. - JORGE LUIS BORGES

God loves the noise as much as the signal.

-L. M. BRANSCOMB

This world, after all our science and sciences, is still a miracle. 


\section{CHAPTER 1}

\section{ORGANIC CHEMICALS IN THE ENVIRONMENT}

\section{A. ENVIRONMENTAL FATES OF ORGANIC CHEMICALS}

This book will mainly be about environmental fate processes, and in particular about a certain subset of these fate processes; namely, organic chemical reactions. Specifically, if a particular organic chemical is introduced into the environment, what will happen to it? How much can we tell from physical measurements of the chemical's properties, how much can we learn from lab experimentation, and how much do we need to learn directly from measurements on the chemical in the actual environment? The sort of questions that have been asked are:

1. Where does it go?

2. How long will it remain?

3. What are the products of its reactions?

We need this information for two reasons: the first is intellectual; that is, the knowledge we gain from such studies helps us to explain the functioning of the natural world and the cycling of naturally occurring materials; secondly, from a practical standpoint, we need the information for large-volume synthetic organic chemicals in order to predict their effects on human health and on ecosystem functioning. In principle, it should be possible to use chemical concepts derived from studies of the natural environment to forecast the fates of chemicals in the human, 
or engineered, environment; or, possibly, the flow of information could proceed in the opposite direction.

Philosophically, environmental organic chemists make use of traditional reductionist assumptions and arguments. An organic compound, when discharged into a milieu that manifests a given array of chemical and physical conditions, should, it is believed, respond in a predictable manner to the constraints of those conditions. Although these responses may depend on an apparently bewildering assortment of chemical, physical, and biological qualifications, given sufficient information the fate of the compound should be predictable.

The subject matter of this book is an attempt to classify and organize what is known about the reactions of environmentally important organic compounds, using concepts and data largely drawn from traditional mechanistic and physical organic chemistry. We hope this approach will help the reader understand these reactions and their importance for the environmental fates of organic compounds of many types. The book has a molecular and mechanistic emphasis. We will take particular organic molecules and look at their fates in an aquatic ecosystem context. We will discuss their reactions in terms that an organic chemist would use. However, we will need to bring in concepts from biology, ecology, geochemistry, and environmental engineering. The purpose of this introductory section is to give background data to assist the reader's understanding of organic chemicals and their fates under environmental conditions.

\section{The Carbon Cycle}

In order to begin a consideration of the fate of organic compounds in nature, it is worthwhile to take a look at the carbon cycle. The discussion of the carbon cycle which follows is largely drawn from Woodwell and Pecan (1973), Bolin (1979) and Bolin and Cook (1983). A diagram of the carbon cycle (Figure 1.1) is intended to show the interconversions and movements of carbonaceous species, both organic and inorganic, throughout the earth's gaseous, liquid, and solid phases, as well as processes mediated by living organisms. Inorganic compounds are located principally on the left and top sides of the diagram, and organic matter is localized in the lower right portions. The boundary between inorganic and organic carbon species is rather arbitrary; metal carbides and cyanides intuitively seem to be inorganic compounds, but salts of organic acids do not. Carbon disulfide, $\mathrm{S}=\mathrm{C}=\mathrm{S}$, is normally considered an "organic solvent," yet carbonyl sulfide, $\mathrm{O}=\mathrm{C}=\mathrm{S}$, has an inorganic quality. Regardless of these borderline cases, in geochemical terms inorganic carbon is overwhelmingly dominated by carbon oxides and carbonates. Similarly, compounds of carbon containing covalent bonds to $\mathrm{C}, \mathrm{H}, \mathrm{O}, \mathrm{N}, \mathrm{S}, \mathrm{P}$, and halogens constitute the vast majority of organic compounds in the carbon cycle.

Fundamentally, the carbon cycle is a series of linked chemical reactions, both biological and abiotic. Many are redox reactions. Although the principal source of energy that drives the global redox system is sunlight, humans have not only diverted naturally occurring sources of energy and carbon to their own use, but are also 


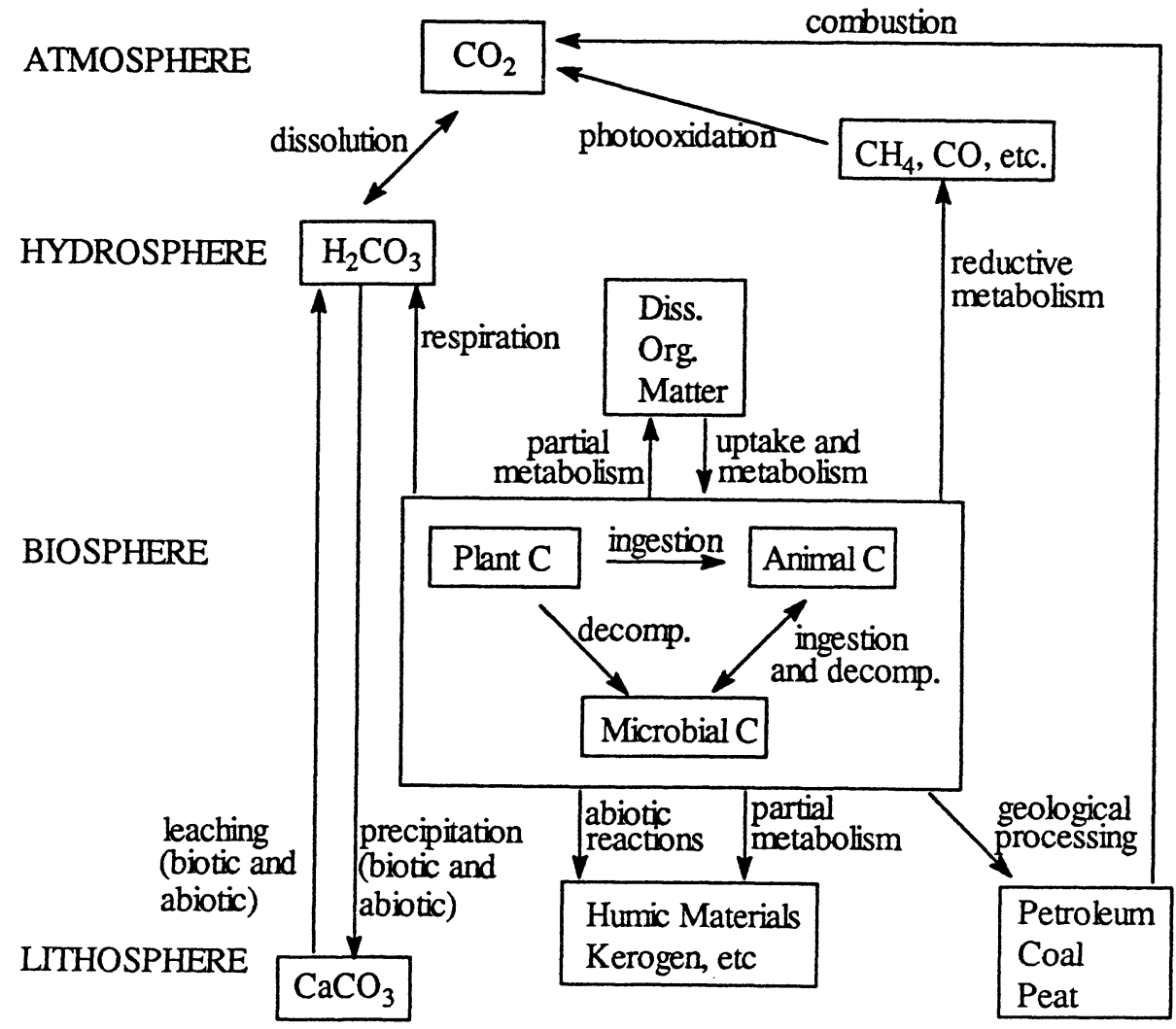

Figure 1.1. Diagram of the carbon cycle, showing movement of oxidized and reduced carbon species between the atmosphere, hydrosphere, biosphere, and geosphere.

contributing ever-increasing amounts of energy (and volatile carbon) to the system by virtue of fuel-burning and managed agriculture. In the Northern Hemisphere, anthropogenically generated energy now exceeds biotic energy flux (photosynthesis). This phenomenon has been called the "civilization engine" (Stumm and Morgan, 1981).

The carbon cycle is not complete-there are some sinks or areas where compounds accumulate, or are at least very slowly turned over. The approximate masses of carbon in the various atmospheric and terrestrial carbon pools and some of their approximate annual rates of conversion are given in Table 1.1.

The most oxidized species, $\mathrm{CO}_{2}$, exists in the atmosphere as a gas whose concentration far exceeds that of other carbon-containing substances. In water, it takes part in a series of equilibrium reactions involving hydration, ionization, and precipitation: 
Table 1.1. Some Components of the Carbon Cycle (Estimated magnitudes in grams of C)

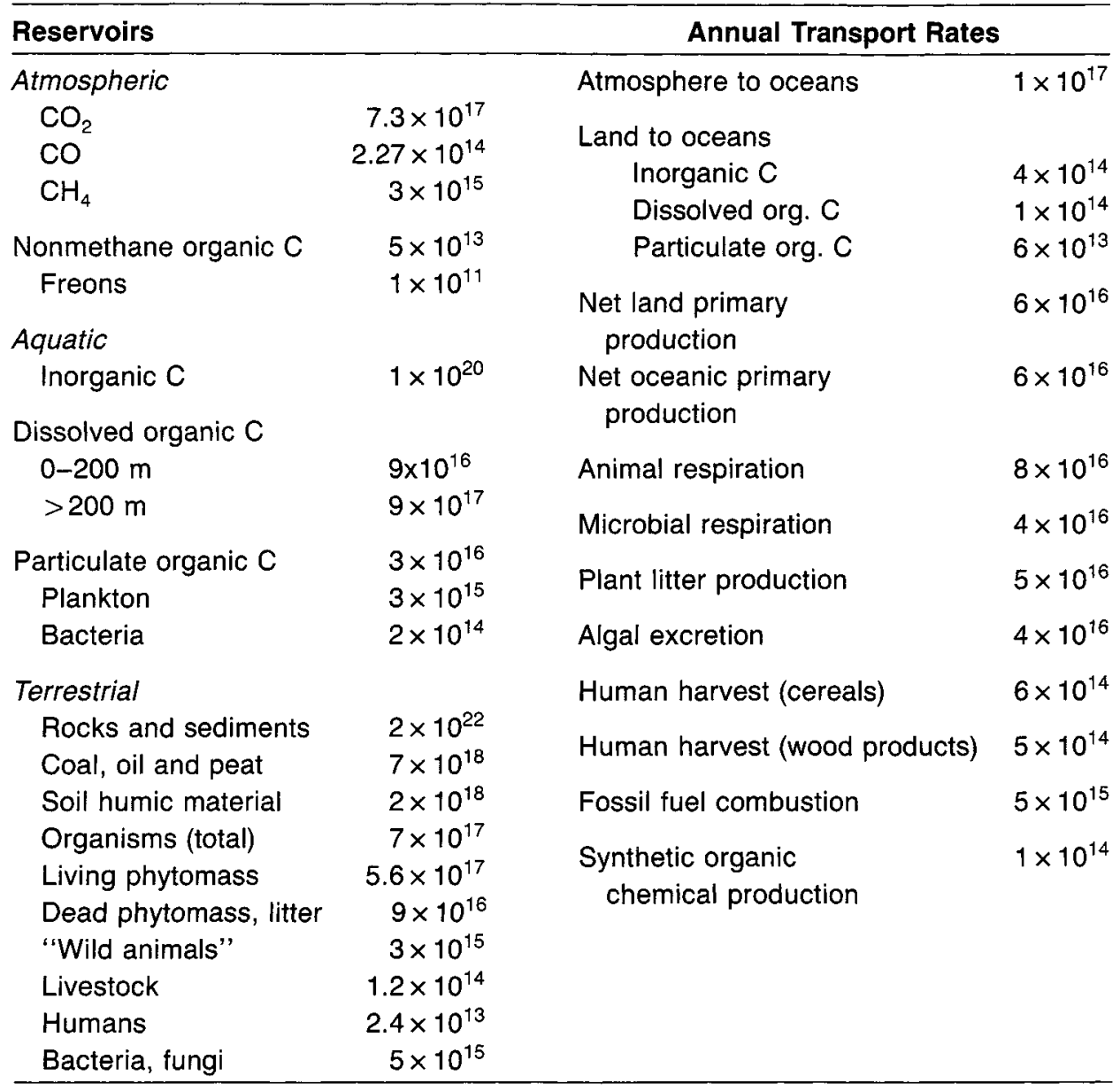

Sources: Woodwell and Pecan (1973), Bolin (1979), and Bolin and Cook (1983).

$$
\mathrm{CO}_{2}(\mathrm{~g}) \rightarrow \mathrm{H}_{2} \mathrm{CO}_{3} \rightarrow \mathrm{HCO}_{3}^{-} \rightarrow \mathrm{CO}_{3}^{2-} \rightarrow \mathrm{CaCO}_{3}
$$

that transport it throughout the aqueous and solid phases. Carbon dioxide gas dissolves in water to form carbonic acid, a weak acid. Therefore, pure water containing $\mathrm{CO}_{2}$ becomes slightly acidic; the $\mathrm{pH}$ of rain water at equilibrium with $\mathrm{CO}_{2}$ is 5.5. (Obviously, atmospheric water containing dissolved nitrogen or sulfur oxides will be much more acidic.) The first proton of carbonic acid ionizes to the monovalent anion, bicarbonate, with a pKa of 6.4. Thus at equilibrium at $\mathrm{pH} \mathrm{6.4,} \mathrm{the}$ concentrations of carbonic acid and bicarbonate will be equal. The second ionization to the divalent anion, carbonate, occurs with a pKa of 10.4. However, in water 
containing calcium ions or other ions that form insoluble carbonates, carbonate anion will rapidly be removed. Calcium carbonate exists in several forms, including limestone.

The photosynthetic activities of plants and, especially, algae that live in water remove some $\mathrm{CO}_{2}$ from the water directly, and also increase the $\mathrm{pH}$ to such an extent that more carbonate occurs and precipitates out. The "shorthand" equation for photosynthesis explains the direct loss of $\mathrm{CO}_{2}$ :

$$
\mathrm{n} \mathrm{CO}_{2}+\mathrm{n} \mathrm{H}_{2} \mathrm{O} \rightarrow(\mathrm{HCOH})_{\mathrm{n}}+\mathrm{n} \mathrm{O}_{2}
$$

This formation of reduced carbon species and the simultaneous release of oxygen from carbon dioxide by plants is called "primary production" in ecological jargon.

A more accurate equation for photosynthesis (Stumm and Morgan, 1981) also explains the $\mathrm{pH}$ increase in natural waters containing photosynthesizing organisms:

$$
\begin{gathered}
\mathrm{CO}_{2}+0.2 \mathrm{NO}_{3}^{+}+0.01 \mathrm{HPO}_{4}^{2-}+1.2 \mathrm{H}_{2} \mathrm{O}+0.2 \mathrm{H}^{+} \rightarrow \\
\mathrm{CH}_{2.6} \mathrm{ON}_{0.2} \mathrm{P}_{0.01}+1.4 \mathrm{O}_{2}
\end{gathered}
$$

The complex expression on the right-hand side of the equation is the average composition of algae. It can be seen that the process of photosynthesis results in a net consumption of hydrogen ions, and thus an increase in $\mathrm{pH}$.

There are mechanisms for reconverting $\mathrm{CaCO}_{3}$ to soluble forms. One is simply to redissolve it using acid, such as acidic precipitation. A second way is to convert it back to bicarbonate using $\mathrm{CO}_{2}$ :

$$
\mathrm{CaCO}_{3}+\mathrm{CO}_{2}+\mathrm{H}_{2} \mathrm{O} \rightarrow \mathrm{Ca}^{2+}+2 \mathrm{HCO}_{3}^{-}
$$

The reverse of this reaction also occurs, for example when bicarbonate-containing water evaporates.

Looking at atmospheric $\mathrm{CO}_{2}$ and its cycling, there is a total of $2.3 \times 10^{18}$ grams of $\mathrm{CO}_{2}$ in the atmosphere. Since the atmosphere weighs about $6.7 \times 10^{21} \mathrm{~g}$, this works out to $0.034 \%$ or $340 \mathrm{ppm}$. This has been increasing at about 1-2 ppm per year since at least 1957 (direct measurement), and probably well before. Samples of trapped air from the preindustrial period show concentrations between 260 and $295 \mathrm{ppm}$.

Concentrations of $\mathrm{CO}_{2}$ are highest in the Northern Hemisphere in winter and drop sharply during the spring and summer. This is consistent with the increase being due to fossil fuel combustion. Estimates of the magnitude of present combustionproduced $\mathrm{CO}_{2}$ are about $5 \times 10^{15} \mathrm{~g}$ of $\mathrm{C}$, (about $3 \mathrm{ppm}$ of atmospheric $\mathrm{CO}_{2}$ ) over and above natural $\mathrm{CO}_{2}$ production by respiration, which is about $1.2 \times 10^{17} \mathrm{~g} \mathrm{C} / \mathrm{yr}$. Estimates of the cycling of naturally produced $\mathrm{CO}_{2}$ are that $14 \%\left(1 \times 10^{17} \mathrm{~g} \mathrm{C} / \mathrm{yr}\right)$ enter the oceans and $16 \%\left(1.2 \times 10^{17} \mathrm{~g}\right)$ is taken up by photosynthetic organisms. Therefore, almost all of the atmospheric $\mathrm{CO}_{2}$ is cycled in a three-year period. The extra carbon from combustion clearly does not all stay in the atmosphere; otherwise the observed increase would be $3 \mathrm{ppm} / \mathrm{yr}$ rather than $1-2 \mathrm{ppm} / \mathrm{yr}$. It is still not certain whether the majority of the "missing" $\mathrm{CO}_{2}$ dissolves in the ocean or is taken 
up by plants. The increased $\mathrm{CO}_{2}$ concentration probably, however, will not translate directly into increased biomass of plants around the world, because $\mathrm{CO}_{2}$ is not usually the limiting substrate for plant growth; most ecologists believe that water and trace mineral nutrients are usually more important.

The respiration (metabolism) of the reduced carbon produced by plants returns it to the atmosphere as $\mathrm{CO}_{2}$. It is assumed that photosynthetic fixation of $\mathrm{CO}_{2}$ from the atmosphere by plants and its return by respiration are in exact balance, but there is really no good way of telling. All that we know is that atmospheric carbon is increasing. An increase in $\mathrm{CO}_{2}$ may affect the earth's surface temperature because the sun emits not only light (visible radiation energy), but also ultraviolet (UV) and infrared (IR or heat) radiation (see Section 6.A). When, for example, visible energy strikes the earth's surface, it loses energy and is partly converted to the lower-energy heat (IR) radiation, some of which is reflected back into space. Carbon dioxide is transparent to visible energy, but it strongly absorbs IR, so some of the heat generated near the earth's surface doesn't escape into the atmosphere. The net result is that the lower atmosphere becomes warmer.

A consideration of terrestrial carbon shows that inorganic carbon (carbonate rocks, mostly) predominates to a tremendous degree over organic carbon. There are very large reserves of "dead" organic carbon (coal, oil, peat, and soil humus), all ultimately derived from animals and plants which have died. Dead carbon (about $10^{19} \mathrm{~g}$ ) exceeds living carbon by about $14: 1$. These materials, taken as an aggregate, are not rapidly recycled at the present rates of human utilization, although readily useful fossil fuels are exploited on a large scale.

Living carbon is largely (more than 80\%) in higher plants. Most of this "phytomass" is in trees. About $30 \%$ of the land area of the earth is forested, but this proportion is decreasing. Tropical forests, which still constitute about $1 / 3$ of the total forest area, are rapidly being cut down as the increasing population in developing countries exerts its requirement for living space and fuel.

The mass of the five billion or so living humans, about 240 billion kilograms, is only a few hundredths of a per cent of the total living biomass. Mankind's domestic livestock herds outweigh us by a factor of about 5, and all the "wild creatures," including all birds, mammals, lizards, fish, etc., by only about 20:1. The biomass of microorganisms, although difficult to estimate precisely, probably amounts to only a few per cent of all the living carbon.

Annually, we harvest about $10^{15} \mathrm{~g}$, or about 50 times our own weight, in plant products including wood, fiber, and food. About $10 \%$ of the earth's land area is now being used for agriculture (including forestry). Other, urban, human institutions (housing, roads, industrial plants) consume between $1 \%$ and $2 \%$ of the surface of the globe (it has been estimated that $1 \%$ of the United States is paved). Densely populated countries have much more of their land area in urban use; for example, the Netherlands has about $9 \%$. Synthetic organic chemical production has increased dramatically over the last 50 years, and now about $4 \times 10^{14} \mathrm{~g}$ of such chemicals are produced annually (an amount close to the annual use of wood products).

To summarize, although the absolute effect of humans on the global quantity and flux of carbon has perhaps been modest, our contribution to changing the pattern of 
the cycle has increased significantly in the last century or so. Given the serious lack of knowledge of the feedback mechanisms that tie various elements of the carbon system together, it would appear to be an urgent priority that we increase our understanding of the effects of our activities on these important planetary operations.

\section{Translocation of Organic Chemicals}

The fates of organic molecules (whether naturally or anthropogenically produced) include, first, translocation, in which the molecular structure of the chemical is not changed; a molecule will be carried between air, surface water, groundwater, organisms, aquatic sediments, and soils by various processes. Rates and equilibria can ideally be obtained to describe these transport processes, often by chemical engineering concepts like mass transfer equations, and to predict their extent. A good summary of environmental transport processes is given by Thibodeaux (1979).

\section{Volatilization}

Transport of organic compounds from the solid or aquatic phases to the gas phase (and back again) is now known to be a highly important process for the dispersion of chemical compounds around the globe. Dissolution into and volatilization from the aqueous phase is an elaborate process that depends on solubility, vapor pressure, turbulence within the two phases, and other physical and chemical factors. Volatilization of materials from the earth's surface into the troposphere can result in their long-range transport and redeposition, with the outcome being that measurable quantities of such substances can be detected far from their point of release.

Many chemicals escape quite rapidly from the aqueous phase, with half-lives on the order of minutes to hours, whereas others may remain for such long periods that other chemical and physical mechanisms govern their ultimate fates. The factors that affect the rate of volatilization of a chemical from aqueous solution (or its uptake from the gas phase by water) are complex, including the concentration of the compound and its profile with depth, Henry's law constant and diffusion coefficient for the compound, mass transport coefficients for the chemical both in air and water, wind speed, turbulence of the water body, the presence of modifying substrates such as adsorbents in the solution, and the temperature of the water. Many of these data can be estimated by laboratory measurements (Thomas, 1990), but extrapolation to a natural situation is often less than fully successful. Equations for computing rate constants for volatilization have been developed by Liss and Slater (1974) and Mackay and Leinonen (1975), whereas the effects of natural and forced aeration on the volatilization of chemicals from ponds, lakes, and streams have been discussed by Thibodeaux (1979).

Once a chemical becomes airborne, atmospheric mixing processes on regional, elevational, and global scales come into play. East-west mixing of air masses is much more efficient than north-south mixing. Because of the intra-hemispheric con- 
straints on the prevailing winds, air masses seldom mix efficiently across the equator. The atmosphere becomes completely mixed only over very long time scales; for organic compounds with lifetimes of even several years, Northern and Southern Hemisphere variations are measurable if (as is usually the case) one hemispheric source predominates. Compounds of industrial origin are usually localized in the Northern Hemisphere, whereas substances derived from marine processes are usually more abundant in the Southern Hemisphere.

We know from studies of gases in solution that the solubility of a gas which does not react with its solvent depends to a considerable degree on its vapor pressure at a given temperature. We can extend these studies to other solutes if we can measure their vapor pressures at higher temperatures and extrapolate them to lower, environmentally realistic temperatures. For the case of air-water partitioning, a simple equation describes the behavior of many substances:

$$
\mathbf{H}=\mathbf{P} / \mathbf{C}
$$

where $\mathbf{H}$ is the Henry's law coefficient for the chemical, $\mathbf{P}$ its vapor pressure, and $\mathbf{C}$ its water solubility. If we know or can estimate the quantities on the right-hand side of the equation, we can obtain $\mathbf{H}$, and this will allow us to estimate the magnitude of the air-water partition.

Henry's law constants for chemicals of environmental interest have been tabulated by many authors, including Mackay and Shiu (1981), Burkhard et al. (1985), Gossett (1987), Murphy et al. (1987), Hawker (1989), and Brunner et al. (1990). If $\mathbf{H}$ has a relatively large value for a particular compound, it means that it has a large tendency to escape from the water phase and enter the atmosphere. To get a large value for $\mathbf{H}$, obviously either a high $\mathbf{P}$ or a low $\mathbf{C}$ (or both) is required. Thus, for example, secbutyl alcohol and decane have vapor pressures that differ by a factor of 10, with the alcohol being the higher, but because the hydrocarbon's water solubility is negligible, it is much more likely to enter the gas phase than is the alcohol. Similarly, although the pesticide DDT is essentially nonvolatile, its water solubility is far less even than decane's. As a result, a small quantity will be volatilized; this accounts for the widespread detection of DDT in environments far from the sites where it was applied. Another heavily applied chemical, the herbicide atrazine, is a little more volatile than DDT, but it is far more soluble, so its tendency to enter the atmosphere is negligible.

The movement of a chemical substance within the vapor phase occurs by the combined driving forces of flow and diffusion. An illustration of these effects can be visualized by considering a smokestack plume; in the absence of wind, the plume will rise vertically in a more or less uniform column until it reaches an elevation where density considerations result in its spreading out into a relatively broad and flat mantle. When wind is factored into the equation, the plume may move in a more nearly horizontal direction, more or less parallel to the surface of the ground, and at certain wind speeds the plume structure can break up into loops or bends due to turbulent aerodynamic effects such as eddy formation. In addition, small eddies can result in the breakdown of the coherent plume structure, with the formation of 
vertical or horizontal regions of increasingly large cross-section and lower concentrations of plume constituents.

\section{Transport Within the Aqueous Phase}

The three-dimensional dispersion of a completely soluble organic solute within a volume of pure water will be governed by its rates of diffusion within the water column and by the flow characteristics of the water itself (also called convection or advection). In actual water bodies, complicating factors include the presence of particles of various sizes within the aqueous phase and the effects of boundary layers such as those associated with the air-water and sediment-water interfaces. Further complications occur in soil-water and groundwater systems in which the aqueous phase is a minor component in the presence of an excess of solid material (Thibodeaux, 1979).

Movement of a soluble chemical throughout a water body such as a lake or river is governed by thermal, gravitational, or wind-induced convection currents that set up laminar, or nearly frictionless, flows, and also by turbulent effects caused by inhomogeneities at the boundaries of the aqueous phase. In a river, for example, convective flows transport solutes in a nearly uniform, constant-velocity manner near the center of the stream due to the mass motion of the current, but the friction between the water and the bottom also sets up eddies that move parcels of water about in more randomized and less precisely describable patterns where the instantaneous velocity of the fluid fluctuates rapidly over a relatively short spatial distance. The dissolved constituents of the water parcel move with them in a process called eddy diffusion, or eddy dispersion. Horizontal eddy diffusion is often many times faster than vertical diffusion, so that chemicals spread sideways from a point of discharge much faster than perpendicular to it (Thomas, 1990). In a temperature- and densitystratified water body such as a lake or the ocean, movement of water parcels and their associated solutes will be restricted by currents confined to the stratified layers, and rates of exchange of materials between the layers will be slow.

The other method of diffusion of a chemical through a liquid phase, molecular diffusion, is driven by concentration gradients. It is normally orders of magnitude slower in natural waters than eddy-driven processes, unless the water body is abnormally still and uniform in temperature (Lerman, 1971). Such situations are found only in isolated settings such as groundwaters and sediment interstitial waters. Even here, however, empirical measurements often indicate that actual dispersion exceeds that calculated from molecular diffusion alone.

The transport of a substance through a water body to an interface may involve eddy or molecular diffusion through aqueous sectors of differing temperature, such as those characteristic of stratified lakes (cf. Section 1.B.2c), and through interfacial films such as air-water surface layers (Thomas, 1990). Conditions near a phase boundary are very difficult to model accurately. The resistance to diffusion through various regions may vary by large amounts, and the overall transfer rate is governed by the slowest step, which usually occurs in a thin film or boundary layer near the 
interface where concentration gradients are large and molecular diffusion becomes influential.

Transport of a dissolved substance through a porous medium like a sandy soil, in which interaction between the solute and the solid phase is negligible, is governed by laws of mass transport that are similar to those that apply in solutions. When interactions with a solid phase such as a soil become significant, a situation similar to solid-liquid chromatography develops; solutes with less interaction with the "support," or soil, are moved along with the "solvent front" of water leaching through the medium, whereas others are held back in proportion to their degree of binding. Studies of this phenomenon in artificial microcosms such as soil columns or thinlayer chromatography plates are useful in helping to predict which compounds are likely to contaminate groundwater (see Section 1.B.2e). The predictions can be tested in field studies using wells or lysimeters.

\section{Partition into Solid Phases}

The transfer of molecules from solution into an environmental solid phase such as a soil or sediment is referred to as sorption, with the reverse process usually called desorption (Karickhoff, 1984; Weber et al., 1991). A variety of solid phases are available in the aquatic environment: small suspended particles, both living and nonliving, the anatomical surfaces of larger biota such as fish, and bulk soils and bottom sediments. Even colloidal organic "solutes" such as humic macromolecules might be thought of as separate phases to which a dissolved molecule could be sorbed. Each of these surfaces may be thought of as a source or a sink for compounds in solution.

The passage of a compound from solution into a solid environment can be promoted or inhibited by a variety of factors. Sorption and desorption equilibria are, for example, strongly temperature-dependent. In addition, the surface area of the solid, as well as its physicochemical characteristics (charge distribution and density, hydrophobicity, particle size and void volume, water content) are major factors that determine the importance and extent of sorption for a particular solute. In thermodynamic terms, for sorption to occur, the energy barrier associated with bringing the interacting species into proximity must be overcome by a greater decrease in free energy in the sorbed system. By measuring the heat of adsorption, some insight can be gained as to whether the sorption process is primarily due to physical (van der Waals-type) uptake or to chemical reaction, with physical uptake usually involving much lower $(<50 \mathrm{~kJ} / \mathrm{mol})$ energy differentials than chemical reactions, which have heats of adsorption in the range of 150 to $400 \mathrm{~kJ} / \mathrm{mol}$.

Although distinctions are sometimes made between adsorption (uptake of compounds by the surface of a solid phase) and absorption (diffusion of molecules into the interior of a solid), it is usually not possible to distinguish between these cases in environmental situations. A complicating factor in sorption studies is that natural solid phases are not only not chemically and physically homogeneous, but are normally coated with extraneous materials such as transition metal oxides, microor- 
ganisms and their excretion products, and humic substances that often almost completely disguise the sorption properties of the underlying mineral.

Sorption is important from the viewpoint of chemical reactivity, as well. A compound that is sorbed usually goes from a situation in which it is entirely surrounded by water molecules to one in which it is in a mineral environment rich in organic matter. In fact, a chemical substance in a suspension of natural particulate matter will exist in a complex equilibrium in which a fraction of the material is dispersed into several disparate phases that may contribute differently to the reactions the substance may undergo.

Studies of the uptake of organic compounds by many types of natural solid phases (soils and sediments) in the presence of water have clearly shown that only two types of interactions are important: first, a coulombic interaction, in which organic compounds of opposite (positive) charge are sometimes taken up by the (usually) negatively charged solid material; and, generally more important, a hydrophobic interaction in which nonpolar organic compounds are attracted into the solid phase.

Among the most important constituents of most natural soils and sediments are the clay minerals (see Section 1.B.3a). These minerals usually exist as very fine $(<1$ $\mu \mathrm{M})$ particles with high surface area and (usually) negative charge. This makes them potent adsorbents for cations, either inorganic or organic, and leads to the possibility of cation-exchange displacement reactions. There may also be important $\mathrm{pH}$ effects at clay surfaces, especially in soft waters where cations other than $\mathrm{H}^{+}$are not abundant. It has been found that the $\mathrm{pH}$ near the surface of certain types of clay may be as much as 2 units lower $\left(\left[\mathrm{H}^{+}\right] 100\right.$-fold higher) than in the associated solution (McLaren, 1957; see Section 1.B.3a). Obviously, there may be significant effects on the rate of reactions requiring protonation or acid catalysis in such environments.

In general, for both naturally occurring compounds and pollutants,

1. Hydrophobically bound adsorbates are most strongly bound;

2. Cationic adsorbates are next most strongly bound;

3. Anionic species are most weakly bound.

Uptake by clays of charged organic materials is termed hydrophilic sorption. As an example, an organic cation like the herbicide paraquat (1) is very readily

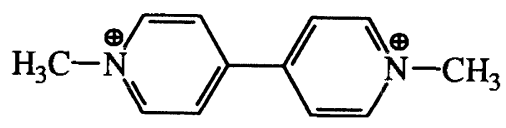

1

taken up by clays, despite its high solubility in water, because of these strong electrostatic interactions. There is also a possibility of weak adsorption of anions by "bridging cations." By this mechanism, anionic compounds like some proteins, carboxylic acids, and humic materials may be associated near the water-solid inter- 
face. Generally, however, the direct uptake of cations by clays is much more important than the indirect (bridging) uptake of anions.

Mention should also be made of another weak mechanism of indirect uptake of strongly hydrogen-bonding materials. Water molecules are quite strongly oriented in the vicinity of certain clays because of attraction between the lone pairs on the oxygen atom of water and the positive charges on cations at the clay surface. This means that an excess of hydrogen atoms will be facing out into solution, and in the presence of molecules with lone pairs (hydroxyl groups, ether oxygen, carbonyl groups, etc.), hydrogen bonding will occur (Figure 1.2), and through these "water bridges," these molecules may, in favorable cases, build up to quite a high degree of adsorption.

Another general type of uptake of organic molecules by solid surfaces is called hydrophobic sorption. This interaction is quite general for natural sediments and soils, and leads to a high degree of concentration of hydrophobic material near the interface. Hydrophobic adsorption is strongly correlated with the organic carbon content of the sediment or soil. It has elements of partitioning; many investigators have, in fact, shown a very clear correlation between the extent of uptake of a chemical by a natural solid phase and the partition coefficient, $K_{p}$, of the chemical; that is, its ratio of concentration or activity between an organic solvent, often octanol, and water:

$$
\mathbf{K}_{\mathrm{p}}=[\text { solvent }] /[\text { water }]
$$

The partition coefficient is not the same as the ratio of the solubilities of a chemical in the two pure solvents, because at equilibrium the solvent phase contains some water and the water phase contains some solvent. Values of $\mathrm{K}_{\mathrm{p}}$ sometimes vary with solute concentration, but are seldom much affected by temperature.

Many data are specifically available on the octanol/water partition coefficients $\left(\mathrm{K}_{\mathrm{ow}}\right)$ of organic molecules (see, for example, Tewari et al., 1982; Miller et al., 1984, and Lyman, 1990a), and it has been repeatedly demonstrated that chemicals with high $\mathrm{K}_{\text {ow }}$ 's are very readily sorbed by natural sediments. For example, the extremely nonpolar compound DDT has a $\mathrm{K}_{\mathrm{ow}}$ of about $10^{6}$ (it is a million times more soluble in octanol than in water), and it is almost completely associated with the solid phase in a two-phase water-sediment system. For atrazine, a chemical of intermediate polarity, the $\mathrm{K}_{\mathrm{ow}}$ is still high $\left(3 \times 10^{3}\right)$, but far less than that for DDT, so the extent of

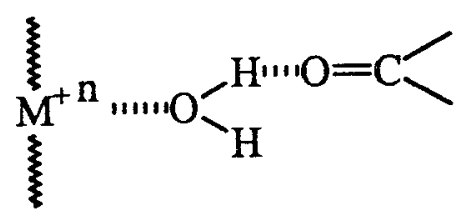

Figure 1.2. A water bridge, showing how hydrogen bonding may assist in bringing certain organic molecules into the vicinity of clay surfaces. 
association with sediments would be expected to be far less pronounced. For quite polar organic compounds, such as acetic acid, the octanol-water partition coefficient is far lower (0.5), and the distribution in the two-phase system would favor water. Because soil organic matter is so highly oxidized, current thinking is that it must have extensive nonpolar regions, perhaps alkyl chains, that are responsible for the partitioning (see Section 1.B.3c). (The quantity $\mathrm{K}_{\mathrm{ow}}$ has also been shown to correlate well with other environmental parameters that depend on distribution between hydrophobic and aqueous phases, such as bioconcentration in aquatic organisms, uptake by mammalian skin, water solubility, and toxicity within a given series of compounds; Verschueren, 1983).

For soils and sediments of differing organic matter content, the useful concept of $\mathrm{K}_{\mathrm{oc}}$ has been introduced; this form of the partition coefficient makes the simplifying assumption that only the organic carbon is active in the sorption process, and the partition coefficient expression can be rewritten

$$
\mathrm{K}_{\mathrm{oc}}=\mathrm{K}_{\mathrm{p}} /[\text { fraction organic carbon] }
$$

Values of $K_{o c}$ for selected chemicals have been tabulated (Lyman, 1990b). Data for many herbicides and polycyclic organic compounds (Walker and Crawford, 1968; Hassett et al., 1980) have confirmed the general applicability of this expression. However, at low organic carbon concentrations, such as are found in sandy soils and some clays, sorption still occurs for many chemicals, and the above equation does not fit the data particularly well.

Octanol-water partitioning and aqueous solubility are closely related, and one can be predicted fairly accurately from the other using a relationship devised by Mackay et al. (1980):

$$
\ln \mathrm{K}_{\mathrm{ow}}=7.494-\ln \mathrm{C}_{\mathrm{w}}
$$

where $C_{w}$ is the water solubility in moles/L. Many other forms of this equation have been promulgated (cf. Lyman, 1990a) that appear to predict solubility more or less accurately for a given series of compounds.

At equilibrium, the uptake of a dissolved compound can often be expressed in the simple terms of the Freundlich isotherm equation,

$$
[\mathrm{A}]_{\mathrm{s}}=\mathrm{K}_{\mathrm{p}}[\mathrm{A}]_{\mathrm{w}}^{1 / \mathbf{n}}
$$

where $[A]_{s}$ and $[A]_{w}$ are, respectively, concentrations of the compound in the solid and water phase; $\mathrm{K}_{\mathrm{p}}$ is an appropriate partition coefficient; and $1 / \mathrm{n}$ is an empirical exponential factor, often close to 1.0. Achievement of equilibrium, however, is often difficult to measure in studies with natural soils or sediments; kinetics of uptake may be complex, with a fraction of the solute rapidly taken up and a residual uptake period that may last for days or weeks. Pollutant uptake and release (desorption) kinetics are dependent on particle chemical characteristics, mass transfer properties for the solute in the sorbent phase, aggregation state of particles, and ability of the 
solid state to swell or shrink after incorporation of organic matter (Karickhoff, 1984; Karickhoff and Morris, 1985).

\section{Transformation of Organic Compounds}

\section{a. Reaction Mechanisms}

The transformation of organic chemicals most often occurs in several molecular events referred to as elementary reactions. An elementary reaction is defined as a process in which reacting chemical species pass through a single transition state without the intervention of an intermediate. A sequence of individual elementary reaction steps constitutes a reaction mechanism. For example, the overall reaction for the hydrolysis of a Schiff base is written:

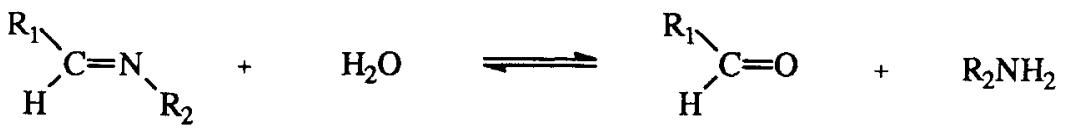

The reaction mechanism for this seemingly simple reaction is in fact quite complex, and is composed of four elementary reactions (Cordes and Jencks, 1963).
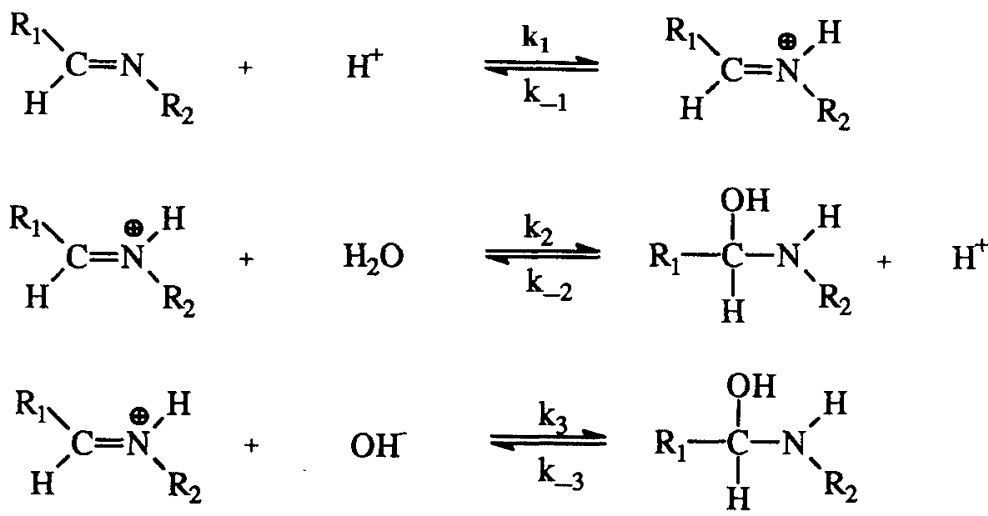<smiles>[R]N([R2])C([R])([2H])O</smiles>

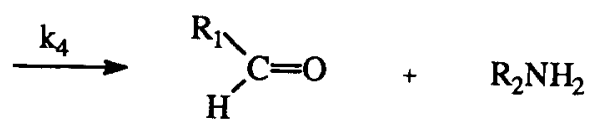

A reaction mechanism is actually a hypothesis or model that has been constructed from experimental evidence. As new experimental evidence is obtained, changes in the proposed reaction mechanism may be required. Chemical kinetics is probably the most powerful tool for the investigation and development of reaction mecha- 
nisms. The consistency of a reaction mechanism can be verified in the laboratory by determining the dependence of reaction rates on concentration.

Once a reaction mechanism consisting of a sequence of individual elementary reactions has been proposed it is possible to develop rate equations, which predict the dependence of the observed reaction rate on concentration. The principle of mass action, which states the rate at which an elementary reaction takes place is proportional to the concentration of each chemical species participating in the molecular event, is used to write differential rate equations for each elementary reaction in the proposed reaction mechanism. The goal is then to obtain explicit functions of time, which are referred to as integrated rate laws, from these differential rate equations. For simple cases, analytical solutions are readily obtained. Complex sets of elementary reactions may require numerical solutions.

It is useful to classify elementary reactions according to their molecularity, which is defined as the sum of the exponents appearing in a rate equation for a single elementary reaction. The term unimolecular reaction is used to describe an elementary reaction involving one chemical species. A bimolecular reaction involves the interaction of two chemical species. The interaction of three chemical species, or a termolecular reaction, is quite rare and will not be considered for further discussion. Molecularity is often confused with the order of a reaction, which refers to the sum of the exponents appearing in an experimental rate equation.

\section{b. Kinetics}

Rate expressions. Initially, to determine how rate equations are developed from a proposed reaction mechanism. we will consider simple reaction mechanisms consisting of only one elementary reaction For example, the differential rate equation for the hypothetical reaction in Equation 1.15

$$
A \rightarrow B
$$

can be written as

$$
-\mathrm{d}[\mathrm{A}] / \mathrm{dt}=\mathrm{k}_{1}[\mathrm{~A}]
$$

For experimental determination of $\mathrm{k}$, the integrated form of Equation 1.16 is conveniently written

$$
[\mathrm{A}]=[\mathrm{A}]_{0} \mathrm{e}^{-\mathbf{k t}}
$$

or

$$
\ln \mathrm{A}=\ln \mathrm{A}_{\mathrm{o}}-\mathrm{kt}
$$

Thus a plot of $\ln A$ versus $t$ should be linear for a first order reaction with a slope of $-k$, which has units of time ${ }^{-1}$, and a y-intercept of $[A]_{0}$. When experimental data 
obtained in the laboratory are in close agreement with this theoretical expectation, we can say that the reaction obeys first-order kinetics. This allows us to speak of an experimental rate law as opposed to a theoretical rate law based on mechanistic considerations.

When comparing the reactivity of chemicals, it is convenient to speak in terms of the half-life $\left(t_{1 / 2}\right)$ of a reaction or the time for $50 \%$ of the chemical to disappear. For first-order reactions, if we set $[\mathrm{A}]=1 / 2[\mathrm{~A}]_{0}$, and substitute into Equation 1.18, the expression for $\mathrm{t}_{1 / 2}$ becomes:

$$
t_{1 / 2}=0.693 / k
$$

The half-life for a first-order reaction, therefore, is independent of the initial concentration of the chemical of interest.

For the more complex reaction containing two reacting chemical species, $\mathrm{A}$ and $\mathrm{B}$ (Equation 1.20)

$$
\mathrm{A}+\mathrm{B} \rightarrow \mathrm{C}
$$

the rate of disappearance of $\mathrm{A}$ is given by Equation 1.21.

$$
\mathrm{d}[\mathrm{A}] / \mathrm{dt}=\mathrm{k}_{2}[\mathrm{~A}][\mathrm{B}]
$$

The integrated form of Equation 1.21 is:

$$
\ln \left[\left(\mathrm{B}_{\mathrm{o}}^{*} \mathrm{~A}\right) /\left(\mathrm{A}_{\mathrm{o}}{ }^{*} \mathrm{~B}\right)\right]=\mathrm{k}_{2} \mathrm{t}\left(\mathrm{A}_{\mathrm{o}}-\mathrm{B}_{\mathrm{o}}\right)
$$

Thus for bimolecular reactions, plotting $\ln \left[\mathrm{B}_{0}(\mathrm{~A}) / \mathrm{A}_{0}(\mathrm{~B})\right]$ versus $t$ gives a line with slope $k_{2}\left(A_{o}-A_{b}\right)$.

If one of the concentrations of a chemical species in a second-order reaction is present in excess, and as a result does not effectively change during the course of the reaction, the observed behavior of the system will be first order. Such a system is said to follow pseudo-first-order kinetics. If the concentration of the chemical species $B$ in Equation 1.20 were in large excess of $A$, the disappearance of $A$ could be written as:

$$
\mathrm{d}[\mathrm{A}] / \mathrm{dt}=\mathrm{k}_{\mathrm{obs}}[\mathrm{A}]
$$

where

$$
\mathrm{k}_{\mathrm{obs}}=\mathrm{k}_{2}[\mathrm{~B}]
$$

Reaction mechanisms for the transformation of organic chemicals usually involve several elementary reactions. The kinetic expressions resulting from such mechanisms can become quite complex and difficult to handle. Often, simplifying assumptions can be used to analyze these systems. We shall examine one simplifying as- 
sumption referred to as the steady-state approximation. It can be illustrated with the hypothetical reaction scheme:

$$
\begin{gathered}
\mathrm{A} \stackrel{\mathrm{k}_{1}}{\leftrightarrows} \mathrm{B} \\
\mathrm{k}_{-1} \\
\mathrm{~B} \stackrel{\mathrm{k}_{2}}{\rightarrow} \mathrm{C}
\end{gathered}
$$

If $B$ is a reactive, unstable species its concentration will remain low. Applying the steady-state assumption, we assume that the rate of formation of the reactive species is equal to its rate of destruction:

$$
\mathrm{k}_{1}[\mathrm{~A}]=\mathrm{k}_{-1}[\mathrm{~B}]+\mathrm{k}_{2}[\mathrm{~B}]
$$

Solving for the steady-state concentration of B, we find that:

$$
[\mathrm{B}]=\mathrm{k}_{1}[\mathrm{~A}] /\left(\mathrm{k}_{-1}+\mathrm{k}_{2}\right)
$$

If we assume that the conversion of $\mathrm{B}$ to $\mathrm{C}$ is rate-limiting or the rate-determining step, the overall rate of the reaction will be:

$$
\mathrm{d}[\mathrm{C}] / \mathrm{dt}=\mathrm{k}_{2}[\mathrm{~B}]
$$

Substituting the term for the steady-state concentration of B (Equation 1.28) into Equation 1.29 gives:

$$
\mathrm{d}[\mathrm{C}] / \mathrm{dt}=\left(\mathrm{k}_{2} \mathrm{k}_{1}[\mathrm{~A}]\right) /\left(\mathrm{k}_{-1}+\mathrm{k}_{2}\right)
$$

If the experimental rate law was determined to be $d[C] / d t=k_{o b s}[A]$, then $k_{\text {obs }}$ would be related to the elementary reaction rate constants by:

$$
\mathrm{k}_{\mathrm{obs}}=\mathrm{k}_{2} \mathrm{k}_{1} /\left(\mathrm{k}_{-1}+\mathrm{k}_{2}\right)
$$

Arrhenius equation. The measurement of rate constants in the laboratory for transformation processes that are exceedingly slow ( $\mathrm{t}_{1 / 2}$ on the order of months to years) can be quite difficult. To circumnavigate this problem, kinetic measurements are made at elevated temperatures to accelerate reaction kinetics. Of course, it is then necessary to extrapolate measured rate constants to environmentally significant temperatures. The temperature dependence of observed rate constants is given by the Arrhenius equation:

$$
\mathrm{k}_{\mathrm{obs}}=\mathrm{A} \exp \left(-\mathrm{E}_{\mathrm{a}} / \mathrm{RT}\right)
$$


where $\mathrm{A}$ is the preexponential factor, $\mathrm{E}_{\mathrm{a}}$ is the activation energy, $\mathrm{R}$ is the gas constant, $1.987 \mathrm{cal} \mathrm{K}^{-1} \mathrm{~mol}^{-1}$, and $\mathrm{T}$ is the temperature in degrees Kelvin. From the logarithmic form of the Arrhenius equation it is apparent that the preexponential term $A$ and the energy of activation $E_{a}$ can be calculated from logarithms of the observed rate constants versus the reciprocal of the absolute temperatures. In the absence of experimental data to calculate $E_{a}$, a useful approximation for extrapolation is that rate constants will vary by a factor of 10 for each $20^{\circ} \mathrm{C}$ change in temperature. This corresponds to an activation energy of $20 \mathrm{kcal} / \mathrm{mol}$.

\section{c. Linear Free Energy Relationships}

Correlation Analysis. Numerous empirical models have been developed in organic chemistry that describe relationships between structure and reactivity. The most successful and intensively investigated are the linear free energy relationships (LFER), which correlate reaction rate constants and equilibrium constants for related sets of reactions. As Hammett stated: "From its beginning the science of organic chemistry has depended on the empirical and qualitative rule that like substances react similarly and that similar changes in structure produces similar changes in reactivity" (Hammett, 1970). "Linear free energy relationships constitute the quantitative specialization of this fundamental principle" (Chapman and Shorter, 1970). The origin of the LFER can be better understood by considering the relationship between the changes in free energy involved in the kinetic and equilibrium processes. If two reactions exhibit a LFER, we can write:

$$
\log \mathrm{k}-\log \mathrm{k}_{\mathrm{o}}=\mathrm{m}\left(\log \mathrm{K}-\mathrm{K}_{\mathrm{o}}\right)
$$

Substituting for $\mathrm{k}$ and $\mathrm{K}$ with the appropriate terms for free energy of activation (from transition-state theory) and free energy of reaction gives:

$$
\begin{aligned}
-\Delta \mathrm{G}^{\ddagger} / 2.3 \mathrm{RT}+\Delta \mathrm{G}_{\mathrm{o}}^{\ddagger} / 2.3 \mathrm{RT} & =\mathrm{m}\left(-\Delta \mathrm{G} / 2.3 \mathrm{RT}+\Delta \mathrm{G}_{\mathrm{o}} / 2.3 \mathrm{RT}\right) \\
-\Delta \mathrm{G}^{\ddagger}+\Delta \mathrm{G}_{\mathrm{o}}^{\ddagger} & =\mathrm{m}\left(-\Delta \mathrm{G}+\Delta \mathrm{G}_{\mathrm{o}}\right) \\
\Delta \Delta \mathrm{G}^{\ddagger} & =\mathrm{m} \Delta \Delta \mathrm{G}
\end{aligned}
$$

From this analysis, it is apparent that a relationship between $\mathrm{k}$ and $\mathrm{K}$ (at constant temperature) is essentially a relationship between free energies. The LFER therefore indicates that the change in free energy of activation $\left(\Delta \mathrm{G}^{\ddagger}\right)$ exerted by a series of substituents is directly proportional to the change in free energy of reaction $(\Delta G)$.

The use of LFERs constitutes one of the most powerful means for the elucidation of reaction mechanisms. LFERs also provide us a means to predict reaction rates or bioactivity from more easily measured equilibrium constants such as octanol-water partition coefficients $\left(\mathrm{K}_{\mathrm{ow}}\right)$, ionization constants $\left(\mathrm{K}_{\mathrm{a}}\right)$, or acidity constants $\left(\mathrm{K}_{\mathrm{HB}}\right)$. Brezonik (1990) has summarized the major classes of LFERs applicable to reactions in aquatic ecosystems (Table 1.2). These empirical correlations pertain to a variety 
Table 1.2. Major Classes of LFERs Applicable to Reactions in Aquatic Systems

\begin{tabular}{|c|c|c|}
\hline Relationship & Types of Reaction or Reactants & Basis of LFER \\
\hline Brønsted & $\begin{array}{l}\text { Acid- or base-catalyzed reactions: } \\
\text { hydrolysis, dissociation, association }\end{array}$ & $\begin{array}{l}\text { Rate related to } K_{\mathrm{a}} \text { or } K_{\mathrm{b}} \text { of } \\
\text { product or catalyst }\end{array}$ \\
\hline $\begin{array}{l}\text { Hammett } \\
\text { (sigma) }\end{array}$ & $\begin{array}{l}\text { Reactions of para- or meta- } \\
\text { substituted aromatic compounds: } \\
\text { hydrolysis, hydration of alkenes, } \\
\text { substitution, oxidation, enzyme- } \\
\text { catalyzed oxidations; some } \\
\text { photooxidations }\end{array}$ & $\begin{array}{l}\text { Electron withdrawal and/or } \\
\text { donation from/to reaction site } \\
\text { by substituents on aromatic } \\
\text { rings via resonance effects }\end{array}$ \\
\hline Taft & $\begin{array}{l}\text { Hydrolysis and many other reactions } \\
\text { of aliphatic organic compounds }\end{array}$ & $\begin{array}{l}\text { Steric and polar effects of } \\
\text { substituents }\end{array}$ \\
\hline Marcus & $\begin{array}{l}\text { Outer-sphere electron exchange } \\
\text { reactions of metal ions, chelated } \\
\text { metals, and metal ion oxidation by } \\
\text { organic oxidants such as pyridines } \\
\text { and quinones }\end{array}$ & $\begin{array}{l}\text { The three components of } \\
\text { energy needed to produce } \\
\text { transition state; for related } \\
\text { redox reactions, in } k \text { propor- } \\
\text { tional to } E^{\circ}\end{array}$ \\
\hline
\end{tabular}

of transformation processes, including hydrolysis, nucleophilic substitution, reduction, and oxidation.

Hammett equation. One of the first methods for relating structure and reactivity was developed by Hammett (1937). Hammett found that the reactivities of benzoic acid esters were directly related to the ionization constants, $K_{a}$, of the corresponding benzoic acids (Figure 1.3). Using substituted benzoic acids as his standard reference reaction, Hammett developed a LFER in the form:

$$
\log \left(\mathrm{k}_{\mathrm{x}} / \mathrm{k}_{\mathrm{o}}\right)=\rho \log \left(\mathrm{K}_{\mathrm{x}} / \mathrm{K}_{\mathrm{o}}\right)
$$

where $\mathrm{O}$ denotes unsubstituted benzoic acid and $\mathrm{x}$ denotes differently $\mathrm{X}$-substituted benzoic acids in the $\mathrm{m}$ - and $\mathrm{p}$-positions and $\rho$ is the reaction constant. Hammett defined the $\log$ of the ratio of the ionization constants as a substituent constant, $\sigma$,

$$
\sigma_{\mathrm{x}}=\log \left(\mathrm{K}_{\mathrm{x}} / \mathrm{K}_{\mathrm{o}}\right)
$$

Substitution of Equation 1.38 into Equation 1.37 gives Equation 1.39:

$$
\log \left(\mathrm{k}_{\mathrm{x}} / \mathrm{k}_{\mathrm{o}}\right)=\rho \sigma_{\mathrm{x}}
$$




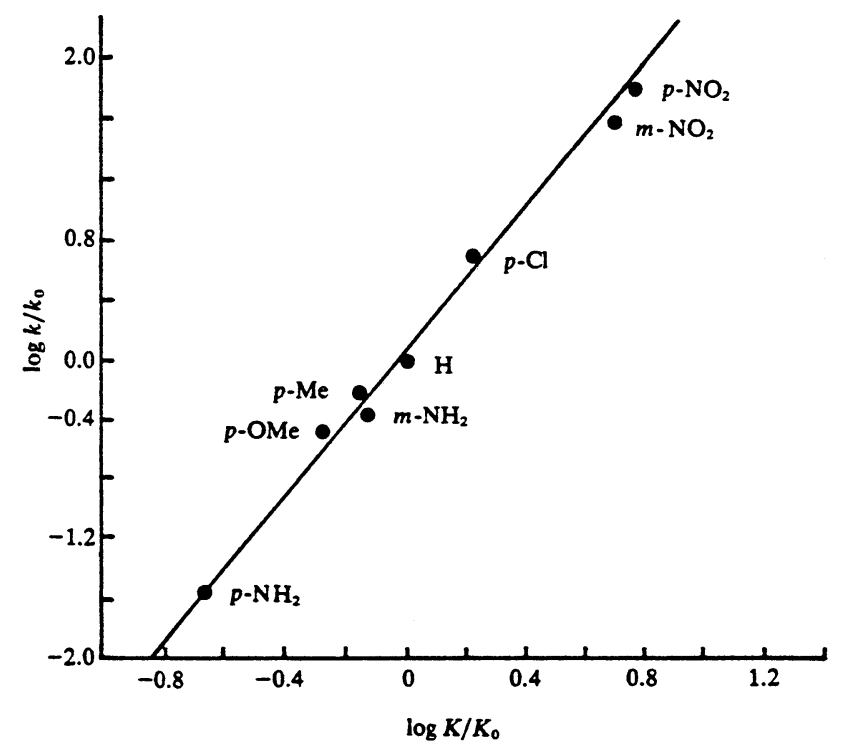

Figure 1.3. Correlation of acid dissociation constants of benzoic acids with rates of alkaline hydrolysis of ethyl benzoates. Reprinted from Hammett (1937) by permission of the American Chemical Society.

Values for the substituent constant, $\sigma$, have been determined for a large number of substituent groups by measurement of the dissociation constant of the substituted benzoic acids. Select values of $\sigma_{\mathrm{m}}$ and $\sigma_{\mathrm{p}}$ for substituents in the meta- and parapositions, respectively, are summarized in Table 1.3. These substituent groups perturb the electron density at the reactive center through resonance, inductive, or field effects. In principle, $\sigma$ values are independent of the nature of the reaction that is being investigated. The Hammett equation does not apply to ortho substituents because these groups may affect the reaction center through steric interactions. The sign of $\sigma$ reflects the effect that a particular substitutent has on developing charge at the reactive site. Electron-withdrawing substituents have positive values and electron-donating substituents have negative values.

The value of $\rho$ for the ionization of benzoic acids, the standard reaction, is arbitrarily assigned a value of 1 . The value of $\rho$ for a given reaction is determined from the slope of the line of a plot of $\log \left(\mathrm{k}_{\mathrm{x}} / \mathrm{k}_{\mathrm{o}}\right)$ versus $\sigma$. A straight line indicates that the linear free energy of Equation 1.39 is valid. The magnitude of $\rho$ reflects the susceptibility of a reaction to substituent effects. The sign of $\rho$ is of diagnostic value because it indicates the type of charge development in the transition state for the rate limiting step. Reactions with negative $\rho$ values (e.g., the hydrolysis of benzyl chlorides: Table 1.4) have positive charge development occurring in the transition state. Accordingly electron-donating substituents will stabilize the transition state, result- 
Table 1.3. Substituent Constants ${ }^{a}$

\begin{tabular}{|c|c|c|c|c|c|c|c|}
\hline \multicolumn{2}{|c|}{ Substituent Group } & \multirow{2}{*}{$\frac{\sigma_{m}}{0.21}$} & \multirow{2}{*}{$\frac{\sigma_{p}}{-0.01}$} & \multirow{2}{*}{$\frac{\sigma^{+}}{-0.25}$} & \multirow[t]{2}{*}{$\sigma_{t}$} & \multirow{2}{*}{$\frac{\mathbf{F}}{0.47}$} & \multirow{2}{*}{$\frac{\mathbf{R}}{-0.27}$} \\
\hline Acetamido & $\mathrm{AcNH}$ & & & & & & \\
\hline Acetoxy & $\mathrm{AcO}$ & 0.39 & 0.31 & 0.18 & & 0.68 & -0.07 \\
\hline Acetyl & $A c$ & 0.38 & 0.50 & 0.57 & 0.28 & 0.53 & 0.20 \\
\hline Amino & $\mathrm{NH}_{2}$ & -0.16 & -0.66 & -1.11 & 0.13 & 0.04 & -0.68 \\
\hline Bromo & $\mathrm{Br}$ & 0.39 & 0.23 & 0.02 & 0.45 & 0.72 & -0.18 \\
\hline t-Butyl & $(\mathrm{Me})_{3} \mathrm{C}$ & -0.10 & -0.20 & -0.28 & & -0.10 & -0.14 \\
\hline Chloro & $\mathrm{Cl}$ & 0.37 & 0.23 & 0.04 & 0.47 & 0.69 & -0.16 \\
\hline Cyano & $\mathrm{CN}$ & 0.56 & 0.66 & 0.67 & 0.56 & 0.85 & 0.18 \\
\hline Ethoxy & EtO & 0.10 & -0.24 & -0.58 & & 0.36 & -0.44 \\
\hline Ethyl & Et & -0.07 & -0.15 & -0.22 & & -0.07 & -0.11 \\
\hline Fluoro & $F$ & 0.34 & 0.06 & -0.25 & 0.52 & 0.71 & -0.34 \\
\hline Hydrogen & $\mathrm{H}$ & 0.00 & 0.00 & 0.00 & 0.00 & 0.00 & 0.00 \\
\hline Hydroxy & $\mathrm{OH}$ & 0.12 & -0.37 & -0.85 & 0.30 & 0.49 & -0.64 \\
\hline Methoxy & $\mathrm{MeO}$ & 0.12 & -0.27 & -0.65 & 0.30 & 0.41 & -0.50 \\
\hline Methyl & $\mathrm{Me}$ & -0.07 & -0.17 & -0.26 & -0.05 & -0.05 & -0.14 \\
\hline Nitro & $\mathrm{NO}_{2}$ & 0.71 & 0.78 & 0.74 & 0.63 & 1.11 & 0.16 \\
\hline Phenyl & $\mathrm{Ph}$ & 0.06 & -0.01 & -0.08 & & 0.14 & -0.09 \\
\hline Trifluoromethyl & $\mathrm{CF}_{3}$ & 0.43 & 0.54 & 0.58 & 0.42 & 0.63 & 0.19 \\
\hline Trimethylammonio & $(\mathrm{Me})_{3} \mathrm{~N}^{+}$ & 0.88 & 0.82 & 0.64 & 0.90 & 0.146 & 0.00 \\
\hline
\end{tabular}

${ }^{a}$ Sources: C. G. Swain and E. C. Lupton, Jr., J. Am. Chem. Soc. 90, 4328 (1968), and P. R. Wells, Linear Free Energy Relationships, Academic Press, New York, 1968.

Table 1.4. Reaction Constants ${ }^{a}$

\begin{tabular}{|c|c|}
\hline Reaction & $\rho$ \\
\hline $\mathrm{ArCO}_{2} \mathrm{H} \rightleftarrows \mathrm{ArCO}_{2}^{-}+\mathrm{H}^{+}$, water & 1.00 \\
\hline $\mathrm{ArCO}_{2} \mathrm{H} \rightleftarrows \mathrm{ArCO}_{2}^{-}+\mathrm{H}^{+}, \mathrm{EtOH}$ & 1.57 \\
\hline $\mathrm{ArCH}_{2} \mathrm{CO}_{2} \mathrm{H} \rightleftarrows \mathrm{ArCH}_{2} \mathrm{CO}_{2}^{-}+\mathrm{H}^{+}$, water & 0.56 \\
\hline $\mathrm{ArCH}_{2} \mathrm{CH}_{2} \mathrm{CO}_{2} \mathrm{H} \rightleftarrows \mathrm{ArCH}_{2} \mathrm{CH}_{2} \mathrm{CO}_{2}^{-}+\mathrm{H}^{+}$, water & 0.24 \\
\hline $\mathrm{ArOH} \rightleftarrows \mathrm{ArO}^{-}+\mathrm{H}^{+}$, water & 2.26 \\
\hline $\mathrm{ArNH}_{3}^{+} \rightleftarrows \mathrm{ArNH}_{2}+\mathrm{H}^{+}$, water & 3.19 \\
\hline $\mathrm{ArCH}_{2} \mathrm{NH}_{3}^{+} \rightleftarrows \mathrm{ArCH}_{2} \mathrm{NH}_{2}+\mathrm{H}^{+}$, water & 1.05 \\
\hline $\mathrm{ArCO}_{2} \mathrm{Et}+{ }^{-} \mathrm{OH} \rightarrow \mathrm{ArCO}_{2}^{-}+\mathrm{EtOH}$ & 2.61 \\
\hline $\mathrm{ArCH}_{2} \mathrm{CO}_{2} \mathrm{Et}+{ }^{-} \mathrm{OH} \rightarrow \mathrm{ArCH}_{2} \mathrm{CO}_{2}^{-}+\mathrm{EtOH}$ & 1.00 \\
\hline $\mathrm{ArCH}_{2} \mathrm{Cl}+\mathrm{H}_{2} \mathrm{O} \rightarrow \mathrm{ArCH}_{2} \mathrm{OH}+\mathrm{HCl}$ & -1.31 \\
\hline $\operatorname{ArC}(\mathrm{Me})_{2} \mathrm{Cl}+\mathrm{H}_{2} \mathrm{O} \rightarrow \operatorname{ArC}(\mathrm{Me})_{2} \mathrm{OH}+\mathrm{HCl}$ & -4.48 \\
\hline $\mathrm{ArNH}_{2}+\mathrm{PhCOCl} \rightarrow \mathrm{ArNHCOPh}+\mathrm{HCl}$ & -3.21 \\
\hline
\end{tabular}


ing in an acceleration of the reaction rate. On the other hand, electron-withdrawing groups will inhibit the rate of reaction by destabilizing the transition state.

Taft equation. Taft (1956) has extended the Hammett-type correlation to aliphatic systems. Because steric effects of substituents in aliphatic systems cannot be ignored as they were for $m$ - and $p$-substituted benzene compounds, Taft recognized the need to develop separate terms for the polar and steric effects for substituent constants. Based on the observation that the acid-catalyzed hydrolysis of meta- and parasubstituted benzoic acid esters are only slightly affected by the electronic nature of the substituent group ( $\rho$ values are near 0 ), Taft concluded that the acid-catalyzed hydrolysis of aliphatic esters would also be insensitive to polar effects of substituent groups. Any effect on rate due to substituent groups could therefore be attributed to steric effects. Taft defined a steric substituent constant, $\mathrm{E}_{s}$, by:

$$
\mathrm{E}_{\mathrm{s}}=\log \left(\mathrm{k}_{\mathrm{x}} / \mathrm{k}_{\mathrm{o}}\right)_{\mathrm{A}}
$$

where $\mathrm{k}_{\mathrm{x}}$ and $\mathrm{k}_{\mathrm{o}}$ are the hydrolysis rate constants for XCOOR and $\mathrm{CH}_{3} \mathrm{COOR}$, respectively, and the subscript A denotes acid-catalyzed hydrolysis. The large $\rho$ values measured for basic hydrolysis of benzoate esters demonstrates that the polar effects of substituents cannot be ignored. Assuming that the steric demands of the transition states for the acid- and base-catalyzed hydrolysis of esters are approximately equal, the polar parameter, $\sigma^{*}$, can be defined by:

$$
\sigma^{*}=\left(\log \left(\mathrm{k}_{\mathrm{x}} / \mathrm{k}_{\mathrm{o}}\right)_{\mathrm{B}}-\log \left(\mathrm{k}_{\mathrm{x}} / \mathrm{k}_{\mathrm{o}}\right)_{\mathrm{A}}\right) / 2.48
$$

where B denotes base-catalyzed hydrolysis and the factor 2.48 is used to normalize $\sigma^{*}$ to Hammett's $\sigma$. The general Taft equation for LFERs in aliphatic systems (Pavelich and Taft, 1957) can then be written as:

$$
\log \left(\mathrm{k}_{\mathrm{x}} / \mathrm{k}_{\mathrm{o}}\right)=\sigma^{*} \rho^{*}+\delta \mathrm{E}_{\mathrm{s}}
$$

Several $\mathrm{E}_{\mathrm{s}}$ and $\sigma^{*}$ constants are listed in Table 1.5.

Not many environmentally oriented investigations have applied the Taft equation to the treatment of their results. One of the few such studies that have been reported is actually not on a purely aliphatic system. Based on the general Taft equation (1.42), Wolfe et al. (1980b) established a LFER for the alkaline hydrolysis of phthalate esters that is described by:

$$
\log \mathrm{k}_{\mathrm{OH}}=4.59 \sigma^{*}+1.52 \mathrm{E}_{s}-1.02
$$

This LFER has been useful for the environmental assessment of phthalate esters for which hydrolysis rate constants have not been measured (Wolfe et al., 1980a). 
Table 1.5. Steric and Polar Parameters for Aliphatic Systems ${ }^{a}$

\begin{tabular}{lcc}
\hline \multicolumn{1}{c}{$\boldsymbol{X}$} & $\boldsymbol{E}_{\boldsymbol{S}}$ & $\sigma^{*}$ \\
\hline $\mathrm{H}$ & +1.24 & +0.49 \\
$\mathrm{CH}_{3}$ & 0.00 & 0.00 \\
$\mathrm{CH}_{3} \mathrm{CH}_{2}$ & -0.07 & -0.10 \\
$i-\mathrm{C}_{3} \mathrm{H}_{7}$ & -0.47 & -0.19 \\
$t-\mathrm{C}_{4} \mathrm{H}_{9}$ & -1.54 & -0.30 \\
$n-\mathrm{C}_{3} \mathrm{H}_{7}$ & -0.36 & -0.115 \\
$n-\mathrm{C}_{4} \mathrm{H}_{9}$ & -0.39 & -0.13 \\
$i-\mathrm{C}_{4} \mathrm{H}_{9}$ & -0.93 & -0.125 \\
$n e O-\mathrm{C}_{5} \mathrm{H}_{11}$ & -1.74 & -0.165 \\
$\mathrm{ClCH}_{2}$ & -0.24 & +1.05 \\
$\mathrm{ICH}_{2}$ & -0.37 & +0.85 \\
$\mathrm{Cl}_{2} \mathrm{CH}$ & -1.54 & +1.94 \\
$\mathrm{Cl}_{3} \mathrm{C}$ & -2.06 & +2.65 \\
$\mathrm{CH}_{3} \mathrm{OCH}$ & +0.52 \\
$\mathrm{C}_{6} \mathrm{H}_{5} \mathrm{CH}_{2}$ & -0.19 & +0.215 \\
$\mathrm{C}_{6} \mathrm{H}_{5} \mathrm{CH}_{2} \mathrm{CH}_{2}$ & -0.38 & +0.08 \\
$\mathrm{CH}_{3} \mathrm{CH}_{2} \mathrm{CH}$ & -0.38 & +0.36 \\
$\mathrm{C}_{6} \mathrm{H}_{5}$ & -1.63 & +0.60 \\
\hline $\mathrm{S}_{5}$ & -2.55 &
\end{tabular}

a Source: J. Shorter, Quarter. Rev. (London), 24:423 (1970).

\section{B. OVERVIEW OF THE ENVIRONMENT}

In this section, we will attempt to provide background information that sets the stage for an analysis of the occurrence of environmental organic reactions. Environmental milieux are highly variable in their temperatures, pressures, oxygen content, etc., and reactions that are important in one medium such as the gas phase of the atmosphere may be negligible in another, such as bottom sediments. The section will begin with an overview of the atmosphere and its organic constituents, followed by brief surveys of the organic environments of surface and groundwaters, and of soils and sediments. Emphasis will be on the characteristics of the matrices and the organic materials associated with them; details on the reaction pathways, followed by some of the organic constituents, will be discussed in later chapters.

\section{The Troposphere and the Stratosphere}

Today's atmosphere is the product of thousands of millions of years of evolution; it has changed almost completely since the primeval atmosphere first formed. The evolution of the atmosphere is, of course, continuing. Although the rates of change 
of major atmospheric constituents are very small, significant changes in some minor components are occurring now. For example, the activities of humans over the past century or so have caused a host of novel organic compounds to enter the atmosphere, and the combustion of huge quantities of fossil fuels has significantly increased its $\mathrm{CO}_{2}$ content. Since the late 1960 s, it has become clear that the entire troposphere is a transport system for trace organic compounds, as well as a gigantic reactor where chemical changes in those compounds are taking place under the influence of sunlight and in the presence of highly reactive intermediates.

\section{a. The Thermal Structure of the Atmosphere}

Virtually all $(99.999 \%)$ of the mass of the earth's atmosphere lies within $80 \mathrm{~km}$ of its surface; $80 \%$ is within the lowest $12 \mathrm{~km}$. The atmosphere is not a region of smoothly varying properties, but is distinctly stratified.

The traditional classification of atmospheric regions is based on temperature (Figure 1.4). Closest to the earth lies the troposphere (Greek tropos, change), a region of generally declining temperature in the upward direction. The cause of this thermal effect is the conversion of visible sunlight radiation at the earth's surface to heat (infrared) radiation. At about 10-12 km, a temperature minimum of approximately $210^{\circ} \mathrm{K}$ is reached; this is generally considered the top of the troposphere or tropopause. From 10 to about $50 \mathrm{~km}$ (the stratosphere) the temperature increases to about $270^{\circ} \mathrm{K}$. Little organic chemistry occurs above $50 \mathrm{~km}$. The region from 50 to 90 $\mathrm{km}$ (the mesosphere) is a region of generally declining temperatures, and finally, at still higher elevations (the thermosphere), the temperature increases sharply, to a maximum of about $2000^{\circ} \mathrm{K}$ at a few thousand kilometers.

The stratosphere is heated, principally, by a strongly exothermic, photochemically-driven reaction sequence;

$$
\begin{gathered}
\mathrm{O}_{2}+\mathrm{h} \nu(<242 \mathrm{~nm}) \rightarrow 2 \mathrm{O} \\
\mathrm{O}_{2}+\mathrm{O} \cdot \rightarrow \mathrm{O}_{3}+100 \mathrm{~kJ} \\
\mathrm{O}_{3}+\mathrm{O} \cdot \rightarrow 2 \mathrm{O}_{2}+400 \mathrm{~kJ} \\
\mathrm{O}_{3}+\mathrm{h} \nu(240-290 \mathrm{~nm}) \rightarrow \mathrm{O}_{2}+\mathrm{O} .
\end{gathered}
$$

The sequence is initiated by the homolysis of molecular oxygen. Light with wavelengths shorter than about $240 \mathrm{~nm}$ is virtually all absorbed by constituents of the upper regions of the atmosphere such as molecular $\mathrm{N}_{2}$; however, at the top of the stratosphere the concentration of $\mathrm{O}_{2}$ becomes sufficiently great for Reaction 1.44 to become important. The product of this reaction is two atoms of oxygen, which combine with molecular oxygen exothermically (in the presence of a third body, usually $\mathrm{N}_{2}$ ), to produce ozone. (Ozone also reacts with oxygen atoms in a very exothermic reaction that returns two equivalents of $\mathrm{O}_{2}$.) Molecular ozone, in turn, absorbs $240-290 \mathrm{~nm}$ actinic radiation to regenerate oxygen molecules and atoms. 


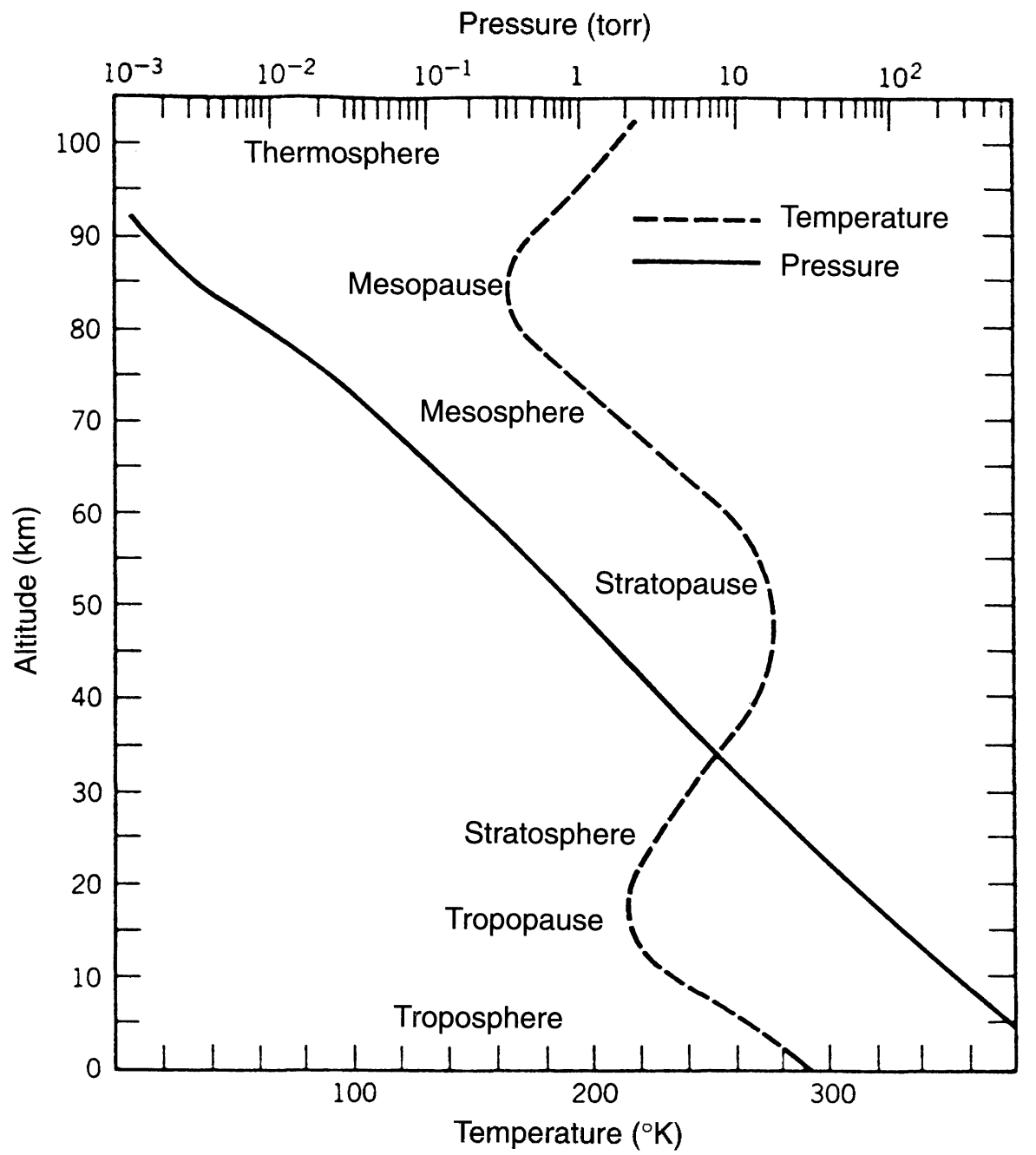

Figure 1.4. Thermal and pressure profiles of the atmosphere with elevation above the earth's surface. From B. J. Finlayson-Pitts and J. N. Pitts, Jr., Atmospheric Chemistry, John Wiley \& Sons 1986. Reprinted by permission.

The concentration of ozone is at a maximum at about $25 \mathrm{~km}$, roughly in the middle of the stratosphere.

The stratosphere, unlike the troposphere, undergoes little vertical mixing and few clouds are present; therefore, molecules that reach the stratosphere $\left(\mathrm{SO}_{2}\right.$ from volcanic eruptions, chlorofluorocarbons, etc.) tend to remain there for some time and are not "rained out" (deposited back to the earth's surface) as compounds in the troposphere can be. 


\section{b. Solar Energy Distribution}

The sun emits radiation whose frequency distribution is closely similar to that predicted for a blackbody radiator at $5900^{\circ} \mathrm{K}$ (Figure 1.5). It essentially begins in the vacuum UV at about $120 \mathrm{~nm}$, rises to a maximum at $400 \mathrm{~nm}$ at the beginning of the visible spectrum, and falls gradually through the visible and infrared regions. The total amount of solar energy received at the earth's surface is about $1370 \mathrm{~J} / \mathrm{m}^{2} / \mathrm{sec}$, and a quantity approximately equal to this is either reflected back into space or absorbed by the atmosphere.

Diurnal and seasonal variations in solar intensity are, of course, of utmost importance to ecosystems. In the extreme polar regions there is no direct solar radiation at all for more than four months of the year, whereas near the equator the overall intensity of sunlight fluctuates less than $10 \%$ annually. The spectral energy distribution also varies with the season. For example, in July in the middle latitudes (ca. $\left.40^{\circ}\right)$, the fraction of shorter-wave UV (290-315 nm) in the total solar radiation is more than three times higher than it is in December, due to the shorter path these easily scattered wavelengths have to traverse through the atmosphere. For similar reasons, shortwave UV is more intense at high elevations, particularly in the tropics where stratospheric ozone is less concentrated (Caldwell et al., 1980).

Because several constituents of the atmosphere $\left(\mathrm{O}_{3}, \mathrm{O}_{2}, \mathrm{CO}_{2}\right.$, and water) have

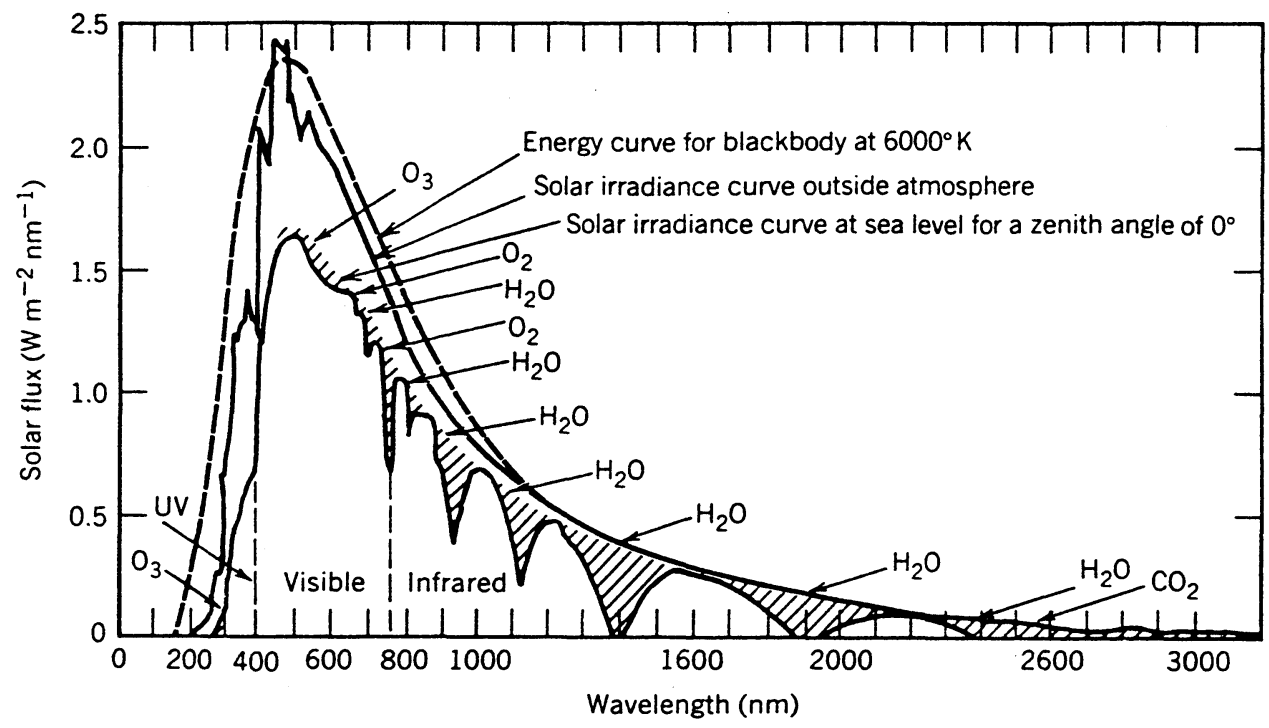

Figure 1.5. Energy flux (in watts per square meter) plotted against wavelength, calculated for a $6000^{\circ} \mathrm{K}$ blackbody radiator, and compared to the observed solar flux at sea level and outside the earth's atmosphere. Reprinted from Chapter 16, "Thermal Radiation," in Handbook of Geophysics, U.S. Air Force Cambridge Research Center, 1960. 
important absorption maxima in various regions of the solar spectrum, the frequency distribution of radiation at the earth's surface differs significantly from that emitted by the sun. Water, in the form of cloud droplets, for example, absorbs energy in the IR region and also reflects and scatters other sunlight wavelengths, so that the earth's surface is cooled when it is present in high concentrations. Other particles in the atmosphere also absorb and scatter incoming light in a complex manner that depends on their size, shape, and composition.

Because tropospheric $\mathrm{CO}_{2}$ levels have been increasing due to fossil fuel combustion over the past 100 or so years, it has been theorized that more and more infrared radiation is being absorbed, warming the troposphere (the so-called greenhouse effect). Other IR-absorbing atmospheric gases such as $\mathrm{CH}_{4}$, nitrous oxide, and chlorofluorocarbons also appear to be important contributors to the hypothesized global warming (Ramanathan et al., 1985; Rowland, 1989; Lashof and Ahuja, 1990). Tropical deforestation also has been implicated in global $\mathrm{CO}_{2}$ increases, since when trees are cut down, the succeeding grassy or weedy plant community can remove only a small fraction of atmospheric $\mathrm{CO}_{2}$, compared to the forest. Furthermore, much of the wood obtained is burned, adding to the $\mathrm{CO}_{2}$ burden directly.

In addition, stratospheric ozone concentrations appear to be declining, due to photolysis by shortwave UV of volatile chlorine-containing compounds such as $\mathrm{CFCl}_{3}$ and its relatives (Reaction 1.48); the $\mathrm{Cl}$ atoms produced in this reaction scavenge $O$ atoms (Reaction 1.49) and

$$
\mathrm{CFCl}_{3}+\mathrm{h} \nu(<250 \mathrm{~nm}) \rightarrow \cdot \mathrm{CFCl}_{2}+\cdot \mathrm{Cl}
$$

catalyze an efficient chain process (Reaction 1.6) that removes ozone molecules and converts them to oxygen molecules (Molina and Rowland, 1974; Rowland, 1989; Rowland, 1991):

$$
\begin{aligned}
& \mathrm{Cl} \cdot+\mathrm{O}_{3} \rightarrow \mathrm{ClO} \cdot+\mathrm{O}_{2} \\
& \mathrm{ClO} \cdot+\mathrm{O} \rightarrow \mathrm{Cl} \cdot+\mathrm{O}_{2}
\end{aligned}
$$

(sum)

$$
\mathrm{O}_{3}+\mathrm{O} \rightarrow 2 \mathrm{O}_{2}
$$

These compounds reach the stratosphere because they are so unreactive in all tropospheric processes, including reactions with $\mathrm{HO} \cdot$ to which they are virtually inert. Measurements of atmospheric ozone in Antarctica (Stolarski et al., 1986), in the Arctic (Zurer, 1990), and even in the temperate latitudes (Watson et al., 1988) all point to a decrease in stratospheric ozone concentrations. Recent attempts to diminish the use of ozone-depleting compounds on a global basis appear to have been successful; however, only minor effects on the rate of ozone destruction are likely to be observed for many years to come. 


\section{c. Chemical Constituents and Their Reactions}

The reactions leading to the transformation of organic compounds in the atmosphere are primarily oxidations; their rates are governed by the reactivities of the various classes of organic substances toward the oxidants (typically reactive oxygencontaining species) present. The majority of these oxygenated forms and the mechanisms of their reactions are discussed in detail in Chapter 4. Only an overview will be presented in this section.

Although a great assortment of organic molecules is present in the troposphere at all times, most occur only in trace concentrations. Because of the enormous extent of the atmosphere, however, it can be a sink for huge quantities of a given compound. One part in $10^{9}$, over the whole of the atmosphere, would correspond to three million tons of a uniformly distributed substance.

A comprehensive list of organic compounds detected in both natural and polluted atmospheres has been compiled by Graedel (1978). The book consists principally of tables, listing more than 1,600 identified compounds by structural class, concentration, and atmospheric lifetime, if known. The tables include substances found in tobacco smoke, forest fires, volcanic eruptions, and industrial emissions.

Hydrocarbons. The simplest hydrocarbon, methane $\left(\mathrm{CH}_{4}\right)$, is also by far the most abundant organic species in the atmosphere. It is largely produced at or slightly below the earth's surface by biotic mechanisms such as the anaerobic microbial decomposition of organic matter in such places as marshes, lake bottoms, landfills, and the stomachs of ruminant animals. Other sources of $\mathrm{CH}_{4}$ of probable lesser importance include natural gas seepages and incomplete combustion. Recent measurements of atmospheric methane concentration show that it has been increasing at about $1 \%$ per year, from typical levels of about $1.5 \mathrm{ppm}$ measured 15 or so years ago, to about 1.75 ppm at present (Rasmussen and Khalil, 1983; Khalil and Rasmussen, 1990). The lifetime of methane in the atmosphere is almost completely determined by its reaction with hydroxyl radical; for details see Chapter 4.B.2. A possible decline in the global levels of atmospheric hydroxyl radicals has been postulated as a contributing reason for the increasing methane concentration (Khalil and Rasmussen, 1985), although these workers believe that increased emission from agricultural and industrial activities contribute the majority of the increased concentration observed.

Higher alkanes found in the atmosphere, sometimes included in a category called nonmethane hydrocarbons or NMHC, principally come from natural gas seepages, transportation, and industrial activities. Normally, either ethane or butane is the second most abundant aliphatic hydrocarbon in atmospheric samples [usually in the 50-100 ppb range, more than an order of magnitude lower in concentration than methane (Cavanagh et al., 1969; Altshuller, 1983)]. Higher alkanes (up to $\mathrm{C}_{40}$ ) have been detected in aerosols and other atmospheric samples (Appel, 1981; Hutte et al., 1984; Sexton and Westberg, 1984; Harkov, 1986; Levsen et al., 1991). In clean environments, $n$-alkanes of odd carbon number from $\mathrm{C}_{23}$ to $\mathrm{C}_{33}$ predominate. The principal source of these compounds is the epicuticular wax layer of plants. 
Branched-chain alkanes in the $\mathrm{C}_{24}-\mathrm{C}_{30}$ range appear to be largely products of vehicular exhaust, and are apparently synthesized during fuel combustion (Boone and Macias, 1987).

Unsaturated aliphatic and cyclic hydrocarbons have numerous biological sources. Ethylene, $\mathrm{H}_{2} \mathrm{C}=\mathrm{CH}_{2}$, the simplest of the series, is emitted by green plants in substantial quantities. It has hormonal activity and has been implicated in the control of many physiological processes in plants. The natural tropospheric concentration of ethylene is very low due to its high reactivity with ozone, $\cdot \mathrm{OH}$, and other atmospheric oxidants (Robinson and Robbins, 1968), but in polluted atmospheres its concentrations can be much higher. It is a product of combustion of wood, coal, oil, natural gas, and petroleum. Elevated levels of ethylene, such as may occur in homes where coal gas is used for cooking, can be very deleterious to plants.

Green plants also release substantial quantities of isoprene (2) as well as monoterpenoid hydrocarbons such as $\alpha$-pinene (3), myrcene (4), and limonene (5). These compounds contribute significantly to atmospheric organic concentrations in remote or forested areas (Altshuller, 1983; Hutte et al., 1984). It has been estimated that the global output of these substances may equal about $28 \%$ of the annual output of methane (Rasmussen and Went, 1965).<smiles>C=CC(=C)C</smiles>

2<smiles></smiles>

4<smiles>CC1C2CC3CC1C3(C)C2</smiles>

3<smiles>C=C(C)C1CC=C(C)CC1</smiles>

5

Aromatic hydrocarbons are produced anthropogenically and have been identified in urban air. Generally, toluene is the most abundant aromatic hydrocarbon; benzene concentrations range from $1 / 2$ to $2 / 3$ of that of toluene. Simple aromatic compounds such as xylenes and other alkylated benzenes have also been detected at much lower $(0.001$ to $0.010 \mathrm{ppm})$ concentrations (Wathne, 1983). The principal source of these compounds is probably gasoline fuel evaporation, but it has been shown that simple aromatic hydrocarbons can be produced by cracking higher condensed molecules. Diesel exhaust contains a high proportion of two-ring hydrocarbons such as naphthalenes, indans, and tetrahydronaphthalenes (Levins, 1972). 
Polycyclic aromatic hydrocarbons (PAHs), defined as aromatic hydrocarbons with three or more rings, are also found in the atmosphere; they (especially the higher PAHs) are largely associated with particles. The mechanisms of formation of PAHs are discussed in Chapter 4. PAHs having fused ring numbers from two (naphthalene) to seven (coronene) have been observed (Lee et al., 1981; Hoff and Chan, 1987; Levsen et al., 1991). Concentration ranges reported are from less than 1 $\mathrm{ng} / \mathrm{m}^{3}$ to hundreds of $\mathrm{ng} / \mathrm{m}^{3}$. The combustion of almost any organic material produces PAHs (Table 1.6.) Benzo[a]pyrene (6), a particularly active carcinogenic $\mathrm{PAH}$, has been identified repeatedly in urban air studies. Usually, PAH concen-

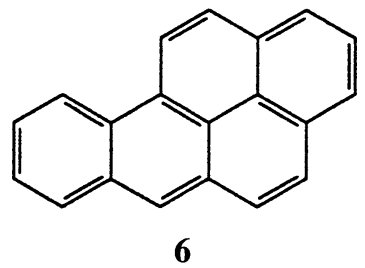

trations are highest in winter months, showing that heating systems are the most important contributors of atmospheric $\mathrm{PAH}$; but relatively large quantities are also produced by automobiles, electricity-generating stations, and refuse burning. Tobacco smoke and "tar" have especially high PAH concentrations; a heavy smoker probably inhales up to $1 \mu \mathrm{g}$ of benzo[a]pyrene daily (Wynder and Hoffmann, 1968). The atmospheric reactions of PAH include oxidations, usually by hydroxyl radical, to give rise to phenols and quinones (König et al., 1983) and also reactions with nitrogen oxides (usually surface-catalyzed) to produce nitro-PAH derivatives (Pitts et al., 1978; Arey et al., 1986; Pitts, 1987).

Fuel-rich conditions and relatively low temperatures permit the processes of PAH formation to continue for a long enough period so that roughly spherical aggregates of organic particles of colloidal dimensions (soot) are produced. In practical terms, a PAH with a molecular weight of about 2,000 can be considered to be a soot particle (Miller and Fisk, 1987). These high-carbon particles are long-lived and appear to be transported over very considerable distances.

Table 1.6. Formation of PAH During Pyrolysis of Various Organic Compounds

\begin{tabular}{lc}
\hline Material Pyrolyzed & Benzo[a]pyrene Produced $(\mu \mathbf{g} / \mathbf{g})$ \\
\hline Glucose & 48 \\
Fructose & 98 \\
Cellulose & 289 \\
Stearic acid & 1200 \\
Dotriacontane & 3130 \\
$\beta$-Sitosterol & 3750 \\
\hline
\end{tabular}

Source: Schmeltz and Hoffmann (1976). 
Hazes in the Arctic have been systematically observed since the late 1970s. Known to contain high concentrations of sulfur oxides as well as carbon, they form in the late autumn when weather and temperature patterns are favorable for transport of sooty particles from the industrial regions of North America and Europe (particularly the former Soviet Union). During the winter, such hazes may cover a region approximating the size of North America and extending vertically to at least $9,000 \mathrm{~m}$. In the spring, increasing atmospheric moisture and rain combine to scavenge and "rain out" the aerosols. It is probable that their carbon constituents may absorb $10 \%$ or more of the incident solar energy over the Arctic ice cap in the late winter months when their extent is greatest. The effects of these hazes on climate or on the Arctic ecosystem are almost entirely unknown (Hileman, 1983; Novakov, 1984).

Atmospheric particles are produced in virtually all combustion processes and are also formed when volatile products of plant origin are irradiated in the presence of a light-absorbing species such as $\mathrm{NO}_{2}$. The bluish atmospheric hazes common in forested mountainous areas have been attributed to the latter process. Traces of $\mathrm{SO}_{2}$ also promote the formation of organic particulate material. These particles, entering the atmosphere, are the principal locus for PAHs.

Oxygen-containing organic compounds. Data on oxygenated species in the atmosphere are relatively scarce, principally due to the lack of suitable analytical procedures for the determination of polar constituents in the presence of a large excess of hydrocarbons. Interest in the area is increasing, however, because of evidence that many reactive oxygen-containing species (epoxides, lactones, and hydroperoxides, for example) may be important in the epidemiology of respiratory disorders and cancer.

Methanol and ethanol occur in crankcase emissions and have been detected in urban air, methanol at levels up to $0.1 \mathrm{ppm}$ (Bellar and Sigsby, 1970). In addition, rather high concentrations of $n$-butanol $(0.019 \mathrm{ppm})$ occurred in the air at Point Barrow, Alaska (Cavanagh et al., 1969); it is likely that biological activity was responsible. Phenol is present at a few thousandths of a ppm; nitrophenols have been detected in rain water (Nojima et al., 1976; Levsen et al., 1991). Alkylphenols and alkyl-substituted nitrophenols have been identified in urban aerosols and in the exhaust from internal combustion engines (Schuetzle et al., 1975; Kuwata et al., 1980).

Carbonyl compounds are probably present at low levels in all air samples (Fung and Grosjean, 1981). A great variety of combustion processes produce aldehydes; they are particularly abundant in wood smoke, and have also been identified in the products of combustion of natural gas and fuel oil, and in engine exhaust samples. It is likely that they are relatively long-lived intermediates in atmospheric photooxidation reactions. Formaldehyde $\left(\mathrm{CH}_{2} \mathrm{O}\right)$, for example, is always an obligatory intermediate in the conversion of methane to $\mathrm{CO}_{2}$. In nearly all air samples so far examined, formaldehyde has been the most abundant aldehyde, with acetaldehyde, propionaldehyde, acrolein, benzaldehyde, crotonaldehyde, and furfural sometimes present at much lower concentrations (Kuwata et al., 1979; Penkett, 1982; Zhou and 
Mopper, 1990; Levsen et al., 1991). In Los Angeles air, higher aldehydes have been reported to be present at concentrations comparable to those of formaldehyde. In rain, fog, and mist samples taken in California, formaldehyde and acetaldehyde were always present, but surprisingly high concentrations of glyoxal and pyruvaldehyde were also detected. One fog sample contained $276 \mu \mathrm{M}(16 \mathrm{mg} / \mathrm{L})$ of glyoxal. It was suggested that the $\alpha$-dicarbonyl compounds were present at such high concentrations in the water because they were either more water-soluble or reacted more slowly with water or sulfur oxides than the monoaldehydes (Steinberg and Kaplan, 1984; Igawa et al., 1989). In Caribbean air samples, a series of aliphatic aldehydes ranging in chain length from $C_{1}$ to $C_{18}$ was identified (Zhou and Mopper, 1990). A forested atmosphere in Colorado was shown to contain (in addition to formaldehyde and acetaldehyde) several higher aldehydes typical of higher plants, including 2-hexenal (7) and $p$-hydroxybenzaldehyde (8: Nondek et al., 1992). Naphthaleneand alkylnaphthaldehydes, anthracene-9-carboxaldehyde (9) and phenanthrene-9carboxaldehyde (10) were identified in diesel exhaust particle extracts, together with some of their alkylated homologs (Choudhury, 1982; Newton et al., 1982).<smiles>CCC/C=C/C=O</smiles>

7<smiles>O=Cc1c2ccccc2cc2ccccc12</smiles>

9

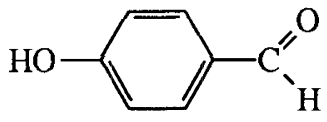

8

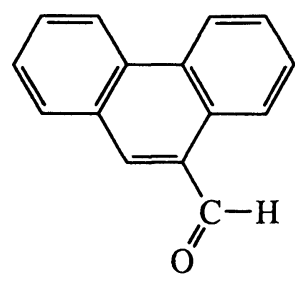

10

Not as much work has been reported on atmospheric ketone concentrations. Acetone was present at $0.001 \mathrm{ppm}$ in the air at Point Barrow, Alaska (Cavanagh et al., 1969) and also, at half that concentration or less, in air over the Atlantic (Penkett, 1982; Zhou and Mopper, 1990); it is also present at higher elevations (Arnold et al., 1986). Phenyl and higher cyclic ketones, a few $\mathrm{C}_{6}-\mathrm{C}_{18}$ aliphatic ketones, butanone, biacetyl and 4-methyl-2-pentanone have also been identified in ambient air (Kawamura and Kaplan, 1983; Ramdahl, 1983; Zhou and Mopper, 1990). Several quinones have been identified by Soxhlet extraction of atmospheric particulate material, including anthraquinone and more complex multi-ring compounds (Choudhury, 1982; Ramdahl et al., 1982). In addition, more than 40 other oxygenated PAHs including aldehydes, ketones, lactones, and anhydrides have also been characterized from airborne particle extracts (Choudhury, 1982; Newton et al., 
1982; Ramdahl et al., 1982; König et al., 1983; Helmig et al., 1992). Fluorenone (11) and its alkyl homologs were particularly abundant in diesel emission particulate material.

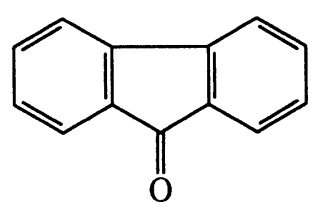

11

Carboxylic acids are produced in major quantities by the combustion of coal and wood. In fact, some time ago it was reported that far higher concentrations of organic acids than hydrocarbons were present in the volatile constituents from a large coal-fired power plant (Cuffe et al., 1964). However, the atmospheric fates of the acids are not completely understood. They do not appear to undergo important chemical reactions, except for keto acids, which photodegrade in a few hours (Grosjean, 1983; Berges and Warneck, 1992). Mostly, they are transferred back to the surface of the earth largely by dry deposition (if in the gas phase) and rainout (if in the particulate phase (Grosjean, 1989).

Formic acid is typically found at concentrations similar to those of the other onecarbon oxygenated compounds, methanol and formaldehyde. Other mono- and dicarboxylic acids are frequently identified in aerosols and other particles such as rain, fog, and mist; acetic acid is usually approximately as abundant as formic acid (Berkenbus, 1983; Kawamura and Kaplan, 1984; Kawamura et al., 1985; Steinberg et al., 1985; Harkov, 1986; Yokouchi and Ambe, 1986; Grosjean, 1989). Pyruvic acid, $\mathrm{CH}_{3} \mathrm{C}=\mathrm{O}-\mathrm{COOH}$, is produced during atmospheric oxidation of aromatic compounds such as $O$-cresol (Grosjean, 1984). It, like other keto acids, photodegrades further in sunlight to a mixture of products including formaldehyde, acetaldehyde, and PAN (Grosjean, 1983; Berges and Warneck, 1992).

Extracts of rain and snow from a southern Indiana location contained a long series of fatty acids, ranging in size from $\mathrm{C}_{12}$ to $\mathrm{C}_{28}$. Concentrations of total acids ranged from 4 to $45 \mu \mathrm{g} / \mathrm{L}$; palmitic and stearic acids $\left(n-\mathrm{C}_{16}\right.$ and $\mathrm{C}_{18}$, respectively) predominated. It was noted that concentrations of fatty acids were highest in the spring, when plant growth and pollen release were contributing organic matter to the atmosphere, and declined in the late autumn when deciduous plants died (Meyers and Hites, 1982). Analyses of atmospheric fallout samples in other areas have also revealed several long-chain fatty acids in the $\mathrm{C}_{8}-\mathrm{C}_{34}$ range, including unsaturated and branched-chain acids. Phenolic acids were also identified from a Japanese sample, including $o-, m$-, and $p$-hydroxybenzoic acids and several hydroxycinnamic acids. It was concluded that volatilization from pollens and other plant parts probably contributed to the occurrence of these compounds in the atmosphere (Matsumoto and Hanya, 1980; Levsen et al., 1991).

Carboxylic esters are very rarely found in atmospheric samples, with the exception of phthalate esters (12). These materials are practically ubiquitous in air and water 
samples (Appel, 1981; Hoff and Chan, 1987). Dibutyl, dioctyl, and di(2-ethylhexyl) phthalates are produced in very large quantities for use as plasticizers, lubricants, and ingredients of inks, cosmetics, adhesives, and coatings. The compounds combine great oxidative and hydrolytic stability with low water solubility and relatively high vapor pressure, and thus enter and persist in the atmosphere.<smiles>[R]OC(=O)c1ccccc1C(=O)O[X]</smiles>

12

Novakov has suggested that "primary oxidants," hydrogen peroxide and organic hydroperoxides (as opposed to the "secondary oxidants" formed in photochemical smog episodes), may play important roles in atmospheric chemistry and may have significant biological effects. The intermediacy of peroxy radicals, of course, is well established (see Section 4.A.1) in atmospheric photooxidation reactions, but the role of relatively long-lived nonradical forms has not been fully explored. Both of these types of oxidants are formed when pure or mixed hydrocarbons are burned in internal combustion engines (Novakov, 1984). Hydroperoxides and peroxy acids such as peracetic acid, $\mathrm{CH}_{3} \mathrm{C}(\mathrm{O}) \mathrm{OOH}$ and hydroxymethyl hydroperoxide, $\mathrm{HOCH}_{2} \mathrm{OOH}$, have also been shown to be formed in laboratory studies from a variety of hydrocarbon and carbonyl compound precursors (Hanst and Gay, 1983; Hewitt and Kok, 1991). Methyl, hydroxymethyl, and hydroxyethyl $\left(\mathrm{HOCH}_{2} \mathrm{CH}_{2} \mathrm{OOH}\right)$ hydroperoxides have been detected in air (Heikes et al., 1987; Hellpointner and Gäb, 1989). The sum of the concentrations of methyl hydroperoxide, hydroxymethyl hydroperoxide, and three other organic peroxides, measured in ambient air sampling studies in Colorado, was found to approximate or slightly exceed that for hydrogen peroxide (Hewitt and Kok, 1991).

Other organic compounds. Volatile organic nitrogen compounds of natural origin include aliphatic amines such as methyl, dimethyl, ethyl, diethyl, $n$-propyl, isopropyl, $n$-butyl, and sec-butyl, which have been identified in cattle feedlot air (Mosier et al., 1973). Dimethylnitrosamine, which could be formed by reactions of secondary amines with nitrogen oxides in the air or have a terrestrial origin, has been detected in ambient air samples in urban areas (Epstein et al., 1976; Fine et al., 1976). A number of heterocyclic nitrogen compounds have been detected in the nanograms/ $\mathrm{m}^{3}$ (parts per trillion) range, including caffeine, isoquinoline, and carbazole (Lee et al., 1981; Kawamura and Kaplan, 1983). Three nitriles (cyano compounds) derived from PAHs have been reported from urban air particles; unidentified isomers of acenaphthene-, anthracene-, and pyrenecarbonitriles (Ramdahl et al., 1982).

Sulfur compounds include alkylthiols (products of anaerobic microbial activity) 
and dimethyl sulfide (Lovelock et al., 1972; Adams et al., 1981; Andrae and Raemdonck, 1983). Thiols are also by-products of pulp and paper bleaching operations. In polycyclic fractions, dibenzothiophene and a few related compounds have been identified (Lee et al., 1981). Several compounds containing both sulfur and oxygen have been reported, including monomethyl and dimethyl sulfate, methanesulfonic acid (Panter and Penzhorn, 1980) and bis-hydroxymethyl sulfone, $\mathrm{HOCH}_{2} \mathrm{SO}_{2} \mathrm{CH}_{2} \mathrm{OH}$ (Eatough and Hansen, 1984; Eatough et al., 1986). The latter compound was proposed to be formed by a series of reactions involving ozone, ethylene, and $\mathrm{SO}_{2}$.

Atmospheric halogen compounds (Penkett, 1982) are of both natural and industrial origin. Probably the most abundant halocarbon in the troposphere is methyl chloride, $\mathrm{CH}_{3} \mathrm{Cl}$, which is present at a level of $0.6-2$ parts in $10^{9}$. It appears to be present in volcanic emissions, formed by microbial fermentation, by the combustion of vegetation (Lovelock, 1975), and by the $\mathrm{SN}_{2}$ reaction of methyl iodide (a constituent of marine algae) with the large excess of chloride ion in seawater (Zafiriou, 1975). Methyl iodide is also present in the atmosphere in highly variable amounts, averaging about one part in $10^{12}$; much higher concentrations are present in seawater (Lovelock et al., 1973). It is likely that other halogenated organic compounds of natural origin are also present in the atmosphere; for example, a host of $\mathrm{Cl}-, \mathrm{Br}$ - and I-containing haloforms and a variety of other halogen compounds have been identified as algal metabolites (Burreson et al., 1975; Gschwend et al., 1985). Organohalogen compounds appear to be much more common in nature than was previously thought; Swedish workers have shown that the concentrations of halogencontaining organic compounds in 135 lakes in southern Sweden were comparable to those of polluted rivers such as the Rhine (Asplund and Grimvall, 1991). These authors rejected the hypothesis of long-range atmospheric transport and concluded that enzymatic halogenation reactions were the source of the bulk of the observed haloorganic compounds.

Other halogenated compounds detected in low concentrations (usually less than 0.03 part in $\left.10^{9}\right)$ include chloroform $\left(\mathrm{CHCl}_{3}\right)$, dichloromethane $\left(\mathrm{CH}_{2} \mathrm{Cl}_{2}\right), 1,1$ dichloroethane $\left(\mathrm{ClCH}_{2} \mathrm{CH}_{2} \mathrm{Cl}\right)$, 1,1-dibromoethane or EDB $\left(\mathrm{BrCH}_{2} \mathrm{CH}_{2} \mathrm{Br}\right), 1,1,1$ trichloroethane $\left(\mathrm{CH}_{3} \mathrm{CCl}_{3}\right)$, trichloroethylene $\left(\mathrm{ClCH}=\mathrm{CHCl}_{2}\right)$ and tetrachloroethylene $\left(\mathrm{Cl}_{2} \mathrm{C}=\mathrm{CCl}_{2}\right)$. Virtually all of these compounds have an anthropogenic origin and, in many cases, their tropospheric concentrations have been increasing (TsaniBazaca et al., 1982; von Düszeln and Thiemann, 1985; Prinn et al., 1987). EDB and 1,1-dichloroethane are added to motor fuels because of their antiknock properties; trichloroethylene, trichloroethane, and tetrachloroethylene are used as solvents or in dry cleaning operations. It is likely that a significant fraction of the atmospheric chloroform is volatilized from drinking water, cooling waters, and wastewaters which have been treated with aqueous chlorine (see Section 5.A.3; Barcelona, 1979). Chloroform and 1,2-dichloroethane are also produced in automobile exhaust (Harsch et al., 1977; Clark et al., 1982).

Polychlorinated biphenyls (PCBs: 13) as well as DDT (14) and related compounds have been detected in air and atmospheric particle samples (Harvey and Steinhauer, 1974; Bidleman and Olney, 1974). Indoor air may contain rather high levels of 


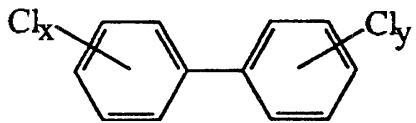

13

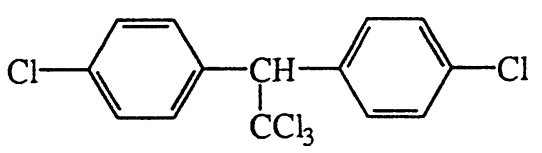

14

PCBs. Many products once contained PCBs and were used primarily inside buildings, such as printing ink, carbonless carbon paper, small electrical capacitors, and fluorescent light ballasts. MacLeod (1981) showed that indoor PCB concentrations in offices, private homes, and laboratories were (in the early 1980s) at least 10x and often 100x higher than outdoor levels. She also sampled an of fice in which a fluorescent light ballast had burned out and noted that immediately after the burnout, concentrations rose to more than $10 \mu \mathrm{g} / \mathrm{m}^{3}$ and then fell gradually over a period of at least three months to more typical values of $200 \mathrm{ng} / \mathrm{m}^{3}$.

Among the chlorinated heterocyclic compounds, chlorinated dibenzodioxins (15) and chlorinated dibenzofurans (16) have received much attention recently because of their high acute toxicity in some systems and their occurrence in the herbicide Agent Orange, in waste oils, and in bleached paper products. The compounds have been observed to be formed in low yields in many combustion-related processes such as municipal waste incineration (Rappe, 1984), and have been measured in ambient air samples by numerous investigators (see, e. g., Czuczwa and Hites, 1986; Marklund et al., 1986). Halogenated PAHs have been identified in flue gas effluents (Eklund and Stromberg, 1983).

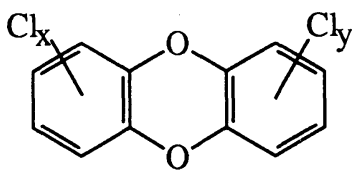

15

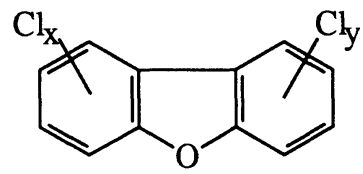

16

\section{Natural Waters}

The earth is unique in having a significant (ca. 70\%) surface covering of liquid water. Table 1.7 summarizes the global distribution of surface and near-surface water. The oceans contain a very large majority of the terrestrial water; most of the remainder is glacial ice.

Almost all of the fresh liquid water is groundwater, with at least half of the total present at depths of greater than $1000 \mathrm{~m}$. (Much less than $1 \%$ of the total is in the root zone of the soil.) Lakes and rivers, despite their extreme importance for humans, are a quantitatively insignificant component of the world's water supply. There is about as much water in the atmosphere as there is in all the world's rivers.

Evaporation and precipitation are in almost exact balance on a global basis. Of the rain and snow falling on land, about a third runs off and enters the ocean via river and lake drainage systems. The other two-thirds is retained temporarily by the 
Table 1.7. Global Distribution of Water

\begin{tabular}{lcc}
\hline & Volume $\mathbf{( k m}^{\mathbf{3}} \mathbf{)}$ & $\%$ \\
\hline Oceans & $1.37 \times 10^{9}$ & 97.3 \\
Ice caps, glaciers & $3.0 \times 10^{7}$ & 2.1 \\
Lakes & $1.2 \times 10^{5}$ & $8 \times 10^{-3}$ \\
Rivers & $1.2 \times 10^{4}$ & $8 \times 10^{-4}$ \\
Ground water & $8.3 \times 10^{6}$ & 0.6 \\
Soil moisture & $2.5 \times 10^{4}$ & $1.8 \times 10^{-3}$ \\
Atmosphere & $1.3 \times 10^{4}$ & $9 \times 10^{-4}$ \\
\cline { 2 - 3 } & $1.41 \times 10^{9}$ & 100.0 \\
\hline
\end{tabular}

soil and returned to the atmosphere directly (by evaporation) or indirectly (by transpiration from plants).

\section{a. Water as Solvent and Reactant}

Water is an angular molecule with an $\mathrm{H}-\mathrm{O}-\mathrm{H}$ bond angle of $104.5^{\circ}$ and an $\mathrm{O}-\mathrm{H}$ bond length of $0.96 \AA$. The energy of dissociation of the $\mathrm{O}-\mathrm{H}$ bond is about $450 \mathrm{~kJ} /$ mol, much higher than that for typical $\mathrm{C}-\mathrm{C}$ bonds which average around $350 \mathrm{~kJ} /$ mol.

Water has a very high latent heat of vaporization $(2300 \mathrm{~J} / \mathrm{g}$, by far the highest of all common liquids), and accordingly, considerable energy must be supplied to the liquid to convert it to the vapor. Nevertheless, the atmosphere always contains water both in the vapor state and in the form of small aerosol droplets. At $20^{\circ} \mathrm{C}$, up to $17 \mathrm{~g}$ water vapor $/ \mathrm{m}^{3}$ can be held in the air.

Liquid water. The structure of liquid water is still controversial. Some models suggest that it can be represented as a slightly disordered ice, although these representations do not account very well for the remarkable degree of supercooling (up to $40^{\circ} \mathrm{C}$ ) that the liquid can exhibit. It would be expected that ice-like assemblages would be efficient nuclei for crystallization.

An early proposal by Pauling (1960) was that liquid water could be considered a self-clathrate (Figure 1.6), with a central, nonhydrogen-bonded "guest" molecule surrounded by a hydrogen-bonded framework of pentagonally and hexagonallyfaced polyhedra. This model appears to be somewhat too "ordered" to account for many of the properties of water (Frank and Quist, 1961), but its central idea of a structure incorporating both "framework" (hydrogen-bonded) and "interstitial" (nonhydrogen-bonded) water molecules has been included in many of the more recent attempts to describe liquid water. The "flickering cluster" model (Nemethy and Scheraga, 1964) has many adherents; it posits the existence of compact, shortlived assemblages of hydrogen-bonded molecules in equilibrium with unassociated, "vapor-like" water. Cluster models can be expressed as an equilibrium between two 


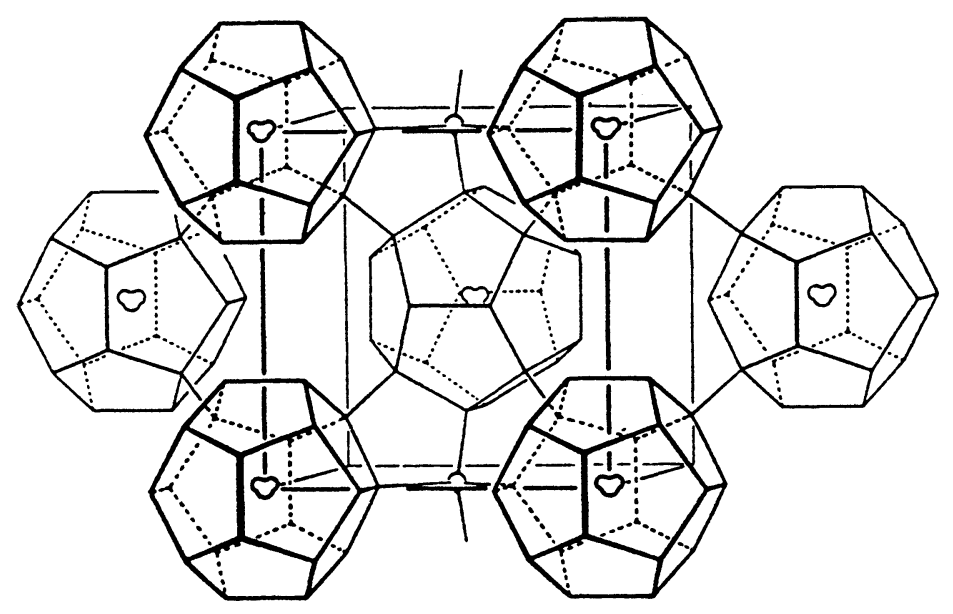

Figure 1.6. Pauling's host-guest model for liquid water structure. The central water molecule is envisioned as not taking part in hydrogen bonding with the surrounding icosahedral assemblage of 20 fully hydrogen-bonded molecules. From J. L. Kavanau (1964), Water and Solute-Water Interactions. Reprinted by permission of Holden-Day, Inc.

forms of water; "bulky" water $\left(\mathrm{H}_{2} \mathrm{O}\right)_{b}$ which is ice-like; that is, consisting of associated, open structures with considerable void space, and "dense" water $\left(\mathrm{H}_{2} \mathrm{O}\right)_{d}$ which is more closely packed and less hydrogen-bonded. Cooling such an assemblage would cause a shift in the equilibrium toward the bulky form, which would eventually crystallize, whereas heating it would increase the proportion of dense water which would escape as vapor.

Water as a solvent. Aqueous solutions can be thought of as rearrangements of the structure of liquid water in order to accommodate foreign molecules, which can interact with the solvent in more or less consequential ways. Two extremes can be imagined; a virtual noninteraction in which the water molecules merely circumvent the solute, arranging themselves around it; and an almost complete incorporation, in which the functional groups of the solute molecule placidly combine in the hydrogen-bonded lattice of the solvent. The former extreme is approximated in solutions of aliphatic hydrocarbons; the second, in solutions of sugars and sugar alcohols.

The molar solubility of aliphatic hydrocarbon gases in water shows a maximum at $\mathrm{C}_{3}-\mathrm{C}_{4}$. This appears to represent the optimum size for a clathrate-like structure in which the host water molecules arrange themselves around the guest hydrocarbon. This is a good example of the so-called "hydrophobic interaction" or "like-dissolveslike" phenomenon. Presumably, larger cages, such as would be required to surround a larger molecule, are less stable. The negative entropy change that occurs when a 
nonpolar gas is dissolved in water is quite considerable, suggesting that a more ordered, "ice-like" state results as the solute exerts a tendency for the water molecules in its vicinity to become more "bulky."

The properties of water in the presence of nonpolar solutes (those not having functional groups that can significantly interact with the water lattice) are to some degree similar to those of water containing nonpolar gases. Thus, for example, there is a roughly inverse linear relationship between the molar volume of a saturated hydrocarbon and its solubility. The aqueous solubilities of aliphatic hydrocarbons decrease sharply with increasing chain length, from about $5 \times 10^{-4} \mathrm{M}$ for $n$-pentane to $2.5 \times 10^{-5} \mathrm{M}$ for $n$-heptane and $1 \times 10^{-7} \mathrm{M}$ for $n$-dodecane (McAuliffe, 1966). It appears as if the formation of structured cavities having water molecules of sufficient size to accommodate hydrocarbons having more than a very few carbon atoms is energetically quite unfavorable.

Aromatic hydrocarbons also decrease in solubility with size, although they are far more soluble (approximately two orders of magnitude on a molar basis) than aliphatic hydrocarbons having the same number of carbon atoms (Mackay and Shiu, 1977; Pearlman et al., 1984). The solubilities of benzene, toluene, and naphthalene are, respectively, $1750 \mathrm{mg} / \mathrm{L}(0.022 \mathrm{M}), 550 \mathrm{mg} / \mathrm{L}\left(6 \times 10^{-3} \mathrm{M}\right)$, and $32 \mathrm{mg} / \mathrm{L}$ $\left(2.5 \times 10^{-5} \mathrm{M}\right)$. Even a rather large aromatic compound such as phenanthrene $\left(\mathrm{C}_{14} \mathrm{H}_{10}\right)$ has a solubility of nearly $1 \mu \mathrm{M}$. It is probable that there are significant charge-transfer interactions between water molecules and the pi electron clouds of aromatic species.

Striking increases in water solubility result when heteroatoms are introduced into hydrocarbon chains, due to the ability of the substituent to take part in hydrogen bonding and assume a position in the structural framework of the liquid. The solubility of $n$-hexane is only about $1 \times 10^{-4} \mathrm{M}$, but that of di- $n$-propyl ether is about $2.5 \times 10^{-2} \mathrm{M}$, and triethylamine is miscible with water. Introduction of polar or charged functional groups with exchangeable or ionizable hydrogens, such as $-\mathrm{OH}$, $-\mathrm{NH}-,-\mathrm{SO}_{3}^{-}$, or $-\mathrm{COO}^{-} /-\mathrm{COOH}$, causes dramatic changes in solubility behavior; hydrophobic interactions become less important than the short-range, stronger interactions between the polar groups and water molecules, unless the polar group is contained in a molecule having extensive nonpolar regions (such as a long-chain alcohol). As an example, a short-chain alcohol such as $n$-butanol may participate in water clusters by forming up to three hydrogen bonds, using the hydrogen atom and two electron pairs on oxygen. The nonpolar end of the molecule is probably surrounded by a clathrate-like region similar to the solvation cages of $n$-alkanes. By analogy to hydrocarbons, aromatic - $\mathrm{OH}$ compounds (phenols) are much more soluble than the corresponding linear alcohols; the $\mathrm{C}_{7}$ aliphatic alcohol $n$-heptanol has a solubility of $8 \times 10^{-3} \mathrm{M}$, and the cresols $\left(\mathrm{H}_{3} \mathrm{C}-\mathrm{Ph}-\mathrm{OH}\right)$ around $0.2 \mathrm{M}$.

As more $\mathrm{OH}$ groups are introduced into a molecule, its solubility characteristics depend to some extent on how well it fits into the framework of the structured component of water. It has been noted that the spacings between oxygen atoms of many very water-soluble compounds correspond rather closely to the first and second nearest-neighbor distances of the ice lattice (Berendsen, 1975). Seemingly minor changes in the stereochemistry of polyfunctional compounds often, however, lead to 
changes in solubility that are not well understood. These differences have been studied for some cyclic polyols and monosaccharides. For example, the oxygen atoms of $\beta$-D-glucose (17), which are all equatorially disposed, fit very well into an ice lattice; the water-water hydrogen bonds of the lattice are replaced by glucosewater bonds, and the solubility of glucose is extremely high $\left(90 \mathrm{~g} / 100 \mathrm{~mL} \mathrm{H}_{2} \mathrm{O}\right)$; but mannose (18), in which the $3-\mathrm{OH}$ is axial, has a solubility of $250 \mathrm{~g} / 100 \mathrm{~mL}$, and $\beta$-Dgalactose (19), with a 5 -axial $\mathrm{OH}$, has a solubility of $58 \mathrm{~g} / 100 \mathrm{~mL}$ (Tait et al., 1973).

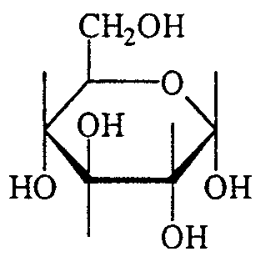

17

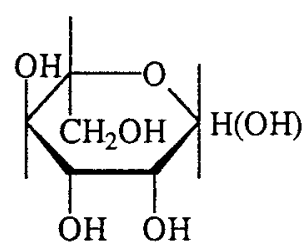

18

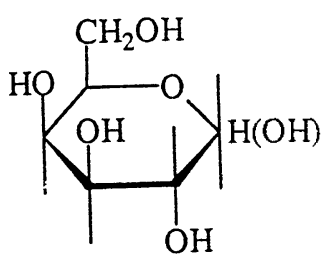

19

Many naturally occurring substances as well as compounds of anthropogenic origin are amphiphilic; that is, contain a highly polar region and a nonpolar region. Fatty acids and synthetic detergents are straightforward examples of this class of compounds, but polymeric dissolved organic species such as humic substances (see Sections 1.B.1f and 1.B.3a) also display these characteristics (Wershaw, 1986; Yonebayashi and Hattori, 1987). At very low concentrations, these substances may exist in true solution, but as their concentrations increase, interactions among their hydrophobic portions become dominant, and they produce oligomeric aggregates which eventually form particles of colloidal dimensions, called micelles (Figure 1.7).

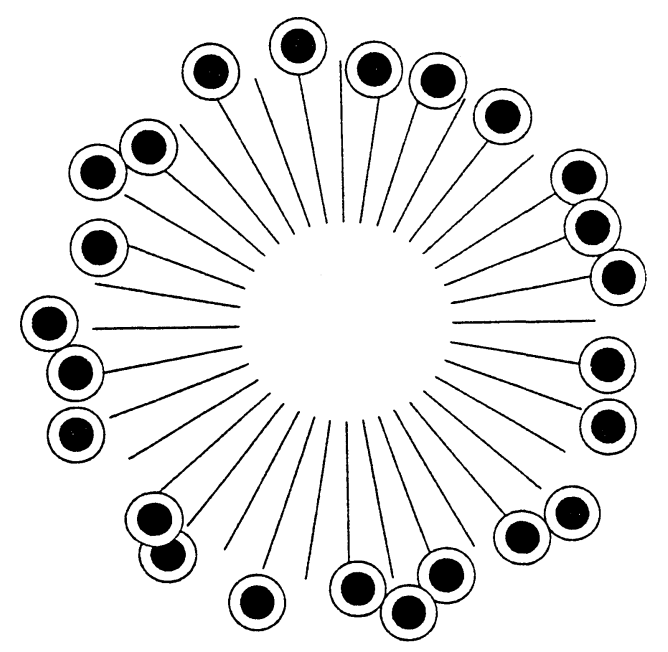

Figure 1.7. An idealized micelle, showing polar, hydrophilic head groups (circles) and hydrophobic chains (lines). 
Humic macromolecules may not form true micelles, but because they appear to include distinct hydrophobic and hydrophilic regions (Wershaw, 1986), they might be classified as "self-micelles." As in the case of completely apolar solutes, the formation of micelles is favored by the reduced volume of water cavity space required to surround the micelle relative to its individual molecules, but in addition, the polar regions of amphiphiles are oriented at the surface of the micelle and provide additional solubilizing capacity through ionic interactions, especially if they are charged.

The aggregates of many surface-active compounds are capable of enhancing the solubility of nonpolar organic compounds by bringing them into association with the hydrophobic portion of the amphiphilic cluster (Kile and Chiou, 1989). Humic aggregates and micelles, in particular, may incorporate nonpolar materials such as hydrocarbons, a property that gives them the ability to act as soaps and detergents and transport hydrophobic substances into the aqueous phase (Carter and Suffet, 1982). In the environment, this property becomes important in spills of materials such as petroleum; some of the insoluble hydrocarbons can become incorporated into naturally occurring micelles. For example, dissolved organic matter from seawater was shown to enhance the solubility of $n$-alkanes, but not branched or aromatic hydrocarbons (Boehm and Quinn, 1973). Other investigators, however, have found that the solubility of aromatic hydrocarbons was increased by some samples of humic material (Gauthier et al., 1987); humic substances with higher aromatic carbon content were generally more efficient at binding pyrene. It is possible that dissolved organic matter may enhance solubility of some, especially aromatic, hydrocarbons and quinones by charge-transfer interactions (Kress and Ziechmann, 1977; Melcer et al., 1987). The solubilities of hydrophobic compounds such as chlorinated pesticides have also been reported by many investigators to be enhanced in the presence of humic and fulvic acids (see, e. g., Chiou et al., 1986), although the enhancements vary greatly, depending on the source and chemical characteristics of the humic material (Chiou et al., 1987).

Amphiphilic compounds are also surface-active; their differently polarized regions cause them to accumulate at interfacial zones in the environment. For example, at the air-water interface, amphiphiles tend to orient themselves in "surface microlayers" or "surface films" (see Section 1.B.2d), where the polar region of the molecule is associated with the water phase and the nonpolar region is forced out of solution and extends up into the air phase. Often these surface layers are visible by the damping effect they exert on wave action (Figure 1.8); they are apparent as smoother patches among the ripples on a lake or in the ocean.

\section{b. Marine Waters and Estuaries}

The oceans. The volume of water contained in the world's oceans (about $1.4 \times 10^{9}$ $\mathrm{km}^{3}$, or $1.4 \times 10^{21}$ liters) defies the imagination. A generalized cross-section of the ocean (Figure 1.9) illustrates that only a small fraction of its water occurs near the surface; approximately half of it is more than $4 \mathrm{~km}$ deep. The range of hydrostatic pressure (1-1000 bars) in the seas is significant because at high pressures water no 


\section{Oragnic Chemicals in the Environment}

Adams, D. F. , S. O. Farwell , E. Robinson, M. R. Pack, and W. L. Bamesberger . 1981. Biogenic sulfur source strengths. Environ. Sci. Technol. 15: $1493-1498$.

Almendros, G. and J. A. Leal . 1990. An evaluation of some oxidative degradation methods of humic substances applied to carbohydrate-derived humic-like polymers. J. Soil Sci. 41: 51-59.

Almgren, T. B. , B. Josefsson, and G. Nyquist . 1975. A fluorescence method for studies of spent sulfite liquor and humic substances in sea water. Anal. Chim. Acta 78: 411-421.

Altshuller, A. P. 1983. Natural volatile substances and their effect on air quality in the United States. Atmos. Environ. 17: 2131-2165.

American Chemical Society . 1978. Cleaning our environment —a chemical perspective. Washington, DC.

Anderson, H. A. and J. D. Russell . 1976. Possible relationship between soil fulvic acid and polymaleic acid. Nature $260: 597$.

Anderson, H. A. , A. R. Fraser , A. Hepburn , and J. D. Russell . 1977. Chemical and infrared spectroscopic studies of fulvic acid fractions from a podzol. J. Soil Sci. 28: 623-633.

Andrae, M. O. and H. Raemdonck . 1983. Dimethyl sulfide in the surface ocean and marine atmosphere: a global view. Science $221: 744-747$.

Andrews, P. and P. J. LeB. Williams . 1971. Heterotrophic utilization of dissolved organic compounds in the sea. III. Measurement of the oxidation rates and concentrations of glucose and amino acids in sea water. J. Mar. Biol. Assoc. U.K. 51: 111-125.

Appel, B. R. 1981. Characterization of carbonaceous materials in atmospheric aerosols by high-resolution mass spectrometric thermal analysis. In G. M. Hidy, ed., The aerosol characterization experiment. Wiley-Interscience, New York.

Arai, S. and K. Kumada . 1983. The determination of 1,2-dicarboxylate structures in humic acid by fluorescein formation. Geoderma 31: 151-162. Arey, J. , B. Zielinska, R. Atkinson , A. M. Winer , T. Ramdahl , and J. N. Pitts jr ,. 1986. The formation of nitro-PAH from the gas-phase reactions of fluoranthene and pyrene with the $\mathrm{OH}$ radical in the presence of NOx. Atmos. Environ. 20: 2339-2345.

Arnold, F. , G. Knop, and H. Ziereis . 1986. Acetone measurements in the upper troposphere and lower stratosphere - implications for hydroxyl radical abundances. Nature 321: 505-507.

Asplund, G. and A. Grimvall . 1991. Organohalogens in nature. Environ. Sci. Technol. 25: 1346-1350.

Atherton, N. M. , P. A. Cranwell , A. J. Floyd, and R. A. Haworth . 1967. ESR spectra of humic acids. Tetrahedron 23: $1653-1667$.

Bada, J. L. and C. Lee . 1977. Decomposition and alteration of organic compounds dissolved in seawater. Mar. Chem. 5: 523-534.

Baier, R. E. , W. D. Goupil , S. Perlmutter, and R. King . 1974. Dominant chemical composition of the sea surface films, natural slicks and foams. J. Res. Atmos. 8: 571-600.

Baker, N. and L. Wilson . 1966. Water-soluble products of UV-irradiated, autoxidized linoleic and linolenic acids. J. Lipid Res. 7: $341-348$.

Barcelona, M. J. 1979. Human exposure to chloroform in a coastal urban environment. J. Environ. Sci. Health A14: $267-283$.

Barcelona, M. J. 1980. Dissolved organic carbon and volatile fatty acids in marine sediment pore waters. Geochim. Cosmochim. Acta 44: 1977-1984.

Barron, P. F. and M. A. Wilson . 1981. Humic soil and coal structure study with magic-angle spinning 13C CP-NMR. Nature 289: $275-276$.

Bartuska, V. I. , G. E. Maciel , H. I. Bolker, and B. I. Fleming . 1980. Structural studies of lignin isolation procedures by 13C NMR. Holzforschung 34: 214-217.

Batistic, L. 1974. Les acides aromatiques et volatils dans les sols. Plant Soil 41: 73-80.

Bazilevitch, N. I. 1974. Soil-forming role of substance and energy exchange in the soil-plant system. Trans. 10th Internat. Congr. Soil Sci., Moscow, 6: 17-27.

Bellar, T. A. and J. E. Sigsby . 1970. Direct gas chromatographic analysis of low molecular weight substituted organic compounds in emissions. Environ. Sci. Technol. 4: 150-156.

Berendsen, H. J. C. 1975. Specific interactions of water with biopolymers. In F. Franks, ed., Water: a comprehensive treatise. Vol. 5. Plenum, New York. pp. 293-330.

Berges, M. G. M. and P. Warneck . 1992. Product quantum yields for the 350-nm photodecomposition of pyruvic acid in air. Ber. Bunsen Ges. Phys. Chem. 96: 413-416.

Berkenbus, B. D. 1983. Methodology for the extraction and analysis of hydrocarbons and carboxylic acids in atmospheric particulate matter Atmos. Environ. 17: 1537-1543.

Bertino, D. J. , P. W. Albro, and J. R. Haas . 1987. Enzymatic hydrolysis of carbohydrates in aquatic fulvic acid. Environ. Sci. Technol. 21: 859-863.

Bidleman, T. F. and C. E. Olney . 1974. Chlorinated hydrocarbons in the Sargasso Sea atmosphere and surface water. Science $183: 516-518$. Black, A. P. and R. F. Christman . 1963a. Characteristics of colored surface waters. J. Amer. Water Works Assoc. 55: $753-769$.

Black, A. P. and R. F. Christman . 1963b. Chemical characteristics of fulvic acids. J. Amer. Water Works Assoc. 55: 897-912.

Boehm, P. D. and J. G. Quinn . 1973. Solubilization of hydrocarbons by the dissolved organic matter in sea water. Geochim. Cosmochim. Acta 34: 2459-2477.

Bolin, B. 1979. The global carbon cycle. John Wiley, Chichester, UK.

Bolin, B. and R. B. Cook, eds. 1983. Major biogeochemical cycles and their interactions. John Wiley, Chichester, UK.

Bollag, J.-M. 1983. Cross-coupling of humus constituents and xenobiotic substances. In R. F. Christman and E. T. Gjessing , eds., Aquatic and terrestrial humic materials. Ann Arbor Sci. Pub., Ann Arbor, MI, pp. 127-141.

Bonn, B. A. and W. Fish . 1991. Variability in the measurement of humic carboxyl content. Environ. Sci. Technol. 25: 232-240.

Boone, P. M. and E. S. Macias . 1987. Methyl alkanes in atmospheric aerosols. Environ. Sci. Technol. 21: 903-909.

Brewer, W. S. and F. K. Pfaender . 1979. The distribution of selected organic molecules in freshwater sediment. Water Res. 13: $237-240$.

Brezonik, P. L. 1990. "Principles of Linear Free-Energy and Structure-Activity Relationships and Their Applications to the Fate of Chemicals in Aquatic Systems," in Aquatic Chemical Kinetics, Stumm, W. Ed., John Wiley, New York, pp. 113-144.

Brook, A. J. W. and K. C. Munday . 1970. The effect of temperature on the interaction of phenols with Sephadex gels. J. Chromatogr. 51: 307-310.

Brown, K. W. and J. C. Thomas . 1984. Conductivity of three commercially available clays to petroleum products and organic solvents. Hazardous Waste 1: 545-553.

Brunner, S. , E. Hornung , H. Santi , E. Wolff , O. G. Piringer , J. Altschuh , and R. Bruggeman . 1990. Henry's law constants for polychlorinated biphenyls: experimental determination and structure-property relationships. Environ. Sci. Technol. 24: 1751-1754.

Buddrus, J. , P. Burba , H. Herzog , and J. Lambert . 1989. Quantitation of partial structures of aquatic humic substances by one-and twodimensional solution 13C nuclear magnetic resonance spectroscopy. Anal. Chem. 61: 628-631.

Buol, S. W. , F. D. Hole, and R. J. McCracken . 1973. Soil genesis and classification. Iowa State Univ. Press, Ames, IA.

Burkhard, L. P. , D. E. Armstrong, and A. W. Andren . 1985. Henry's law constants for the polychlorinated biphenyls. Environ. Sci. Technol. 19: 590-596.

Burreson, B. J. , R. E. Moore, and P. Roller . 1975. Haloforms in the essential oil of the alga Asparagopsis taxiformis (Rhodophyta). Tetrahedron Lett. 473-476.

Caldwell, A. D. and C. A. Black . 1958. Inositol hexaphosphate. I. Quantitative determination in extracts of soils and manures. Proc. Soil Sci. Soc. Amer. 22: 290-293.

Caldwell, M. M. , R. Robberecht, and W. D. Billings . 1980. A steep latitudinal gradient of solar ultraviolet-B radiation in the arctic-alpine life zone. Ecology 61: 600-611.

Cameron, D. W. and M. D. Sidell . 1976. A polychloroquinone from green soils. J. Chem. Soc. Chem. Commun. 252-253. 
Carlson, D. J. and L. M. Mayer . 1980. Enrichment of dissolved phenolic material in the surface microlayer of coastal waters. Nature 286: 482-483.

Carter, C. W. and I. H. Suffet . 1982. Binding of DDT to dissolved humic materials. Environ. Sci. Technol. 16: 735-740.

Cavanagh, L. A. , C. F. Schadt, and E. Robinson . 1969. Atmospheric hydrocarbon and carbon monoxide measurements at Point Barrow, Alaska. Environ. Sci. Technol. 3: 251-257.

Chapman, N. B. and J. Shorter, eds. 1970. Advances in Linear Free Energy Relationships, London: Plenum, Foreword.

Chen, Y. , F. J. Sowden, and M. Schnitzer . 1977. Nitrogen in Mediterranean soils. Agrochimica 21: 7-14.

Cheshire, M. V. 1977. Origins and stability of soil polysaccharide. J. Soil Sci. 28: 1-10.

Cheshire, M. V. , P. A. Cranwell , and R. D. Haworth . 1968. Humic acid -III. Tetrahedron 24: 5155-5167.

Cheshire, M. V. , C. M. Mundie, and H. Shepherd . 1973. The origin of soil polysaccharide: transformation of sugars during the decomposition in soil of plant material labelled with 14C. J. Soil Sci. 24: 54-68.

Chio, K. S. , U. Reiss, B. Fletcher, and A. L. Tappel . 1969. Peroxidation of subcellular organelles: formation of lipofuscinlike fluorescent pigments. Science 166: 1535-1536.

Chiou, C. T. , R. L. Malcolm , T. I. Brinton, and D. E. Kile . 1986. Water solubility enhancement of some organic pollutants and pesticides by dissolved humic and fulvic acids. Environ. Sci. Technol. 20: 502-508.

Chiou, C. T. , D. E. Kile , T. I. Brinton , R. L. Malcolm , J. A. Leenheer , and P. MacCarthy . 1987. A comparison of water solubility enhancements of organic solutes by aquatic humic materials and commercial humic acids. Environ. Sci. Technol. 21: 1231-1234.

Choudhury, D. R. 1982. Characterization of polycyclic ketones and quinones in diesel emission particulates by gas chromatography/mass spectrometry. Environ. Sci. Technol. 16: 102-106.

Christman, R. F. and M. Ghassemi . 1966. Chemical nature of organic color in water. J. Amer. Water Works Assoc. 58: $723-741$.

Clapp, C. E.Jr. , 1957. High molecular weight water-soluble muck: isolation and determination of constituent sugars of a borate complex-forming polysaccharide employing electrophoretic techniques. Diss. Abstr. 17: 963-964.

Clark, A. L. , A. E. McIntyre , J. N. Lester , and R. Perry . 1982. Evaluation of a Tenax GC sampling procedure for collection and analysis of vehicle-related aromatic and halogenated hydrocarbons in ambient air. J. Chromatogr. 252: 147-157.

Cordes, E. H. and W. P. Jencks . 1963. The mechanism of hydrolysis of Schiff bases derived from aliphatic amines. J. Am. Chem. Soc., 85 2843-2848.

Cosovic, B. , V. Vojvodic, and T. Plese . 1985. Electrochemical determination and characterization of surface active substances in freshwaters Water Res. 19: 175-183.

Cuffe, S. T. , R. W. Gerstle , A. A. Orning, and C. H. Schwartz . 1964. Air pollutants from coal-fired power plants; report no. 1. J. Air Pollut. Contr. Assoc. 14: 353-362.

Czuczwa, J. M. and R. A. Hites . 1986. Airborne dioxins and dibenzofurans: sources and fates. Environ. Sci. Technol. 20: 195-200.

Dixon, J. B. and S. B. Weed, eds. 1977. Minerals in soil environments. Soil Sci. Soc. Amer., Madison, WI.

Eatough, D. J. and L. D. Hansen . 1984. Bis-hydroxymethyl sulfone: a major aerosol product of the atmospheric reactions of S02(g). Sci. Total Environ. 36: 319-328.

Eatough, D. J. , V. F. White , L. D. Hansen, N. L. Eatough , and J. L. Cheney . 1986. Identification of gas-phase dimethyl sulfate and monomethyl hydrogen sulfate in the Los Angeles atmosphere. Environ. Sci. Technol. 20: 867-878.

Ehrhardt, M. , C. Osterroht, and G. Petrick . 1980. Fatty-acid methyl esters dissolved in seawater and associated with suspended particulate material. Mar. Chem. 10: 67-76.

Eisenreich, S. J. , A. W. Elzerman , and D. E. Armstrong . 1978. Enrichment of micronutrients, heavy metals, and chlorinated hydrocarbons in wind-generated lake foam. Environ. Sci. Technol. 12: 413-417.

Eklund, G. and B. Stromberg . 1983. Detection of polychlorinated polynuclear aromatics in flue gases from coal combustion and refuse incinerators. Chemosphere 12: 657-660.

Enders, C. and S. Sigurdsson . 1947. Chemie der Huminsaurebildung unter phy-siologischen Bedingungen. Biochem. Z. 318: 44-46.

Epstein, S. S. , D. H. Fine , D. P. Rounbehler, and N. M. Belcher . 1976. N-nitroso compounds: detection in ambient air. Science 192: $1328-1330$.

Ertel, J. R. and J. I. Hedges . 1983. Bulk chemical and spectroscopic properties of marine and terrestrial humic acids, melanoidins and catecholbased synthetic polymers. In R. F. Christman and E. T. Gjessing, eds., Aquatic and terrestrial humic materials. Ann Arbor Sci. Pub., Ann Arbor, MI, pp. 143-163.

Ertel, J. R. , J. I. Hedges, and E. M. Perdue . 1984. Lignin signature of aquatic humic substances. Science 223: 485-487.

Fine, D. H. , D. P. Rounbehler, E. Sawacki , K. Krost , and G. A. DeMarrais . 1976. N-nitroso compounds in the ambient community air of Baltimore, Maryland. Anal. Lett. 9: 595-604.

Flaig, W. 1950. Zur Kenntnis der Huminsauren. I. Mitteilung. Zur chemischen Konstitution der Huminsauren. Z. Pflanzenernähr. Düng. Bodenkunde 51: 193-212.

Flaig, W. 1971. Organic compounds in soil. Soil Sci. 111: 19-33.

Foo, L. Y. and K. R. Tate . 1977. Isolation of chrysotalunin, a red pigment from a New Zealand soil. Experientia 33: 1271.

Frank, H. S. and A. S. Quist . 1961. Pauling's model and the thermodynamic properties of water. J. Chem. Phys. 34: 604-611.

Fujitake, N. , J. Azuma, T. Hamasaki , H. Nakajima, and K. Saiki . 1991. Determination of chrysotalunin, a predominant soil anthraquinone pigment, by high-performance liquid chromatography. Geoderma 48: 83-91.

Fung, K. and D. Grosjean . 1981. Determination of nanogram amounts of carbonyls as 2,4-dinitrophenylhydrazones by high performance liquid chromatography. Anal. Chem. 53: 168-171.

Gardner, W. S. and D. W. Menzel . 1974. Phenolic aldehydes as indicators of terrestrially derived organic matter in the sea. Geochim. Cosmochim. Acta 38: 813-822.

Gardner, W. S. and R. B. Hanson . 1979. Dissolved free amino acids in interstitial waters of Georgia salt marsh soils. Estuaries 2: 113-116.

Garrett, W. D. 1967. The organic chemical composition of the sea surface. Deep-Sea Res. 14: 221-227.

Gauthier, T. D. , W. R. Seitz , and C. L. Grant . 1987. Effects of structural and compositional variations of dissolved humic materials on pyrene Koc values. Environ. Sci. Technol. 21: 243-248.

Ghassemi, M. and Christman, R. F. 1968. Properties of the yellow organic acids of natural waters. Limnol. Oceanogr. 13: 583-597.

Gibbs, R. J. 1972. Water chemistry of the Amazon River. Geochim. Cosmochim. Acta 36: 1061-1066.

Gillam, A. H. and M. A. Wilson . 1983. Application of 13C-nmr spectroscopy to the structural elucidation of dissolved marine humic substances and their phyto-planktonic precursors. In R. F. Christman and E. T. Gjessing , eds., Aquatic and terrestrial humic materials. Ann Arbor Sci. Pub., Ann Arbor, MI, pp. 25-35.

Given, P. H. 1975. Environmental organic chemistry of bogs, marshes, and swamps. In G. Eglinton, ed., Environmental chemistry. Ann. Rep.

Chem. Soc., London, pp. 55-80.

Gjessing, E. T. 1976. Physical and chemical characteristics of aquatic humus. Ann Arbor Sci. Pub., Ann Arbor, MI.

Goldberg, M. C. and E. R. Weiner . 1989. Fluorescence measurements of the volume, shape, and fluorophore composition of fulvic acid from the Suwanee River. In R. C. Averett, J. A. Leenheer, D. M. McKnight, and K. A. Thorn, eds. Humic substances in the Suwanee River, Georgia: interactions, properties, and proposed structures. USGS Report 87-557, Denver, CO, pp. 183-204.

Goni, M. A. and J. I. Hedges . 1990. Cutin-derived CuO reaction products from purified cuticles and tree leaves. Geochim. Cosmochim. Acta 54 : 3065-3072. 
Goodman, B. A. and M. V. Cheshire . 1973. Electron paramagnetic resonance evidence that copper is complexed in humic acid by the nitrogen of porphyrin groups. Nature New Biol. 244: 158-159.

Gossett, J. M. 1987. Measurement of Henry's law constants for C1 and C2 chlorinated hydrocarbons. Environ. Sci. Technol. 21: 202-208.

Graedel, T. E. 1978. Chemical compounds in the atmosphere. Academic Press, New York.

Grosjean, D. 1983. Atmospheric reactions of pyruvic acid. Atmos. Environ. 17: 2379-2382.

Grosjean, D. 1984. Atmospheric reactions of ortho cresol: gas phase and aerosol products. Atmos. Environ. 18: 1641-1652.

Grosjean, D. 1989. Organic acids in southern California air: ambient concentrations, mobile source emissions, in situ formation and removal processes. Environ. Sci. Technol. 23: 1506-1514.

Grov, A. 1963. Carbohydrates in cold water extracts of a pine forest soil. Acta Chem. Scand. 17: 2301-2306.

Gschwend, P. , J. MacFarlane, and K. Newman . 1985. Volatile halogenated organic compounds released to seawater from temperate marine macrolayer. Science 227: 1033-1035.

de Haan, H. 1972. Some structural and ecological studies of soluble humic compounds from Tjeukemeer. Verh. Int. Verein. Limnol. 18: 685-695.

Hall, K. J. and G. F. Lee . 1974. Molecular size and spectral characterization of organic matter in a meromictic lake. Water Res. 8: $239-251$.

Hammett, L. P. 1937. The effect of structure upon the reactions of organic compounds. benzene derivatives, J. Am. Chem. Soc., 59:96-103.

Hammett, L. P. 1970. Physical Organic Chemistry, 2nd edition, McGraw-Hill, New York, p. 347.

Hanst, P. L. and B. W. Gay, Jr. 1983. Atmospheric oxidation of hydrocarbons: formation of hydroperoxides and peroxyacids. Atmos. Environ. 17: 2259-2265.

Hargrave, B. T. and G. A. Phillips . 1975. Estimates of oil in aquatic sediments by fluorescence spectroscopy. Environ. Pollut. 8: 193-215.

Harkov, R. 1986. Semivolatile organic compounds in the atmosphere: a review. J. Environ. Sci. Health A21: 409-433.

Harsch, D. E. , R. A. Rasmussen, and D. Pierotti . 1977. Identification of a potential source of chloroform in urban air. Chemosphere 11: 769-775.

Harvey, G. A. and W. G. Steinhauer . 1974. Atmospheric transport of polychlorinated biphenyls to the North Atlantic. Atmos. Environ. 8: 777-782. Harvey, G. R. , D. A. Boran, L. A. Chesal, and J. M. Tokar . 1983. The structure of marine fulvic and humic acids. Mar. Chem. 12: 119-132. Harvey, G. R. , D. A. Boran , S. R. Piotrowicz, and C. P. Weisel . 1984. Synthesis of marine humic substances from unsaturated lipids. Nature 309: 244-246.

Hassett, J. J. , J. C. Means , W. L. Banwart, and S. G. Wood . 1980. Sorption properties of sediments and energy-related pollutants. EPA Report \#EPA-600/3-80-041, U.S. Environmental Protection Agency, Washington, DC.

Hatcher, P. G. , G. E. Maciel, and L. W. Dennis . 1981a. Aliphatic structure of humic acids: a clue to their origin. Org. Geochem. 3: 43-48.

Hatcher, P. G. , M. Schnitzer , L. W. Dennis, and G. E. Maciel . 1981b. Aromaticity of humic substances in soils. Soil Sci. Soc. Amer. J. 45: 1089-1094.

Hawker, D. W. 1989. Vapor pressures and Henry's law constants of polychlorinated biphenyls. Environ. Sci. Technol. 23: $1250-1253$.

Hayes, M. H. B. and R. S. Swift . 1978. The chemistry of soil organic colloids. In D. J. Greenland and M. H. B. Hayes, eds. The chemistry of soil constituents. Wiley, Chichester, UK, pp. 179-320.

Hedges, J. I. and P. L. Parker . 1976. Land-derived organic matter in surface sediments from the Gulf of Mexico. Geochim. Cosmochim. Acta 40: 1019-1029.

Heikes, B. G. , G. L. Kok, J. G. Walega, and A. L. Lazrus . 1987. H2O2, O3, and SO2 measurements in the lower troposphere over the eastern United States during fall. J. Geophys. Res. 92: 915-931.

Hellebust, J. A. 1965. Excretion of some organic compounds by marine phytoplankton. Limnol. Oceanogr. 10: 192-206.

Hellpointner, E. and S. Gab . 1989. Detection of methyl, hydroxymethyl and hydroxyethyl hydroperoxides in air and precipitation. Nature 337: 631-634.

Helmig, D. , J. W. Arey , W. P. Harger, and J. Lopez-Cancio . 1992. Formation of mutagenic nitrobenzopyranones and their occurrence in ambient air. Environ. Sci. Technol. 26: 622-624.

Henrichs, S. M. and J. W. Farrington . 1979. Amino acids in interstitial waters of marine sediments. Nature 279: 319-322.

Henrichs, S. M. and P. M. Williams . 1985. Dissolved and particulate amino acids and carbohydrates in the sea surface microlayer. Mar. Chem.

17: $141-163$.

Hewitt, C. N. and G. L. Kok . 1991. Formation and occurrence of organic hydroperoxides in the troposphere: laboratory and field observations.

Atmos. Chem. 12: 181-194.

Hileman, B. 1983. Arctic haze. Environ. Sci. Technol. 17: 232A-236A.

Hoff, R. M. and K. W. Chan . 1987. Measurement of polycyclic aromatic hydrocarbons in the air along the Niagara River. Environ. Sci. Technol. 21: $556-561$.

Hurst, H. M. and N. A. Burges . 1967. Lignin and humic acids. In A. D. McLaren and G. H. Peterson, eds., Soil biochemistry, Vol. 1. Marcel

Dekker, New York. pp. 260-286.

Hutchinson, G. E. 1957. A treatise on limnology. John Wiley, New York, p. 360.

Hutte, R. S. , E. J. Williams, J. Staehelin, S. B. Hawthorne, R. M. Barkley, and R. E. Sievers . 1984. Chromatographic analysis of organic compounds in the atmosphere. J. Chromatogr. 302: 173-179.

Igawa, M. , J. W. Munger, and M. R. Hoffmann . 1989. Analysis of aldehydes in cloud-and fogwater samples by HPLC with a postcolumn reaction detector. Environ. Sci. Technol. 23: 556-561.

Johnson, K. M. and J. McN. Sieburth . 1977. Dissolved carbohydrates in seawater. 1. A precise spectrometric analysis for monosaccharides. Mar. Chem. 5: 1-13.

Kalle, K. 1966. The problem of the Gelbstoff in the sea. Mar. Biol. Ann. Rev. 4: 91-104.

Karickhoff, S. W. 1984. Organic pollutant sorption in aquatic systems. J. Hydraul. Eng. 110: 707-735.

Karickhoff, S. W. and K. R. Morris . 1985. Sorption dynamics of hydrophobic pollutants in sediment suspensions. Environ. Toxicol. Chem. 4: 469-479.

Kawamura, K. and I. R. Kaplan . 1983. Organic compounds in the rainwater of Los Angeles. Environ. Sci. Technol. 17: 497-501.

Kawamura, K. and I. R. Kaplan . 1984. Capillary gas chromatography determination of volatile organic acids in rain and fog samples. Anal. Chem. 56: 1616-1620.

Kawamura, K. , S. Steinberg, and I. R. Kaplan . 1985. Capillary GC determination of short-chain dicarboxylic acids in rain, fog, and mist. Internat. J. Environ. Anal. Chem. 19: 175-188.

Khalil, M. A. K. and R. A. Rasmussen . 1985. Causes of increasing atmospheric methane: depletion of hydroxyl radicals and the rise of emissions. Atmos. Environ. 19: 397-407.

Khalil, M. A. K. and R. A. Rasmussen . 1990. Atmospheric methane: recent global trends. Environ. Sci. Technol. 24: 549-553.

Kile, D. E. and C. T. Chiou . 1989. Water solubility enhancements of DDT and trichlorobenzene by some surfactants above and below the critical micelle concentration. Environ. Sci. Technol. 23: 832-838.

Kirk, T. K. and H. M. Chang . 1974. Decomposition of lignin by white-rot fungi. II. Characterization of heavily degraded lignins from decayed spruce. Holzforschung 29: 56-64.

Kleber, R. J. and K. Mopper . 1990. Determination of picomolar concentrations of carbonyl compounds in natural waters, including seawater, by liquid chromatography. Environ. Sci. Technol. 24: 1477-1481.

Konig, J. , E. Balfanz, W. Funcke, and K. Romanowski . 1983. Determination of oxygenated polycyclic organic matter in airborne particulate material by capillary gas chromatography and gas chromatography —mass spectrometry. Anal. Chem. 55: 599-603. 
Kress, B. M. and W. Ziechmann . 1977. Wechselwirkung zwischen Humusstoffen und aromatischen Kohlenwasserstoffen. Chem. Erde. 36: 209-217.

Kuwata, K. , M. Uerobi, and Y. Yamasaki . 1979. Determination of aliphatic and aromatic aldehydes in polluted airs as their 2,4dinitrophenylhydrazones by high performance liquid chromatography. J. Chrornatogr. Sci. 17: 264-268.

Kuwata, K. , M. Uerobi, and Y. Yamasaki . 1980. Determination of phenol in polluted air as p-nitrobenzeneazophenol derivative by reversed phase high performance liquid chromatography. Anal. Chem. 52: 857-860.

Lagaly, G. 1984. Clay-organic interactions. Phil. Trans. Roy. Soc. Lond. A311: 315-332.

Lakshman, G. 1975. Monitoring agricultural pollution using natural fluorescence. Water Resources Res. 11: 705-708.

Larson, R. A. 1978. Dissolved organic matter of a low-coloured stream. Freshwat. Biol. 8: 91-104.

Larson, R. A. , T. L. Bott , L. L. Hunt , and K. Rogenmuser . 1979. Photooxidation products of a fuel oil and their antimicrobial activity. Environ. Sci. Technol. 13: 965-969.

Larson, R. A. and A. L. Rockwell . 1980. Fluorescence spectra of water-soluble humic materials and some potential precursors. Arch. Hydrobiol. 89: $416-425$.

Lashof, D. A. and D. R. Ahuja . 1990. Relative contributions of greenhouse gas emissions to global warming. Nature 344: 529-531.

Laszlo, P. 1987. Chemical reactions on clays. Science 235: 1473-1477.

Lee, M. L. , M. V. Novotny , and K. D. Bartle . 1981. Analytical chemistry of polycyclic aromatic compounds. Academic Press, New York.

Lee, R. F. and P. M. Williams . 1974. Copepod "slick" in the northwest Pacific Ocean. Naturwissenschaften 61: 505-506.

Leenheer, J. A. and T. I. Noyes . 1984. A filtration and column-adsorption system for onsite concentration and fractionation of organic substances from large volumes of water. USGS Water-Supply Paper \#2230. 16 pp.

Leenheer, J. A. , R. L. Malcolm , P. W. McKinley, and L. A. Eccles . 1973. Occurrence of dissolved organic carbon in selected ground-water samples in the United States. J. Res. U. S. Geol. Surv. 2: 361-369.

Leenheer, J. A. , M. A. Wilson, and R. L. Malcolm . 1987. Presence and potential significance of aromatic-ketone groups in aquatic humic substances. Org. Geo-chem. 11: 273-280.

Leenheer, J. A. , D. M. McKnight, E. M. Thurman , and P. MacCarthy . 1989. Structural components and proposed structural models of fulvic acid from the Suwanee River. In R. C. Averett , J. A. Leenheer, D. M. McKnight, and K. A. Thorn, eds. Humic substances in the Suwanee River, Georgia: interactions, properties, and proposed structures. USGS Report 87-557, Denver, CO, pp. 335-359.

Leopold, L. B. , M. G. Wolman, and J. P. Miller . 1964. Fluvial processes in geomorphology. Freeman, San Francisco, p. 51.

Lerman, A. 1971. Time to chemical steady states in lakes and oceans. In J. D. Hem, ed. Nonequilibrium systems in natural water chemistry. Advan. Chem. Ser. \# 106, American Chemical Society, Washington, DC, pp. 30-76.

Levins, P. L. 1972. Analysis of the odorous compounds in diesel engine exhaust. EPA Report \#EPA-R2-73-275. 129 pp.

Levsen, K. , S. Behnert , and H. D. Winkeler . 1991. Organic compounds in precipitation. Fresenius J. Anal. Chem. 340: 665-671.

Lewis, W. M. 1974. An analysis of surface slicks in a reservoir receiving heated effluent. Arch. Hydrobiol. 74: 304-315.

Liss, P. S. and P. G. Slater . 1974. Flux of gases across the air-sea interface. Nature 247: 181-184.

Lovelock, J. E. 1975. Natural halocarbons in the air and in the sea. Nature 256: 193-194.

Lovelock, J. E. , R. J. Maggs, and R. A. Rasmussen . 1972. Atmospheric dimethyl sulfide and the natural sulphur cycle. Nature 237: $452-453$.

Lovelock, J. E. , R. J. Maggs, and R. J. Wade . 1973. Halogenated hydrocarbons in and over the Atlantic. Nature 241: $194-196$.

Lüdemann, H.-D. , H. Lentz , and W. Ziechmann . 1973. Protonenresonanz-spektroskopie von Ligninen und Huminsaren bei 100 Megahertz. Erdöl Kohle 26: 506-509.

Lundquist, K. , B. Josefsson, and G. Nyquist . 1978. Analysis of lignin products by fluorescence spectroscopy. Holzforschung $32: 27-32$. Lyman, W. J. 1990a. Octanol-water partition coefficient. In W. J. Lyman , W. F. Reehl, and D. H. Rosenblatt, eds. Handbook of chemical property estimation methods. American Chemical Society, Washington, DC, pp. 1-1 - 1-51.

Lyman, W. J. 1990b. Adsorption coefficient for soils and sediments. In W. J. Lyman, W. F. Reehl, and D. H. Rosenblatt, eds. Handbook of chemical property estimation methods. American Chemical Society, Washington, DC, pp. 3-4 to 4-33.

Lyons, W. B. , H. E. Gaudette, and A. D. Hewitt . 1979. Dissolved organic matter in pore water of carbonate sediments from Bermuda. Geochim. Cosmochim. Acta 43: 433-437.

Lytle, C. R. and E. M. Perdue . 1981. Free, proteinaceous, and humic-bound amino acids in river water containing high concentrations of aquatic humus. Environ. Sci. Technol. 15: 224-228.

MacIntyre, F. 1974. Nonlipid-related possibilities for chemical fractionation in bubble film caps. J. Rech. Atmos. 8: 515-527.

Mackay, D. and P. J. Leinonen . 1975. Rate of evaporation of low solubility contaminants from water bodies to the atmosphere. Environ. Sci.

Technol. 9: 1178-1180.

Mackay, D. and W. Y. Shiu . 1977. Aqueous solubility of polynuclear aromatic hydrocarbons. J. Chem. Eng. Data 22: $399-402$.

Mackay, D. and W. Y. Shiu . 1981. A critical review of Henry's law constants for chemicals of environmental interest. J. Phys. Chem. Ref. Data 10: 1175-1199.

Mackay, D. , A. Bobra, and W. Y. Shiu . 1980. Relationships between aqueous solubility and octanol-water partition coefficients. Chemosphere 9: 701-711.

MacLeod, K. E. 1981. Polychlorinated biphenyls in indoor air. Environ. Sci. Technol. 15: 926-928.

Marklund, S. , L.-O. Kjeller, M. Hansson, M. Tysklind, C. Rappe, C. Ryan, H. Collazo, and R. Dougherty . 1986. Determination of PCDDs and PCDFs in incineration samples and pyrolytic products. In C. Rappe, G. Choudhary, and L. H. Keith, eds. Chlorinated dioxins and dibenzofurans in perspective. Lewis Publishers, Chelsea, MI. pp. 79-92.

Martin, D. F. and R. H. Pierce Jr. 1971. A convenient method of analysis of humic acid in fresh water. Anal. Lett. 49-52.

Martin, F. E. , P. Dubach, N. C. Mehta, and H. Deuel . 1963. Bestimmung der funktionellen Gruppen von Huminstoffen. Z. Pflanzenernähr. Düng. Bodenk. 103: 29-39.

Martin, J. K. and A. J. Wicken . 1966. Fractionation of organic phosphorus in alkaline soil extracts and the identification of inositol phosphates. New Zealand J. Agric. Res. 9: 529-535.

Matsui, Y. and K. Kumada . 1974. Hydroxyanthroquinones in soil. Soil Sci. Plant Nutr. 20: 333-341.

Matsumoto, G. and T. Hanya . 1980. Organic constituents in atmospheric fallout in the Tokyo area. Atmos. Environ. 14: 1409-1419.

Matthess, G. 1982. The properties of groundwater. Wiley-Interscience, New York.

McAuliffe, C. 1966. Solubility in water of paraffin, cycloparaffin, olefin, acetylene, cycloolefin, and aromatic hydrocarbons. J. Phys. Chem. 70: 1267-1275.

McCarty, P. L. , M. Reinhard, and B. E. Rittmann . 1981. Trace organics in ground-water. Environ. Sci. Technol. 15: 40-51.

McGrath, D. 1967. Nature and distribution in Irish soils of a new soil pigment. Nature 215: 1414.

McKnight, D. M. , E. M. Thurman , R. L. Wershaw, and H. H. Hemond . 1985. Biogeochemistry of aquatic humic substances in Thoreau's Bog, Concord, Massachusetts. Ecology 66: 1339-1352.

McLaren, A. D. 1957. Concerning the pH dependence of enzyme reactions on cells, particulates and in solution. Science 125: 697 .

Melcer, M. E. , M. S. Zalewski, M. A. Brisk, and J. P. Hassett . 1987. Evidence for a charge-transfer interaction between dissolved humic materials and organic molecules: study of the binding interaction between humic materials and chloranil. Chemosphere 16: 1115-1121.

Meybeck, M. 1981. Carbon dioxide effects research and assessment program: flux of organic carbon by rivers to the ocean. In Flux of organic carbon by rivers to the oceans, USDOE Report CONF-8009140, pp. 219-269.

Meyers, P. A. and R. A. Hites . 1982. Extractable organic compounds in midwest rain and snow. Atmos. Environ. 16: $2169-2175$. 
Mikita, M. A. , C. Steelink, and R. L. Wershaw . 1981. Carbon-13 enriched nuclear magnetic resonance method for the determination of hydroxyl functionality in humic substances. Anal. Chem. 53: 1715-1717.

Miller, J. A. and G. A. Fisk . 1987. Combustion chemistry. Chem. Eng. News. (Aug. 31). pp. 22-46.

Miller, M. M. , S. Ghodbane , S. P. Wasik , Y. B. Tewari , and D. E. Martire . 1984. Aqueous solubilities, octanol/water partition coefficients, and entropies of melting of chlorinated benzenes and biphenyls. Chem. Eng. Data 29: 184-190.

Moeller, J. R. , G. W. Minshall , K. W. Cummins, R. C. Petersen , C. E. Cushing, J. R. Sedell , R. A. Larson , and R. L. Vannote . 1979. Transport of dissolved organic carbon in streams of differing physiographic characteristics. Org. Geochem. 1: 139-150.

Molina, M. J. and F. S. Rowland . 1974. Stratospheric sink for chlorofluorome-thanes: chlorine atom-catalysed destruction of ozone. Nature 249:

810-812.

Mopper, K. , R. Dawson , G. Leibezelt , and V. Ittekott . 1980. The monosaccharide spectra of natural waters. Mar. Chem. 10: 55-56.

Morris, R. J. 1974. Lipid composition of surface films and zooplankton from the eastern Mediterranean. Mar. Pollut. Bull. 5: $105-109$.

Mosier, A. R. , C. E. Andre, and F. G. Viets, Jr. 1973. Identification of aliphatic amines volatilized from cattle feedyard. Environ. Sci. Technol. 7: 642-644.

Mulholland, P. J. and J. A. Watts . 1982. Transport of organic carbon to the oceans by rivers of North America: a synthesis of existing data. Tellus 34: 176-186.

Müller-Wegener, U. 1977. Fluoreszenzspektroskopische Untersuchungen an Humin-säuren. Z. Pflanzenernahr. Bodenkunde 32: 27-32.

Murphy, T. J. , M. D. Mullin, and J. A. Meyer . 1987. Equilibration of polychlorinated biphenyls and toxaphene with air and water. Environ. Sci. Technol. 21: 155-162.

Nemethy, G. and H. Scheraga . 1964. Structure of water and hydrophobic bonding in proteins. IV. The thermodynamic properties of liquid deuterium oxide. J. Chem. Phys. 41: 680-689.

Newton, D. L. , M. D. Erickson , K. B. Tomer, E. D. Pellizzari , P. Gentry, and R. B. Zweidinger . 1982. Identification of nitroaromatics in diesel exhaust particulates using gas chromatography/negative ion chemical ionization mass spectrometry and other techniques. Environ. Sci. Technol. 16: 206-213.

Nissenbaum, A. 1974. Deuterium content of humic acids from marine and submarine environments. Mar. Chem. 2: 59-63.

Nissenbaum, A. and I. R. Kaplan . 1972. Chemical and isotopic evidence for the in situ origin of marine humic substances. Limnol. Oceanogr. 17: 570-582.

Nojima, K. , K. Fukuya , S. Fukui , S. Kanno , S. Nishiyama, and Y. Wada . 1976. Formation of nitrophenols by the photochemical reaction of toluene in the presence of nitrogen monoxide and nitrophenols in rain. Chemosphere 5: 25-30.

Nondek, L. , D. R. Rodler, and J. W. Birks . 1992. Measurement of sub-ppbv concentrations of aldehydes in a forest atmosphere using a new HPLC technique. Environ. Sci. Technol. 26: 1174-1178.

Novakov, T. 1984. The role of soot and primary oxidants in atmospheric chemistry. Sci. Total Environ. 36: 1-10.

Orem, W. H. and P. G. Hatcher . 1987. Solid-state 13C NMR studies of dissolved organic matter in pore waters from different depositional environments. Org. Geochem. 11: 73-82.

Painter, H. A. and M. Viney . 1959. Composition of a domestic sewage. J. Biochem. Microbiol. Technol. Eng. 1: 143-162

Panter, R. and R. D. Penzhorn . 1980. Alkyl sulfonic acids in the atmosphere. Atmos. Environ. 14: 149-151.

Pauling, L. 1960. The nature of the chemical bond. 3rd ed. Cornell Univ. Press, Ithaca, NY, pp. 469-473.

Pavelich, W. A. and R. W. Taft . 1957. The evaluation of inductive and steric effects on reactivity. The methoxide ion-catalyzed rates of methanolysis of $l$-menthyl esters in methanol, J. Am. Chem. Soc., 79:4935-4940.

Payne, J. R. and C. R. Phillips . 1985. Photochemistry of petroleum in water. Environ. Sci. Technol. 19: 569-579.

Pearlman, R. S. , S. H. Yalkowsky, and S. Banerjee . 1984. Water solubilities of polynuclear aromatic and heteroaromatic compounds. J. Phys. Chem. Ref. Data 13: 555-562.

Pellenbarg, R. E. 1978. Spartina alterniflora litter and the aqueous surface microlayer in the salt marsh. Estuar. Coast. Mar. Sci. 6: $187-195$. Penkett, S. A. 1982. Non-methane organics in the remote troposphere. In E. D. Goldberg, ed., Atmospheric chemistry, Springer, Berlin, pp. 329-355.

Perdue, E. M. , J. H. Reuter , and M. Ghosal . 1980. The operational nature of acidic functional group analyses and its impact on mathematical descriptions of acid-base equilibria in humic substances. Geochim. Cosmochim. Acta 44: 1841-1851.

Pitts, J. N.Jr. 1987. Nitraton of gaseous polycyclic aromatic hydrocarbons in simulated and ambient urban atmospheres: a source of mutagenic nitroarenes. Atmos. Environ. 21: 2531-2547.

Pitts, J. N.Jr. , K. A. Van Cauwenberghe, D. Grosjean, J. P. Schmid, D. R. Fitz, W. L. Belser Jr. , G. B. Knudson , and P. M. Hynds . 1978. Atmospheric reactions of polycyclic aromatic hydrocarbons: Facile formation of mutagenic nitro derivatives. Science 202: 515-519.

Pojasek, R. B. and O. T. Zajicek . 1978. Surface microlayers and foams - source and metal transport in aquatic systems. Water Res. 12: 7-10. Popoff, T. and Theander, O. 1972. Formation of aromatic compounds from carbohydrates. I. Reaction of D-glucuronic acid, D-galacturonic acid, D-xylose, and L-arabinose in slightly acidic, aqueous solution. Carbohydrate Res. 22: 135-149.

Popoff, T. and Theander, O. 1976. Formation of aromatic compounds from carbohydrates. III. Reaction of D-glucose and D-fructose in slightly acidic, aqueous solution. Acta Chem. Scand. 30: 397-402.

Preston, C. M. and J. A. Ripmeester . 1982. Application of solution and solid-state 13C NMR to four organic soils, their humic acids, fulvic acids, humins and hydrolysis residues. Can. J. Spectrosc. 21: 99-105.

Prinn, R. , D. Cunnold, R. Rasmussen, P. Simmonds, F. Alyea, A. Crawford, P. Fraser, and R. Rosen . 1987. Atmospheric trends in methylchloroform and the global average for the hydroxyl radical. Science 238: 945-950.

Ramanathan, V., R. J. Cicerone, H. B. Singh, and T. Kiehl . 1985. Trace gas trends and their potential role in climate change. J. Geophys. Res. 90: 5547-5566.

Ramdahl, T. , G. Becher, and A. Bjørseth . 1982. Nitrated polycyclic aromatic hydrocarbons in urban air particles. Environ. Sci. Technol. 16: 861-865.

Ramdahl, T. 1983. Polycyclic aromatic ketones in environmental samples. Environ. Sci. Technol. 17: 660-670.

Rappe, C. 1984. Analysis of polychlorinated dioxins and furans. Environ. Sci. Technol. 18: 78A-90A.

Rasmussen, R. A. and M. A. K. Khalil . 1983. Global production of methane by termites. Nature 301: 700-702.

Rasmussen, R. A. and F. W. Went . 1965. Volatile organic material of plant origin in the atmosphere. Proc. Nat. Acad. Sci. U.S. 53: 215-220.

Riess-Kautt, M. , J. P. Kintzinger, and P. Albrecht . 1988. Omega-feruloyloxyacids, a novel class of polar lipids in peat soil. Naturwissenschaften 75: 305-307.

Riley, J. P. and D. A. Segar . 1970. The seasonal variation of the free and combined dissolved amino acids in the Irish Sea. J. Mar. Biol. Assoc. U.K. 50: 713-720.

Robinson, E. and R. C. Robbins . 1968. Sources, abundance, and fate of gaseous atmospheric pollutants. Stanford Research Institute Project Report \#PR-6755, Huntsville, AL. 123 pp.

Rowland, F. S. 1989. Chlorofluorocarbons and the depletion of stratospheric ozone. Amer. Scientist 77: 36-45.

Rowland, F. S. 1991. Stratospheric ozone in the 21st century: the chlorofluorocarbon problem. Environ. Sci. Technol. 25: 622-628.

Sargent, J. R. 1978. Marine wax esters. Sci. Progr. (Oxf.) 65: 437-458.

Sato, O. 1976. The chemical nature of components of PG (green fraction of P type humic acid). Soil Sci. Plant Nutr. 22: 485-488.

Schmeltz, I. and D. Hoffman . 1976. Formation of polynuclear aromatic hydrocarbons from combustion of organic matter. In R. Freudenthal and P. W. Jones, eds. Carcinogenesis: a comprehensive survey. Vol. 1. Polynuclear aromatic hydrocarbons: chemistry, metabolism, and carcinogenesis. Raven Press, New York. 
Schnitzer, M. 1985. Nature of nitrogen in humic substances. In G. R. Aiken , D. M. McKnight, R. L. Wershaw, and P. MacCarthy , eds. Humic substances in soil, sediment, and water. Wiley, New York, pp. 303-325.

Schnitzer, M. and U. C. Gupta . 1965. Determination of acidity in soil organic matter. Soil Sci. Soc. Amer. Proc. 29: 274-277.

Schnitzer, M. and S. U. Khan . 1972. Humic substances in the environment. Marcel Dekker, New York.

Schnitzer, M. and M. I. Ortiz de Serra . 1973. The chemical degradation of a humic acid. Can. J. Chem. 51: 1554-1556.

Schuetzle, D. , D. Cronn , A. L. Crittenden, and R. J. Charlson . 1975. Molecular composition of secondary aerosol and its possible origin.

Environ. Sci. Technol. 9: 838-845.

Schütte, K. H. and J. F. Ellsworth . 1954. The significance of large pH fluctuations observed in some South African vleis. J. Ecol. 42: 148-150.

Scully, F. E.Jr. , G. D. Howell , R. Kravitz , J. T. Jewell , V. Hahn , and M. Speed . 1989. Proteins in natural waters and their relation to the formation of chlorinated organics during water disinfection. Environ. Sci. Technol. 22: 537-542.

Sequi, P. , G. Guidi , and G. Petruzzelli . 1975. Distribution of amino acid and carbohydrate components in fulvic acid fractionated on polyamide. Can. J. Soil Sci. 55: 439-445.

Sexton, K. and H. Westberg . 1984. Nonmethane hydrocarbon composition of urban and rural atmospheres. Atmos. Environ. 18: 1125-1132. Shaw, D. G. and B. A. Baker . 1978. Hydrocarbons in the marine environment of Port Valdez, Alaska. Environ. Sci. Technol. 13: $1200-1205$.

Sieburth, J. McN. and A. Jensen . 1968. Studies on algal substances in the sea. 1. Gelbstoff (humic material) in terrestrial and marine waters. J. Exp. Mar. Biol. Ecol. 2: 174-189.

Skujins, J. J. 1967. Enzymes in soil. In A. D. McLaren and G. H. Peterson, eds., Soil biochemistry, Vol. 1. Marcel Dekker, New York. pp. $371-416$.

Smart, P. L. , B. L. Finlayson, W. D. Rylands, and C. M. Ball . 1976. The relationship of fluorescence to dissolved organic carbon in surface waters. Water Res. 10: 805-811.

Snape, C. E. , D. E. Axelson , R. E. Botto , J. J. Delpeuch , P. Tekely , B. C. Gerstein , M. Pruski , G. E. Maciel , and M. A. Wilson . 1989. Quantitative reliability of aromaticity and related measurements on coals by $13 \mathrm{C} \mathrm{n.} \mathrm{m.} \mathrm{r.} \mathrm{A} \mathrm{debate.} \mathrm{Fuel} \mathrm{68:} \mathrm{547-560.}$

Soma, Y. , M. Soma, and I. Harada . 1983. Raman spectroscopic evidence of formation of p-dimethoxybenzene cation on Cu-and Rumontmorillonite. Chem. Phys. Lett. 94: 475-478.

Spiteller, M. and M. Schnitzer . 1983. A comparison of the structural characteristics of polymaleic acid and a soil fulvic acid. J. Soil Sci. 34 525-537.

Steelink, C. , M. A. Mikita, and K. A. Thorn . 1983. Magnetic resonance studies of humates and related model compounds. In R. F. Christman and E. T. Gjessing , eds., Aquatic and terrestrial humic materials. Ann Arbor Sci. Pub., Ann Arbor, MI, pp. 83-105.

Steinberg, S. and I. R. Kaplan . 1984. The determination of low molecular weight aldehydes in rain, fog and mist by reversed phase liquid chromatography of the 2,4-dinitrophenylhydrazone derivatives. Int. J. Environ. Anal. Chem. 18: 253-266.

Steinberg, S. , K. Kawamura, and I. R. Kaplan . 1985. The determination of a-keto acids and oxalic acid in rain, fog and mist by HPLC. Int. J. Environ. Anal. Chem. 19: 251-260.

Stevenson, F. J. 1969. Organic acids in soil. In A. D. McLaren and G. H. Peterson, eds., Soil biochemistry, Vol. 1. Marcel Dekker, New York. pp. 119-146.

Stevenson, F. J. 1982. Humus chemistry: genesis, composition, reactions. Wiley-Interscience, New York.

Stevenson, F. J. and J. H. A. Butler . 1969. Chemistry of humic acids and related pigments. In G. Eglinton and M. J. Murphy , eds. Organic geochemistry. Springer Verlag, New York. pp. 534-557.

Stiver, W. and D. Mackay . 1984. Evaporation rate of spills of hydrocarbons and petroleum mixtures. Environ. Sci. Technol. 18: 834-840.

Stiver, W. , W. Y. Shiu, and D. Mackay . 1989. Evaporation times and rates of specific hydrocarbons in oil spills. Environ. Sci. Technol. 23:

101-105.

Stolarski, R. S. 1986. Nimbus 7 satellite measurements of the springtime Antarctic ozone decrease. Nature 322: 808-812.

Strahler, A. N. 1957. Quantitative analysis of watershed geomorphology. Trans. Amer. Geophys. Union 83: $913-920$.

Stumm, W. and J. J. Morgan . 1981. Aquatic chemistry. 2nd ed., Wiley-Interscience, New York.

Swain, F. M. 1963. Geochemistry of humus. In I. A. Breger, ed. Organic geochemistry. Pergamon, ;New York, pp. 81-147.

Sweet, M. S. and E. M. Perdue . 1982. Concentration and speciation of dissolved sugars in river water. Environ. Sci. Technol. 16: 692-698.

Taft, R. W.Jr. 1956. Separation of polar, steric, and resonance effects in reactivity, in Steric Effects in Organic Chemistry, M. S. Newman, Ed., John Wiley, New York, pp. 556-675.

Tait, M. J. , A. Suggett , F. Franks , S. Ablett , and P. A. Quikenden . 1973. Hydration of monosaccharides: a study by dielectric and nuclear magnetic relaxation. J. Solution Chem. 1: 131-151.

Tan, K. H. and F. E. Clark . 1969. Polysaccharide constituents in fulvic and humic acids extracted from soil. Geoderma 2: $245-255$.

Tate, K. R. and H. A. Anderson . 1978. Phenolic hydrolysis products from gel chromatographic fractions of humic acids. J. Soil Sci. $29: 76-83$.

Tegelaar, E. W. , J. W. de Leeuw, and C. Saiz-Jimenez . 1989. Possible origin of aliphatic moieties in humic substances. Sci. Total Environ. 81/82: 1-17.

Terentev, V. M. , R. I. Tsareva, and O. V. Shchutskaya . 1968. Isotopes and radiation in soil organic-matter studies. Inti. Atomic Energy Agency, Vienna, p. 421.

Tewari, Y. B. , M. M. Miller , S. P. Wasik, and D. E. Martire . 1982. Aqueous solubility and octanol/water partition coefficient of organic compounds at $25 \cdot 0^{\circ} \mathrm{C}$. J. Chem. Eng. Data 27: 451-454.

Theng, B. K. G. 1974. The chemistry of clay-organic reactions. Wiley, New York.

Thibodeaux, L. J. 1979. Chemodynamics. Wiley, New York.

Thomas, R. G. 1990. Volatilization from water. In W. J. Lyman, W. F. Reehl, and D. H. Rosenblatt, eds. Handbook of chemical property estimation methods. American Chemical Society, Washington, DC, pp. 11-15 - 15-34.

Thorn, K. A. 1989. Nuclear-magnetic-resonance spectrometry investigations of fulvic and humic acids from the Suwanee River. In Thurman, E. M. and R. L. Malcolm . 1989. Nitrogen and amino acids in humic and fulvic acids from the Suwanee River. USGS Report 87-557, Denver, CO, pp. 251-309.

Thurman, E. M. 1985. Organic geochemistry of natural waters. Martinus Nijhoff/Dr. W. Junk Pub., Dordrecht, Netherlands.

Tsani-Bazaca, E. , A. McIntyre , J. Lester , and R. Perry . 1982. Ambient concentrations and correlations of hydrocarbons and halocarbons in the vicinity of an airport. Chemosphere 11: 11-23.

Tsutsuki, K. and S. Kuwatsawa . 1978. Composition of oxygen-containing functional groups of humic acids. Soil Sci. Plant Nutr. 24: 547-570.

Vannote, R. L. , G. W. Minshall , K. W. Cummins , J. R. Sedell , and C. E. Cushing . 1980. The river continuum concept. Can. J. Fish. Aquat. Sci. 37: 130-137.

Verschueren, K. 1983. Handbook of environmental data on organic chemicals. 2nd ed. Van Nostrand-Reinhold, New York.

Visser, S. A. 1983. Fluorescence phenomena of humic matter of aquatic origin and microbial cultures. In R. F. Christman and E. T. Gjessing eds., Aquatic and terrestrial humic materials. Ann Arbor Sci. Pub., Ann Arbor, MI, pp. 183-202.

von Düszeln, J. and W. Thiemann . 1985. Volatile chlorinated hydrocarbons in a coastal urban atmosphere. Sci. Total Environ. 41: 187-194.

Walker, A. and D. V. Crawford . 1968. The role of organic matter in adsorption of the triazine herbicides by soils. Proc. Sympos. Radiation in Soil Org. Matter Studies, pp. 91-108.

Wathne, B. 1983. Measurements of benzene, toluene and xylenes in urban air. Atmos. Environ. 17: 1713-1722.

Watson, R. T. , M. J. Prather, and M. J. Kurylo . 1988. Present state of knowledge of the upper atmosphere 1988: an assessment report. NASA

Ref. Publ. \#1208, Washington, DC. 
Weber, W. J.Jr. , P. M. McGinley, and L. E. Katz . 1991. Sorption phenomena in subsurface systems: concepts, models and effects on contaminant fate and transport. Water Res. 25: 499-528.

Wershaw, R. L. 1986. A new model for humic materials and their interactions with hydrophobic organic chemicals in soil-water or sediment-water systems. J. Contam. Hydrol. 1: 29-45.

Wershaw, R. L. and G. R. Aiken . 1985. Molecular size and weight measurements of humic substances. In G. R. Aiken , D. M. McKnight, R. L. Wershaw, and P. MacCarthy, eds. Humic substances in soil, sediment, and water. Wiley, New York, pp. 477-492.

Williams, P. M. 1971. The distribution and cycling of organic matter in the ocean. In S. J. Faust and J. V. Hunter, eds. Organic compounds in aquatic environments. Marcel Dekker, New York. pp. 145-163.

Wilson, A. L. 1959. Determination of fulvic acids in water. J. Appl. Chem. 9: 501-510.

Wilson, M. A. 1981. Applications of NMR spectroscopy to the study of the structure of soil organic matter. Soil Sci. 32: $167-186$.

Wilson, M. A. , A. J. Jones, and B. Williamson . 1978. NMR spectroscopy of humic materials. Nature 276: 487-489.

Wilson, M. A. , P. J. Collin , and K. R. Tate . 1983. 1H-nuclear magnetic resonance study of a soil humic acid. J. Soil Sci. 34: $297-304$.

Wilson, M. A. , K. M. Goh , P. J. Collin , and L. G. Greenfield . 1986. Origin of humus variation. Org. Geochem. 9: $225-231$.

Wolfe, N. L. , L. A. Burns and W. C. Steen . 1980a. Use of linear free energy relationships and an evaluation model to assess the fate and transport of phthalate esters in the aquatic environment, Chemosphere, 9:393-402.

Wolfe, N. L. , W. C. Steen and L. A. Burns . 1980b. "Phthalate Ester Hydrolysis: Linear Free Energy Relationships," Chemosphere, 9:403-408. Wolfe, N. L. , U. Mingelgrin , and G. C. Miller . 1990. Abiotic transformations in water, sediments, and soil. In Pesticides in the soil environment; SSSA Book Series \#2. Soil Sci. Soc. Amer., Madison, WI. pp. 103-168.

Wood, J. C. , S. E. Moschopedis, and W. den Hertog . 1961. Studies in humic acid chemistry. II. Humic anhydrides. Fuel 40: $491-502$. Woodwell, G. M. and E. V. Pecan, eds. 1973. Carbon and the biosphere. 24th Brookhaven Symposium in Biology. 1973.

Wright, R. T. and J. E. Hobbie . 1965. The uptake of organic solutes in lake water. Limnol. Oceanogr. 10: 22-28.

Wright, R. T. and N. M. Shah . 1977. The trophic role of glycolic acid in coastal seawater. II. Seasonal changes in concentration and heterotrophic use in Ipswich Bay, Massachusetts, USA. Marine Biol. 43: 257-263.

Wynder, E. L. and D. Hoffmann, eds. 1968. Tobacco and tobacco smoke: studies in experimental carcinogenesis. Academic Press, New York. Yokouchi, Y. and Y. Ambe . 1986. Characterization of polar organics in airborne particulate matter. Atmos. Environ. 20: $1727-1734$.

Yonebayashi, K. and T. Hattori . 1987. Surface active properties of soil humic acids. Sci. Total Environ. 62: 55-64.

Zafiriou, O. C. 1975. Reaction of methyl halides with seawater and marine aerosols. J. Mar. Res. 33: 75-81.

Zepp, R. G. and P. F. Schlotzhauer . 1981. Comparison of photochemical behavior of various humic substances in water. III. Spectroscopic properties of humic substances. Chemosphere 10: 479-486.

Zhou, X. and K. Mopper . 1990. Measurement of sub-parts-per-billion levels of carbonyl compounds in marine air by a simple cartridge trapping procedure followed by liquid chromatography. Environ. Sci. Technol. 24: 1482-1485.

Zoeteman, B. C. J. , K. Harmsen , J. B. H. J. Linderts , C. F. H. Morra, and W. Slooff . 1980. Persistent organic pollutants in river water and ground water of the Netherlands. Chemosphere 9: 231-249.

Zsolnay, A. 1977. Inventory of non-volatile fatty acids and hydrocarbons in the oceans. Mar. Chem. 5: 465-475.

Zurer, P. S. 1990. Chlorine eroding arctic as well as antarctic ozone, scientists confirm. Chem. Eng. News (Mar. 15), 22-23.

\section{Hydrolysis}

Bailey, G. W. , J. L. White, and T. Rothberg . 1968. Adsorption of organic herbicides by montmorillonite: Role of $\mathrm{pH}$ and chemical character of adsorbate, Soil Sci. Soc. Am. Proc., 32:222-234.

Bank, S. , and R. J. Tyrrell . 1984. Kinetics and mechanisms of alkaline and acid hydrolysis of aldicarb, J. Agric. Food Chem., 32:1223-1232.

Bank, S. , and R. J. Tyrrell . 1985. Copper(II)-promoted aqueous decomposition of aldicarb, J. Org. Chem., 50:4938-4943.

Barbash, J. E. , and M. Reinhard . 1989a. Abiotic dehalogenation of 1,2-dichloroethane and 1,2-dibromoethane in aqueous solution containing hydrogen sulfide, Environ. Sci. Technol. 23(11): 1349-1358.

Barbash, J. E. , and M. Reinhard . 1989b. Reactivity of sulfur nucleophiles toward halogenated organic compounds in natural waters, in Biogenic Sulfur in the Environment, Saltzman, E. and W. Cooper, Eds. (Washington, D.C.: American Chemical Society), pp. $1011-1139$.

Bartlett, P. D. , and C. G. Swain . 1949. Kinetics of hydrolysis and displacement reactions of $\beta, \beta$ '-dichlorodiethyl sulfide (mustard gas) and of $\beta$ chloro- $\beta$ '-hydroxydiethyl sulfide (mustard chlorohydrin), H2O2, O3, and SO2 J. Am. Chem. Soc., 71:1406-1415.

Becker, A. R. , J. M. Janusz, and T. C. Bruice . 1979. Solution chemistry of the syn- and tftf//-tetrahydrodiol epoxides, the syn-and antitetrahydrodimethoxy epoxides, and the 1,2-and 1,4-tetrahydro epoxides of naphthalene, J. Am. Chem. Soc., 101:5679-5687.

Bender, M. L. 1960. Mechanisms of catalysis of nucleophilic reactions of carboxylic acid derivatives, Chem. Rev., 60:53-113.

Bender, M. L. , and L. J. Brubacher . 1973. Catalysts and Enzyme Action. (New York, NY: McGraw-Hill).

Bender, M. L. , and R. J. Thomas . 1961. The concurrent alkaline hydrolysis and isotopic oxygen exchange of a series of $p$-substituted acetanilides, J. Am. Chem. Soc. 83:4183-4196.

Bergon, M. , N. J. Hamida, and J. Calmon . 1985. Isocyanate formation in the decomposition of phenmedipham in aqueous media, J. Agric. Food Chem. 33:577-583.

Beyer, E. M. , M. J. Duffy , J. V. Hay, and D. D. Schlueter . 1987. Sulfonylureas, in Herbicides: Chemistry, Degradation and Mode of Action, Vol. 3, P. C. Kearney, and D. D. Kaufman, Eds. (New York, NY: Dekker), pp. 117-189.

Blanchet, P.-F. , and A. St. George . 1982. Kinetics of chemical degradation of organophosphorus pesticides; hydrolysis of chlorpyrifos and chlorpyrifos-methyl in the presence of copper(II), Pesticide Sci., 13:85-91.

Bolt, M. M. , R. J. Laib , and J. G. Filser . 1982. Reactive metabolites and carcinogenicity of halogenated ethylenes, Biochem. Pharmacol., 31:1-4.

Brown, H. M. 1990. Mode of action, crop selectivity, and soil relations of the sulfonylurea herbicides, Pestic. Sci., 29:263-281.

Buckingham, D. A. 1977. Metal-OH and its ability to hydrolyze (or hydrate) substrates of biological interest, in Biological Aspects of Inorganic Chemistry, A. W. Addison, W. R. Cullen, D. Dolphin, and B. R. James, Eds. (New York, NY: Wiley).

Buckingham, D. A. , and C. R. Clark . 1981. Reactions of acyl phosphates. Base hydrolysis of [Co (NH3)5OPO3COCH3]+ and the metal hydroxide promoted hydrolysis of acetyl phenyl phosphate, Aust. J. Chem., 34:1769-1773.

Buckingham, D. A. , and C. R. Clark . 1982. Metal-hydroxide promoted hydrolysis of activated esters. Hydrolysis of 2,4-dinitrophenyl acetate and 4-nitrophenyl acetate, Aust. J. Chem., 35:431-436.

Burlinson, N. E. , L. A. Lee, and D. H. Rosenblatt . 1982. Kinetics and products of hydrolysis of I,2-dibromo-3-chloropropane, Environ. Sci. Technol., 16(9):627-632.

Camilleri, P. 1984. Alkaline hydrolysis of some pyrethroid insecticides, J. Agric. Food Chem., 32:1122-1124.

Capon, B. , and S. P. McManus . 1976. Neighboring Group Participation, New York, NY: Plenum.

Chiou, C. T. , P. E. Porter, and D. W. Schmedding . 1983. Partition equilibria of nonionic organic compounds between soil organic matter and water, Environ. Sci. Technol., 17:227-231.

Choundry, G. C. 1984. In Humic Substances, Vol. 7, Current Topics in Environmental and Toxicological Chemistry Series. (New York, NY: Gordon and Breach), pp. 143-169. 
Coleman, K. D. 1988. "Acid Catalyzed Abiotic Hydrolysis of Sorbed Pesticides," M.S. Thesis, Colorado School of Mines.

Deeley, G. M. , M. Reinhard, and S. M. Stearns . 1991. Transformation and sorption of I,2-dibromo-3-chloropropane in subsurface samples collected at Fresno, California, J. Environ. Qual., 20:547-556.

Duboc, C. 1978. The correlation analysis of nucleophilicity, in Correlation Analysis in Chemistry: Recent Advances, N.B. Chapman , and J.

Shorter , Eds., (New York, NY: Plenum Press), pp. 313-315.

Edwards, J. O. 1954. Correlation of relative rates and equilibria with a double basicity scale, J. Am. Chem. Soc., 76:1540-1547.

Edwards, J. O. 1956. Polarizability, basicity and nucleophilic character, J. Am. Chem. Soc., 78:1819-1820.

El-Amamy, M. M. , and T. Mill . 1984. Hydrolysis kinetics of organic chemicals on montmorillonite and kaolinte surfaces as related to moisture content, Clays \& Clay Minerals, 32(1):67-73.

Emerson, S. 1976. Early diagenesis in anaerobic lake sediments: Chemical equilibriums in in interstitial waters, Geochim. Cosmochim. Acta, 40:925-934.

Fendler, J. H. , and E. J. Fendler . 1975. Catalysis in Micellar and Macromolecular Systems (New York, NY: Academic Press).

Fest, C. , and K. J. Schmidt . 1983. Organophosphorus insecticides in Chemistry of Pesticides, K. H. Buchel, Ed. (New York, NY: John Wiley \& Sons), pp. 49-125.

Frenkel, M. 1974. Surface acidity of montmorillonites, Clays and Clay Minerals, 22:435-441.

Gleave, J. L. , E. D. Hughes, and C. K. Ingold . 1935. Mechanism of substitution at a saturated carbon atom, J. Chem. Soc. p. 236.

Gonzalez, A. C. , and M. R. Hoffman . 1989. The kinetics and mechanism of the catalytic hydrolysis of nitrophenyl acetates by metal oxide surfaces, J. Phys. Chem.

Haag, W. R. , and T. Mill . 1988a. Effect of a subsurface sediment on hydrolysis of haloalkanes and epoxides, Environ. Sci. Technol., 22(6):658-663.

Haag, W. R. , and T. Mill . 1988b. Some reactions of naturally occurring nucleophiles with haloalkanes in water, Environ. Toxicol. Chem. 7:917-924.

Harris, J. C. 1981. Rate of hydrolysis, in Handbook of Chemical Property Estimation Methods. Environmental Behavior of Organic Compounds. W. J. Lyman, W. F. Reehl, and D. H. Rosenblatt, Eds. (New York, NY: McGraw-Hill), pp. 1-7 to 7-48.

Hay, J. V. 1990. Chemistry of sulfonylurea herbicides, Pestic. Sci., 29:247-261.

Hay, R. W. 1987. Lewis acid catalysis and the reactions of coordinated ligands, in Comprehensive Coordination Chemistry, Vol. 6 Applications, G. Wilkinson, J. A. Gillard, and J. A. McCleverty, Eds. (Oxford, England: Pergamon).

Hay, R. W. , and P. J. Morris . 1976. Metal ion-promoted hydrolysis of amino acid esters and peptides, in Metal lons in Biological Systems, Vol. 5, Sigel, H. , Ed., (New York, NY: Marcel Dekker), pp. 173-243.

Hegarty, A. F. , and L. N. Frost . 1973. Elimination-addition mechanism for the hydrolysis of carbamates. Trapping of an isocyanate intermediate by an o-amino group, J. Chem. Soc., Perkin Trans. 2, 1719.

Hill, IV J. , H. P. Kollig , D. F. Paris, N. L. Wolfe, and R. G. Zepp . 1976. Dynamic behavior of vinyl chloride in aquatic ecosystems, U.S. Environmental Protection Agency. EPA-600/3-76-001.

Hine, J. , A. M. Dowell, Jr. , and J. E. Singley, Jr. 1956. Carbon dihalides as intermediates in the basic hydrolysis of haloforms. IV. Relative reactivities of haloforms, J. Am. Chem. Soc., 78:479-482.

Hine, J. , and P. B. Langford . 1956. The effect of halogen atoms on the reactivity of other halogen atoms in the same molecule. VII. The reaction of $\beta$-haloethyl bromides with sodium hydroxide, J. Am. Chem. Soc., 78:5002-5004.

Hoffmann, M. R. , 1990. Catalysis in aquatic environments, in Aquatic Chemical Kinetics, W. Stumm, Ed. (New York, NY: John Wiley \& Sons), pp. 71-112.

Houghton, R. P. 1979. Metal Complexes in Organic Chemistry, (Cambridge, England: Cambridge University Press).

Hudson, R. F. 1965. Structure and Mechanism in Organophosphorus Chemistry, (New York, NY: Academic Press).

Ingold, C. K. 1969. Structure and Mechanism in Organic Chemistry, 2nd ed., (Ithaca, NY: Cornell University Press), p. 1131.

IUPAC . 1981. Manual of symbols and terminology for physicochemical quantities and units, Appendix $V$, Symbolism and terminology in chemical kinetics, Pure Appl. Chem., 53:753.

Jackson, R. E. , R. J. Patterson, B. W. Graham, J. Bahr, D. Belanger, J. Lockweed, and M. Priddle . 1985. Series No. 141, NHRI Paper No. 23: National Hydrology Research Institute Inland Water Directorate: Ottawa, Canada.

Jeffers, P. M. , L. M. Ward , L. M. Woytowitch and N. L. Wolfe . 1989. Homogeneous hydrolysis rate constants for selected chlorinated methanes, ethanes, ethenes, and propanes, Environ. Sci. Technol., 23(8):965-969.

Jencks, W. P. 1987. Covalent catalysis, in Catalysis in Chemistry and Enzymology, (New York, NY: Dover), pp. $78-107$.

Jensen, W. B. 1978. The Lewis acid-base definitions: A status report, Chemical Reviews, 78(1): 1-22.

Jerina, D. M. , H. Yagi, R. E. Lehr, D. R. Thakker, M. Schaeffer-Ridder, J. M. Karle, W. Levin , A. W. Wood, R. L. Chang, and A. H. Conney . 1978. The bay-region theory of carcinogenesis by polycyclic aromatic hydrocarbons, in Polycyclic Hydrocarbons and Cancer, Vol 1., H. V.

Gelboin and P. O. Ts'o , Eds., (New York, NY: Academic Press), pp. 173-188.

Junglaus, G. A. , and S. Z. Cohen . 1986. Hydrolysis of ethylene dibromide, Abstr. Div. Env. Chem. Am. Chem. Soc., 26(1): 12-16.

Karickhoff, S. W. 1980. Sorption kinetics of hydrophobic pollutants in natural sediments, in Contaminants and Sediments, R. A. Baker, Ed. (Ann Arbor, MI: Ann Arbor Science), pp. 193-205.

Karickhoff, S. W. 1984. Organic pollutant sorption in aquatic systems, J. Hydraulic Engineering, 110(6):707-735.

Karickhoff, S. W. , and G. W. Bailey . 1976. Protonation of organic bases in clay-water systems, Clays and Clay Minerals, 24:170-176.

Keith, L. H. , and W. A. Telliard . 1979. Priority pollutants. I -A perspective view, Environ. Sci. Technol., 13:416-423.

Ketalaar, J. A. , H. R. Gersmann, and M. M. Beck . 1956. Metal-catalyzed hydrolysis of thiophosphoric esters, Nature, 177:392-393.

Khan, S. U. 1978. Kinetics of hydrolysis of atrazine in aqueous fulvic acid solution, Pestic. Sci. 9:39-43.

Kirby, A. J. , and S. G. Warren . 1967. The Organic Chemistry of Phosphorus, (New York, NY: Elsevier Publishing Company).

Li, G. C. , and G. T. Felbeck, Jr. 1972. Atrazine hydrolysis as catalyzed by humic acids, Soil Sci. 114:201-209.

Livingston, D. A. 1963. Chemical composition of rivers and lakes, Geol. Surv. Prof. Paper. 440-G.

Long, F. A. , and J. G. Pritchard . 1956. Hydrolysis of substituted ethylene oxides in H2O18 solutions, J. Am. Chem. Soc., 78(12):2663-2667.

Mabey, W. , and T. Mill . 1978. Critical review of hydrolysis of organic compounds in water under environmental conditions, J. Phys. Chem. Ref. Data, 7(2):383-415.

Mabey, W. R. , A. Baraze, and T. Mill . 1978. In Environmental Pathways of Environmental Pathways of Selected Chemicals, Part I, EPA Final Report, EPA 600/7-77-113.

Mabey, W. R. , H. Drossman , A. M. Liu , and T. Mill . 1984. Toxic Substances Process Data Generation, EPA Final Report, EPA Contract 68-03-2921, Task 18.

Macalady, D. L. , and N. L. Wolfe . 1984. Abiotic hydrolysis of sorbed pesticides, in ACS Symposium Series, No. 259 Treatment \& Disposal of Pesticide Wastes, Krueger, R. F. , and J. N. Seiber, Eds., (Washington, DC: American Chemical Society), pp. 221-244.

Macalady, D. L. , and N. L. Wolfe . 1985. Effects of sediment sorption and abiotic hydrolyses. 1. Organophophorothioate esters, J. Agric. Food Chem., 33(2): 167-173.

Macalady, D. L. , P. G. Tratnyek, and N. L. Wolfe . 1989. Influences of natural organic matter on the abiotic hydrolysis of organic contaminants in aqueous systems, in Aquatic Humic Substances, Suffet, I.H. , and P. MacCarthy, Eds., (Washington, DC: American Chemical Society), pp. 323-332.

March, J. 1985. Advanced Organic Chemistry, 3rd ed. (New York, NY: John Wiley \& Sons). 
Mason, R. E. , D. D. McFadden, V. G. Iannacchione, and D. S. McGrath . 1981. Survey of DBCP Distribution in Groundwater Supplies and Surfacewater Ponds, U.S. Environmental Protection Agency, EPA Report No. 68-015848.

Metwally, M. E. , and N. L. Wolfe . 1990. Hydrolysis of chlorostilbene oxide II. Modeling of hydrolysis in aquifer samples and in sediment-water systems, Environ. Toxicol. Chem., 9:963-973.

Mill, T. , and W. Mabey . 1988. Hydrolysis of organic chemicals, in The Handbook of Environmental Chemistry, Volume 2D: Reactions and Processes, Hutzinger, O. Ed., (New York, NY: Springer-Verlag), pp. 71-111.

Mingelgrin, U., S. Saltzman and B. Yaron . 1977. A possible model for the surface-induced hydrolysis of organophosphorus pesticides on kaolinite clays, Soil Sci. Soc. Am. J., 41:519-523.

Mortland, M. M. 1970. Clay-organics complexes and interactions, Advan. Agron., 22:75-117.

Muir, D. C.G. 1988. Phosphate esters, in The Handbook of Evironmental Chemistry, Volume 3, Part C: Anthropogenic Compounds, O. Hutzinger , Ed., (New York, NY: Springer-Verlag), pp. 41-66.

Nelson, S. J. , M. Iskander, M. Volz, S. Khalifa, and R. Haberman . 1981. Studies of DBCP in subsoils, The Science of the Total Environment, 21:35-40.

Okamoto, T. , K. Shuddo, N. Miyata , Y. Kitahara , and S. Nagata . 1978. Reactions of K-region oxides of carcinogenic and noncarcinogenic aromatic hydrocarbons. Comparative studies on reactions with nucleophiles and acid-catalyzed reactions, Chem. Pharm. Bull., 26(7):2014-2026. Page, G. W. 1981. Comparison of groundwater and surface water for patterns and levels of contamination by toxic substances, Environ. Sci. Technol., 15:1475-1481.

Parker, R. E. , and N. S. Isaacs . 1959. Mechanisms of epoxide reactions, Chem. Rev., 59:737-799.

Pearson, R. G. 1963. Hard and soft acids and bases, J. Am. Chem. Soc., 85:3533-3539.

Pearson, R. G. 1973. Hard and Soft Bases, (Stroudsburg, PA: Dowden, Hutchinson, and Ross).

Pearson, R. G. 1983. Absolute hardness: companion parameter to absolute electronegativity, J. Am. Chem. Soc., 105:7512-7516.

Perdue, E. M. 1983. Association of organic pollutants with humic substances: Partitioning equilibria and hydrolysis kinetics, in Aquatic and Terrestrial Humic Materials, R. F. Christman and E. T. Gjessing, Eds. (Ann Arbor, MI: Ann Arbor Science), pp. 441-460.

Perdue, E. M. , and N. L. Wolfe . 1982. Modification of pollutant hydrolysis kinetics in the presence of humic substances, Environ. Sci. Technol. 16:847-852.

Perdue, E. M. , and N. L. Wolfe . 1983. Prediction of buffer catalysis in field and laboratory studies of pollutant hydrolysis reactions, Environ. Sci. Technol., 17:635-642.

Pignatello, J. J. 1986. Ethylene dibromide mineralization in soils under aerobic conditions, Appl. Environ. Microbiol., 51(3):588-592.

Plastourgou, M. , and M. R. Hoffmann . 1984. Transformation and fate of organic esters in layered-flow systems: The role of trace metal catalysis, Environ. Sci. Technol., 18:756-764.

Pritchard, J. G. , and F. A. Long . 1956. Hydrolysis of substituted ethylene oxides in H2O18 solutions, J. Am. Chem. Soc., 78:2663-2667.

Pusino, A. , C. Gessa and H. Kozlowski . 1988. Catalytic hydrolysis of quinalphos on homoionic clays, Pestic. Sci., 24:1-8.

Roberts, A. L. , P. N. Sanborn, and P. M. Gschwend . 1992. Nucleophilic substitution reactions of dihalomethanes with hydrogen sulfide, Environ. Sci. Technol., 26:2263-2274.

Ross, A. M. , T. M. Pohl , K. Pizza , M. Thomas , B. Fox and D. L. Whalen . 1982. Vinyl epoxide hydrolysis reactions, J. Am. Chem. Soc., 104:1658-1665.

Saltzman, S. , B. Yaron and U. Mingelgrin . 1976. The surface catalyzed hydrolysis of parathion on kaolinite, Soil Sci. Soc. Amer. Proc.,

38:231-234.

Saltzman, S. , U. Mingelgrin , and B. Yaron . 1976. Role of water in the hydrolysis of parathion and methylparathion on kaolinite, J. Agric. Food

Chem., 24(4):739-743.

Samuel, D. , and B. L. Silver . 1965. Oxygen isotope exchange reactions of organic compounds, Advan. Phys. Org. Chem., 3:123-186.

Santodonato, J. , S. S. Lande , P. H. Howard , D. Orzel , and D. Bogy . 1980. Investigation of selected potential environmental contaminants: Epichlorohydrin and epibromohydrin, U.S. Environmental Protection Agency. EPA-560/11 - 80-006.

Schmidt, K. J. 1975. Chemical aspects of organophosphate pesticides in view of the environment, in Environmental Quality and Safety, Vol. 4: Global Aspects of Chemistry, Toxicology and Technology as Applied to the Environment, F. Coul-ston, and F. Korte , Eds. (New York, NY: Academic Press), pp. 96-108.

Schmidt, K. J. , and C. Fest . 1982. The Chemistry of Organophosphorus Pesticides, (New York, NY: Springer-Verlag),

Schwarzenbach, R. P. , W. Giger, C. Schaffner, and O. Wanner . 1985. Groundwater contamination by volatile halogenated alkanes: Abiotic formation of volatile sulfur compounds under anaerobic conditions, Environ. Sci. Technol. 19(4): 322-327.

Stone, A. T. 1988. The effect of Dismal Swamp dissolved organic matter on the adsorption and surface-enhanced hydrolysis of monophenyl terephthalate in aluminum oxide suspension, J. Colloid and Interface Sci., 132(I):81-87.

Stone, A. T. 1989. Enhanced rates of monophenyl terephthalate hydrolysis in aluminum oxide suspensions, J. Colloid Interface Sci.,

127(2):429-441.

Streitwieser, A. 1962. Solvolytic Displacement Reactions, (New York, NY: McGraw-Hill).

Swain, C. G. , and C. B. Scott . 1953. Quantitative correlation of relative rates. Comparison of hydroxide ion with other nucleophilic reagents toward alkyl halides, esters epoxides and acyl halides, J. Am. Chem. Soc., 75:141-147.

Sykes, P. 1986. A Guidebook to Mechanism in Organic Chemistry, (New York, NY: John Wiley), pp. 95-96.

Takahashi, N. , N. Mikami, T. Matsuda and J. Miyamoto . 1985a. Hydrolysis of the pyrethroid insecticide cypermethrin in aqueous media, J.

Pesticide Sci., 10:643-648.

Takahashi, N. , N. Mikami , H. Yamada and J. Miyamoto . 1985. Hydrolysis of the pyrethroid insecticide fenpropathrin in aqueous media, Pestic.

Sci., 16:113-118.

Tinsley, I. J. 1979. Modifications of chemicals in the environment, in Chemical Concepts in Pollutant Behavior, (New York, NY: John Wiley \&

Sons), p. 113.

Torrents, A. , and A. T. Stone . 1991. Hydrolysis of phenyl picolinate at the mineral/water interface, Environ. Sci. Technol., 25:143-149.

Turekian, K. K. 1969. The oceans, streams, and atmosphere, in Handbook of Geochemistry, Vol. 1, K. H. Wedepohl, Ed. (New York, NY:

Springer-Verlag) pp. 297-323.

Ukachukwu, V. C. , J. J. Blumenstein , and D. L. Whalen . 1986. Evidence for reversible formation of an intermediate in the spontaneous hydrolysis reaction of $p$-methoxystyrene oxide, J. Am. Chem. Soc., 108(16):5039-5040.

Van Duuren, B. L. , C. Katz , B. M. Goldschmidt , K. Frenkel , and A. Sivak . 1972. Carcinogenicity of halo-ethers. II. Structure-activity relationships of analogs of bis (chloromethyl) ether. J. Natl. Cancer Inst. 48(5): 1431-1439.

Vogel, T. M. , and M. Reinhard . 1986. Reaction products and rates of disappearance of simple bromoalkanes, 1,2-dibromopropane and 1,2dibromoethane in water, Environ. Sci. Technol., 20(10):992-997.

Voudrias, E. A. , and M. Reinhard . 1986. Abiotic organic reactions at mineral surfaces: A review, in Geochemical Processes at Mineral Surfaces, J. A. Davis, and K. F. Hayes, Eds., ACS Symp. Series, pp. 486-642.

Wanner, O. , T. Egll , T. Fleischmann , K. Lanz, P. Reichert, and R. P. Schwarzen-bach . 1989. Behavior of the insecticides disulfoton and thiometon in the Rhine River: A chemodynamic study, Environ. Sci. Technol., 23:1232-1242.

Weintraub, R. A. , G. W. Jex, and H. A. Moye . 1986. Chemical and microbial degradation of 1,2-dibromoethane (EDB) in Florida groundwater, soil and sludge, in Evaluation of Pesticides in Ground Water, W. Y. Garner , R. C. Honeycutt and H. N. Nigy, Eds., (Washington, DC: American Chemical Society), pp. 294-310.

Weintraub, R. A. , and H. A. Moye . 1987. Ethylene dibromide (EDB) transformations in abiotic-reducing aqueous solutions in the presence of hydrogen sulfide, Abstr. Amer. Chem. Soc. Div. Env. Chem., 27(2):236-240. 
Williams, A. J. 1972. Alkaline hydrolysis of substituted phenyl N-phenylcarbamates. Structure-reactivity relations consistent with an ElcB mechanism, J. Chem. Soc., Perkin Trans. 2, 6:808-812.

Wolfe, N. L. , R. G. Zepp , D. F. Paris , G. L. Baughman and R. C. Hollis . 1977. Methoxychlor and DDT degradation in water: Rates and products, Environ. Sci. Technol. 11(12): 1077-1081.

Wolfe, N. L. , R. G. Zepp, and D. F. Paris . 1978. Use of hydrolytic persistence of carbamate pesticides, Water Res. 12:561-563.

Wolfe, N. L. , W. C. Steen, and L. A. Burns . 1980. Phthalate ester hydrolysis: Linear free energy relationships, Chemosphere, 9:403-408.

Wolfe, N. L. , U. Mingelgrin, and G. C. Miller . 1990. Abiotic transformations in water, sediments, and soil, in Pesticides in the Soil Environment, H. H. Cheng, Ed., (Madison, Wl: Soil Science Society of America) pp. 103-168.

\section{Reduction}

Adhya, T. K. , Sudhakar-Bakar and N. Sethunathan . 1981a. Fate of fenitrothion, methyl parathion, and parathion in anoxic sulfur-containing soil systems, Pestic. Biochem. Phys. 16:14-20.

Adhya, T. K. , Sudhakar-Barik and N. Sethunathan . 1981b. Stability of commercial formulations of fenitrothion, methyl parathion, and parathion in anaerobic soils, J. Agric. Food Chem., 29:90-93.

Ames, B. N. , J. McCann and E. Yamasaki . 1975. Methods for detecting carcinogens and mutagens with the salmonella- mammalian microsome mutagenicity, Mutat. Res., 31:347-364.

Ayanaba, A. , W. Verstraete and M. Alexander . 1973. Formation of dimethylnitrosamine, a carcinogen and mutagen, in soils treated with nitrogen compounds, Proc. Am. Soil Sci., 37:565-568.

Bank, S. and D. A. Juckett . 1975. Reactions of aromatic radical anions. 11: kinetic studies of the reaction of sodium naphthalene and anthracene with $\Lambda$-hexyl bromide and chloride, J. Am. Chem. Soc., 97:567-573.

Bank, S. and D. A. Juckett . 1976. Reactions of aromatic radical anions. 12: kinetic studies of the reaction of radical anions of varying reduction potential with $n$ - hexyl bromides, iodides, and chlorides, J. Am. Chem. Soc., 98:7742-7746.

Baughman, G. L. , E. J. Weber and M. S. Brewer . 1992. Sediment reduction of anthraquinone dyes and related compounds: anthrone formation, Presented at the American Chemical Symposium on the Oxidation-Reduction Transformations of Inorganic and Organic Species in the Environment, San Francisco, CA, April 5-10, 1992.

Baxter, R.M. 1990. Reductive dechlorination of certain chlorinated organic compounds by reduced hematin compared with their behavior in the environment, Chemosphere, 21(4 and 5):451-458.

Beland, F. A. , S. O. Farwell , and R. D. Geer . 1974. Anaerobic degradation of I,I,I,2-tetrachloro-2,2-bis (p-chlorophenyl)ethane (DTE), J. Agric. Food Chem., 22:1148-1149.

Beland, F. A. , S. O. Farwell , A. E. Robocker, and R. D. Geer . 1976. Electrochemical reduction and anaerobic degradation of lindane, J. Agric. Food Chem., 24(4):753-756.

Bolt, H. M. , R. J. Laib and J. G. Filser . 1982. Reactive metabolites and carcinogenicity of halogenated ethylenes, Biochem. Pharmac., 31(1): 1-4.

Bryant, F. O. , D. D. Hale and J. E. Rogers . 1991. Regiospecific dechlorination of pentachlorophenol by dichlorophenol-adapted microorganisms in freshwater, anaerobic sediment slurries, Appl. Environ. Microbiol., 57(8):2293-2301.

Buffle, J. and R. S. Altmann . 1987. Interpretation of metal complexes by heterogeneous complexants, in Aquatic Surface Chemistry, Stumm, W. ed. (New York, NY: Wiley).

Castro, C. E. , and W. C. Kray, Jr. 1963. The cleavage of bonds by low valent transition metal ions. The homogeneous reduction of alkyl halides by chromous sulfate, J. Am. Chem. Soc. 85:2768-2773.

Castro, C. E. 1964. The rapid oxidation of iron(II)porphyrins by alkyl halides. A possible mode of intoxification or organisms by alkylhalides, J. Am. Chem. Soc. 86:2310-2311.

Chung, K. , B. E. Fulk and M. Egan . 1978. Reduction of azo dyes by intestinal anaerobes, Appl. Environ. Microbiol., 35:558-562.

Clarke, E. A. and R. Anliker, 1980. Organic dyes and pigments, in Handbook of Environmental Chemistry: Vol. 3, Part A, Anthropogenic Compounds, O. Hutzinger, Ed. (Berlin: Springer), pp. 181-215.

Criddle, C. S. , P. L. McCarty, M. C. Elliott and J. F. Barker . 1986. Reduction of hexachloroethane to tetrachloroethylene in groundwater, J. Contam. Hydrol. 1:133-142.

Curtis, G. P. and M. R. Reinhard . 1989. Reductive dehalogenation of hexachloroethane by aquifer materials, paper presented at the 197th meeting of the American Chemical Society, Dallas, T.X. , April 9-14.

Delgado, M. C. and N. L. Wolfe . 1992. Structure-activity relationships for the reduction of $p$-substituted nitrobenzenes in anaerobic sediments, Presented at the American Chemical Symposium on the Oxidation-Reduction Transformations of Inorganic and Organic Species in the Environment, San Francisco, C.A. , April 5-10, 1992.

Dubin, P. and K. L. Wright . 1975. Reduction of azo food dyes in cultures of proteus vulgaris, Xenobiotica, 5:563-571.

Dunnivant, F. M. , R. P. Schwarzenbach and D. L. Macalady . 1992. Reduction of substituted nitrobenzenes in aqueous solutions containing natural organic matter, Environ. Sci. Technol., 26(11):2133-2141.

Eberson, L. 1987. Electron Transfer Reactions in Organic Chemistry, (Springer-Verlag: Berlin, Germany)

Entwistle, I. D. , R. A. W. Johnstone and A. H. Wilby . 1982. Rapid reduction of N-nitrosoamines to N,N-disubstituted hydrazines; the utility of some low-valent titanium reagents, Tetrahedron, 38(3):419-423.

Farwell, S. O. , F. A. Beland and R. D. Geer . 1975. Interrupted-sweep voltammetry for the identification of polychlorinated biphenyls and naphthalenes, Anal. Chem., 47:895-903.

Fathepure, B. Z. , J. M. Tiedge and S. A. Boyd . 1988. Reductive dechlorination of hexachlorobenzene to tri-and dichlorobenzenes in anaerobic sewage sludge, Appl. Environ. Microbiol., 54(2):327-330.

Florence, T. M. 1965. Polarography of aromatic azo compounds, Aust. J. Chem., 18:609-618.

Fushiwaki, Y. , N. Tase, A. Saeki and K. Urano . 1990. Pollution by the fungicide pentachloronitrobenzene in an intensive farming area in Japan, Sci. Tot. Environ., 92:55-67.

Gambrell, R. P. , B. A. Taylor, K. S. Reddy, and W. H., Jr., Patrick . 1984. Fate of toxic compounds under controlled redox potential and pH conditions in soil and sediment-water systems, EPA-600/3-83-018, U.S. Environmental Protection Agency, Springfield, VA, NTIS PB81-213266. Gantzer, C. J. and L. P. Wackett . 1991. Reductive dechlorination catalyzed by bacterial transition-metal coenzymes, Envrion. Sci. Technol. 25:715-722.

Geer, R. D. 1978. Predicting the anaerobic degradation of organic chemical pollutants in waste water treatment plants from their electrochemical behavior. Montana University Joint Water Resources Research Center Rep. No. 95, Bozeman, Montana, 61 pp.

Glass, B. L. 1972. Relation between the degradation of DDT and the iron redox system in soils, J. Agr. Food Chem. 20(2):324-327.

Goswami, K. P. and R. E. Green . 1971. Microbial degradation of the herbicide atrazine and its 2-hydroxy analog in submerged soils, Environ. Sci. Technol., 5:426-430.

Hale, D. D. , J. E. Rogers and J. Wiegel . 1991. Environmental factors correlated to dichlorophenol dechlorination in anoxic freshwater sediments, Environ. Toxicol. Chem. 10:1255-1265.

Hartman, W. W. and H. L. Silloway . 1955. Org. Syn. Coll. Vol 3, (New York, NY: John Wiley), p. 82.

Hassall, K. A. 1982. The Chemistry of Pesticides, (New York, NY: John Wiley), 373 pp. 
Helling, C. S. 1976. Dinitroaniline herbicides in soils, J. Environ. Qual., 5:1-15.

Holmstead, R. L. 1976. Studies of the degradation of mirex with an iron (II)porphy-rin model system, J. Agric. Food Chem., 24(3):620-624.

Hudlicky, M. 1984. Reductions in Organic Chemisty, (New York, NY: Halsted Press), p. 74.

Hutzinger, O. , S. Safe and V. Zitko . 1974. The Chemistry of PCB's, (Cleveland, OH: CRC Press).

Jafvert, C. T. and N. L. Wolfe . 1987. Degradation of selected halogenated ethanes in anoxic sediment-water systems, Environ. Toxicol. Chem., 6:827-837.

Kaplan, D. L. and A. M. Kaplan . 1982. 2,4,6-Trinitrotoluene-surfactant complexes: decomposition, mutagenicity, and soil leaching studies.

Environ. Sci. Technol. 16:566-571.

Kaplan, D. L. 1990. Biotransformation pathways of hazardous energetic organo-nitro compounds, in Advances in Applied Biotechnology, 4: Biotechnology and Biodegradation, Kamely, D. , A. Chakrabarty and G. S. Omen, eds., (The Woodlands, TX: Portfolio Publishing), pp. 155-182. Kearney, P. C. , J. E. Oliver , C. S. Helling , A. R. Isensee and A. Konston . 1977. Distribution, movement, persistence, and metabolism of Nnitrosoatrazine in soils and a model aquatic ecosystem, J. Agric. Food Chem., 25(5): 1177-1181.

Khalifa, S. , R. L. Holmstead and J. E. Casida . 1976. Toxaphene degradation by iron (II)protoporphyrin systems, J. Agric. Food Chem., $24: 277-282$

Klecka, G. M. and S. J. Gonsior . 1984. Reductive dechlorination of chlorinated methanes and ethanes by reduced iron (II)porphyrins, Chemosphere, 13:391-402.

Kray Jr., W. C. and C. E. Castro . 1964. The cleavage of bonds by low-valent transition metal ions. The homogeneous dehalogenation of vicinal dihalides by chromous sulfate, J. Am. Chem. Soc., 86:4603-4608.

Kriegman-King, M. R. and M. Reinhard . 1991. Reduction of hexachloroethane and carbon tetrachloride at surfaces of biotite, vermiculite, pyrite, and marcasite, in Organic Substances and Sediments in Water, Vol 2. Baker, R. A., ed., (Chelsea, MI: Lewis Publisher), pp. 349-364.

Kriegman-King, M. R. and M. Reinhard . 1992. Transformation of carbon tetrachloride in the presence of sulfide, biotite, and vermiculite, Environ. Sci. Technol. 26(11):2198-2206.

Krone, U. E. , R. K. Thauer and H. P. C. Hogenkamp . 1989. Reductive dehalogenation of chlorinated C1-hydrocarbons mediated by corrinoids, Biochemistry, 28(11):4908-4914.

Kuhn, E. P. and J. M. Suflita . 1989a. Dehalogenation of pesticides by anaerobic microorganisms in soils and groundwater-a review, in Reactions and Movement of Organic Chemicals in Soils, Sawhney, B. L. and K. Brown, Eds. SSSA special publication No.22, Madison, WI. Kuhn, E. P. and J. M. Suflita . 1989b. Sequential reductive dehalogenation of chloroanilines by microorganisms from a methanogenic aquifer, Environ. Sci. Technol., 23:848-852.

Kulkarni, S. V. , C. D. Blackwell , A. L. Blackard , C. W. Stackhouse . 1985. Textile dyes and dyeing equipment: classification, properties, and environmental aspects, U.S. Environmental Protection Agency, Resource Triangle Park: NC, EPA-600/2-85/010.

Kuwatsuka, S. 1977. Studies of the fate and behavior of herbicides in soil and plants, Nippon Noyaku Gakkaishi, 2:201-213.

Lightfoot, E. N. , P. S. Thorne, R. L. Jones, J. L. Hansen and R. R. Romine . 1987. Laboratory studies on mechanisms for the degradation of aldicarb, aldicarb sulfoxide and aldicarb sulfone, Environ. Toxicol. Chem., 6:377-394.

Littler, J. S. 1970. Homolytic oxidation and reduction of organic compounds by metallic ions, In Essays on Free-Radical Chemistry. Special Publication No. 24, (London, Chemical Society), pp. 383-408.

Macalady, D. L. and N. L. Wolfe . 1992. Hydrophobic effects in the reduction of anthropogenic organic chemicals by natural organic matter, paper presented at the American Chemical Symposium on Environmental Chemistry. San Francisco, CA., April 5-10.

Macalady, D. L. , P. G. Tratnyek and T. J. Grundl . 1986. Abiotic reactions of anthropogenic organic chemicals in anaerobic systems: a critical review, J. Contain. Hydrol. 1:1-28.

Maguire, R. J. and R. J. Tkacz . 1991. Occurrence of dyes in the Yamaska River, Quebec, Water Poll. Res. J. Canada, 26(2): $145-161$.

March, J. 1985. Advanced Organic Chemistry, 3rd Ed., (New York, NY: Wiley).

McCormick, N. G. , F. E. Feeherry, and H. S. Levinson . 1976. Microbial transformation of 2,4,6-trinitrotoluene and other nitroaromatic compounds, Appl. Environ. Microbiol. 31(6): 949-958.

Mikesell, M. D. and S. A. Boyd . 1985. Reductive dechlorination of the pesticides 2,4-D, 2,4,5-T, and pentachlorophenol in anaerobic sludges, J. Environ. Qual., 14:337-340.

Miles, C. J. and J. J. Delfino . 1985. Fate of aldicarb, aldicarb sulfoxide, and aldicarb sulfone in Floridian groundwater, J. Agric. Food Chem., 33:455-460.

Nies, L. and T. M. Vogel . 1990. Effects of organic substrates on dechlorination of aroclor 1242 in anaerobic sediments, Appl. Environ. Microbol., 56(9):2612-2617.

Oliver, J. E. and A. Kontson . 1978. Formation and persistence of N-nitrosobutralin in soil, Bull. Env. Contam. Tox., 20:170-173.

Ong, J. M. and C. E. Castro . 1977. Oxidation of iron(II)porphyrins and hemoproteins by nitro aromatics, J. Am. Chem. Soc., 99:6740-6745. Ou, T. , L. H. Carreira, R. W. Schottman and N. L. Wolfe . 1992.Nitroreduction of 2,4,6-trinitrotoluene (TNT) in contaminated soils, presented at the 203rd American Chemical Society Symposium on Oxidation-Reduction Transformations of Inorganic and Organic Species in the Environment. San Francisco, CA, April 5-10. 32(1):513-514.

Peijnenburg, W. J. G. M. , M. J. 't Hart, H. A. den Hollander, D. van de Meent , H. H. Verboom and N. L. Wolfe . 1991. QSARs for predicting biotic and abiotic reductive transformation rate constants of halogenated hydrocarbons in anoxic sediment systems, Sci. Total Environ. 109/110: 283-300.

Peijnenburg, W. J. G. M. , M. J. 't Hart , H. A. den Hollander , D. van de Meent , H. H. Verboom and N. L. Wolfe . 1992a. Reductive transformation of halogenated aromatic hydrocarbons in anaerobic water-sediment systems: kinetics, mechanisms, and products, Environ. Toxicol. Chem. 11:289-300.

Peijnenburg, W. J. G. M. , M. J. 't Hart, H. A. den Hollander, D. van de Meent, H. H. Verboom and N. L. Wolfe . 1992b. QSARs for predicting reductive transformation rate constants of halogenated aromatic hydrocarbons in anoxic water-sediment systems, Environ. Toxicol. Chem. 11:301-314.

Preussmann, R. and B. W. Stewart . 1984. N-nitroso carcinogens, in C.E. Searle (Ed.), Chemical Carcinogens, Vol. 2, ACS Monograph 182, American Chemical Society, Washington, pp. 643-828.

Quensen III, J. F. , J. M. Tiedje and S. A. Boyd . 1988. Reductive dechlorination of polychlorinated biphenyls by anaerobic microorganisms from sediments, Science, 242:752-754.

Quensen III, J. F. , S. A. Boyd and J. M. Tiedje . 1990. Dechlorination of four commercial polychlorinated biphenyl mixtures (aroclors) by anaerobic microorganisms from sediments, Appl. Environ. Microbiol., 56(8):2360-2369.

Quirke, J. M. E. , A. S. M. Marei and G. Eglinton . 1979. The degradation of DDT and its degradative products by reduced iron(II)porphyrins and ammonia, Che - mosphere, 3:151-155.

Rowland, I. R. and P. Grasso . 1975. Degradation of N-nitrosamines by intestinal bacteria, Appl. Microbiol., 29(1):7-12.

Rusling, J. F. and C. L. Miaw . 1989. Kinetic estimation of standard reduction potentials of polyhalogenated biphenyls, Environ. Sci. Technol., 23:476-479.

Saleh, M. A. , W. V. Turner and J. E. Casida . 1977. Polychlorobornane components of toxaphene: structure-toxicity relations and metabolic reductive dechlorination, Science, 198:1256-1258.

Sanders, P. and N. L. Wolfe . 1985. Reduction of nitroaromatic compounds in anaerobic, sterile sediments, presented at the 190th National Meeting of the American Chemical Society, Chicago, IL, September.

Schwarzenbach, R. P. and P. M. Gschwend . 1990. Chemical transformations of organic pollutants in the aquatic environment, in Aquatic Chemical Kinetics, Stumm, W. Ed., (New York, NY: John Wiley), pp. 199-233. 
Schwarzenbach, R. P. , R. Stierli , K. Lanz , and J. Zeyer . 1990. Quinone and iron porphyrin mediated reduction of nitroaromatic compounds in homogeneous aqueous solution, Environ. Sci. Technol. 24:1566-1574.

Semenov, N. N. 1958. Some Problems in Chemical Kinetics and Reactivity, (Princeton, NJ: Princeton University Press).

Smith, R. H. , J. E. Oliver and W. R. Lusby . 1979. Degradation of pendimethalin and its N-nitroso and N-nitro derivatives in anaerobic soils, Chemosphere, 11/12:855-861.

Southwick, L. M. and G. H. Willis . 1974. Interaction of trifluralin with soil components under flooded anaerobic conditions, Presented in the Division of Pesticide Chemistry at the 176th National American Chemical Society Meeting, Washington, D.C.

Steelinck, C. and G. Tollin . 1967. Free radicals in soil, in Soil Biochemistry, McLaren, A. D. and G. H. Peterson, eds., (New York, NY: Marcel Dekker), pp. 147-169.

Struijs, J. and J. E. Rogers . 1989. Reductive dehalogenation of dichloroanilines by anaerobic microorganisms in fresh and dichlorophenolacclimated pond sediment, Appl. Environ. Microbiol., 55(10):2527-2531.

Suflita, J. M. , A. Horowitz, D. R. Shelton , and J. M. Tiedje . 1982. Dehalogenation: a novel pathway for the anaerobic biodegradation of haloaromatic compounds, Science, 218:1115-1117.

Tate III, R. L. and M. Alexander . 1975. Stability of nitrosamines in samples of lake water, soil, and sewage, J. Natl. Cancer Inst., 54:327-330.

Tatsumi, K. , H. Yamada and S. Kitamura . 1983. Reductive metabolism of $\mathrm{N}$-nitrosodiphenylamine to the corresponding hydrazine derivative, Archives of Biochemistry and Biophysics, 226(1): 174-1881.

Terpko, M. O. and R. F. Heck . 1980. Palladium-catalyzed triethylammonium formate reductions. 3. Selective reduction of dinitroaromatic compounds, J. Org. Chem., 45:4992.

Thurman, E. M. 1985. Organic Geochemistry of Natural Waters, (Boston, MA: Nijhoff)

Timms, P. and I. C. MacRae . 1983. Reduction of fensulfonthion and accumulation of the product, fensulfothion sulfide, by selected microbes,

Bull. Environ. Contam. Toxicol., 31:112-115

Tincher, W. 1978. Survey of the Coosa Basin for organic contaminants from carpet processing, Final Report, Project E-27-630. Textile

Engineering Department, Georgia Institute of Technology, Atlanta, GA.

Tollin, G. , T. Reid and C. Steelink . 1963. Structure of humic acid. IV. Electron paramagnetic resonance studies, Biochimica et Biophysica, 66(2):444-447.

Tomizawa, C. 1975. Degradation of organophophorus pesticides in soils with special reference to anaerobic soil conditions, Environ. Qual. Saf., 4:117-127.

Tratnyek, P. G. and N. L. Wolfe . 1988. Reduction of phorate sulfoxide in anaerobic sediment slurries, Paper presented at the 195th meeting of the American Chemical Society, Dallas, TX, April 9-14.

Tratnyek, P. G. and N. L. Wolfe . 1990. Characterization of the reducing properties of anaerobic sediment slurries using redox indicators, Environ. Toxicol. Chem., 9:289-295.

Tratnyek, P. G. and D. L. Macalady . 1989. Abiotic reduction of nitro aromatic pesticides in anaerobic laboratory systems, J. Agric. Food Chem. 37:248-254.

Tratnyek, P. G. , J. Hoigné , J. Zeyer and R. P. Schwarzenbach 1991. QSAR analyses of oxidation and reduction rates of environmental organic pollutants in model systems, Sci. Total Environ. 109/110:327-341.

Tsukano, Y. , and A. Kobayashi . 1972. Formation of y-BTC in flooded rice field soils treated with y-BHC. Agric. Biol. Chem., 36:116-117.

Vogel, T. M. ; C. S. Criddle and P. L. McCarty . 1987. Transformations of halogena-ted aliphatic compounds, Environ. Sci. Technol.,

21(8):722-736.

Wade, R. S. and C. E. Castro . 1973. Oxidation of iron (II) porphyrins by alkyl halides, J. Am. Chem. Soc., 95(1):226-230.

Wahid, P. A. and A. Sethunathan . 1979. Involvement of hydrogen sulfide in the degradation of parathion in flooded acid sulphate soil, Nature (London), 282:401-402.

Wahid, P. A. , C. Ramakrishna and N. Sethunathan . 1980. Instantaneous degradation of parathion in anaerobic soils, J. Eviron. Qual. 9:127-130.

Walker, R. 1970. The metabolism of azo compounds: a review of the literature, Food Cosmet. Toxicol., 8:659-676.

Walter-Echols, G. and E. P. Lichtenstein . 1977. Microbial reduction of phorate sulfoxide to phorate in a soil-lake mud-water microcosm, J. Econ. Entomol., 70:505-509.

Wang, C. H. and F. E. Broadbent . 1973. Effect of soil treatments on losses of two chloronitrobenzene fungicides, J. Environ. Qual., 2:511-515.

Weber, E. J. and N. L. Wolfe . 1987. Kinetic studies of the reduction of aromatic azo compounds in anaerobic sediment/water systems, Environ. Toxicol, and Chem. 6:911-919.

Weber, E. J. Environmental fate studies of N-nitosoamines, paper presented at the Ninth Annual Meeting of the Society of Environmental Toxicology and Chemistry, Arlington, VI (1988), p. 73.

Weber, E.J. 1991. Studies of benzidine-base dyes in sediment-water systems, Environ. Sci. Chem. 10:609-618.

Weber, E. J. 1988. Reduction of disperse blue 79 in anaerobic sediment-water systems, in Preprints of Papers Presented at the 196th ACS

National Meeting, Los Angeles, CA, September, 25-30. pp. 177-180.

Wheland, G. W. 1944. The Theory of Resonance, (New York, NY: Wiley), p. 195.

Williams, P. P. , K. L. Davidson and E. J. Thacker . 1968. In vitro and in vivo rumen microbiological studies with 2-chloro-4,6-bis (isopropylamino)s-triazine (propa-zine), J. Anim. Sci., 27:1472-1476.

Willis, G. H. , R. C. Wander and L. M. Southwick . 1974. Degradation of trifluralin in soil suspensions as related to redox potential, J. Environ. Quality, 3(3):262-265.

Wolfe, N. L. , B. E. Kitchens, D. L. Macalady and T. J. Grundl . 1986. Physical and chemical factors that influence the anaerobic degradation of methyl parathion in sediment systems, Environ. Toxicol. Chem. 5:1019-1026.

Yen, C.P. C. , T. A. Perenich and G. L. Baughman . 1991. Fate of commercial disperse dyes in sediment, Environ. Toxicol. Chem. 10:1009-1017. Yu, Y. S. and G. W. Bailey . 1992. Reduction of nitrobenzene by four sulfide minerals: kinetics, products, and solubility, J. Environ. Qual. 21:86-94.

ZoBell, C. E. 1946. Studies on redox potential of marine sediments, Bull. Am. Assoc. Petrol. Geol., 30:477-513.

Zoro, J. A. , J. M. Hunter , G. Eglinton and G. C. Ware . 1974. Degradation of $p, p^{\prime}$-DDT in reducing environments, Nature, 247:235-236.

\section{Environmental Oxidations}

Adewuyi, Y. G. , and G. R. Carmichael . 1986. Kinetics of oxidation of dimethyl sulfide by hydrogen peroxide in acidic and alkaline medium. Environ. Sci. Technol. 20: 1017-1022.

Ahling, B. , A. Bjdrseth, and G. Lunde . 1978. Formation of chlorinated hydrocarbons during combustion of poly(vinyl chloride). Chemosphere 7 : 799-806.

Al Akeel, N. Y. , and D. J. Waddington . 1984. Reactions of oxygenated radicals in the gas phase. Part 16. Decomposition of isopropoxyl radicals. J. Chem. Soc. Perkin Trans. II. 1575-1579.

Altshuller, A. P. 1983. Natural volatile organic substances and their effect on air quality in the United States. Atmos. Environ. 17: $2131-2165$. Altshuller, A. P. , S. L. Kopczynski , D. Wilson , W. A. Lonneman , and F. D. Sutterfield . 1969. Photochemical reactivities of n-butane and other paraffinic hydrocarbons. J. Air Pollut. Control Assoc. 19: 787-796. 
Amberlang, J. C. , R. H. Kline , O. M. Lorenz, C. R. Parks , C. Wadelin , and J. R. Shelton . 1963. Antioxidants and antiozonants for general purpose elastomers. Rubber Chem. Technol. 36: 1497-1541.

Anderson, J. G. , H. J. Grassl , R. E. Shetter, and J. J. Margitan . 1981. HO2 in the stratosphere: three in situ observations. Geophys. Res. Lett. 8: 289-292.

Arnold, S. J. , E. A. Ogryzlo, and H. Witzke . 1964. Some new emission bands of molecular oxygen. J. Chem. Phys. 40: 1769-1770.

Atkinson, R. 1986. Kinetics and mechanisms of the gas phase reactions of the hydroxyl radical with organic compounds under atmospheric conditions. Chem. Rev. 86: 69-201.

Atkinson, R. 1991. Kinetics and mechanism of the gas-phase reaction of the NO3 radical with organic compounds. J. Phys. Chem. Ref. Data 20: 459-507.

Atkinson, R. and W. P. L. Carter . 1984. Kinetics and mechanism of the gas phase reactions of ozone with organic compounds under atmospheric conditions. Chem. Rev. 84: 437-470.

Atkinson, R. , K. R. Darnall , A. C. Lloyd , A. M. Winer , and J. N. Pitts, Jr. 1979. Kinetics and mechanisms of the reaction of the hydroxyl radical with organic compounds in the gas phase. Advan. Photochem. 11: 375-488.

Atkinson, R. , C. N. Plum , W. P. L. Carter, A. M. Winer, and J. N. Pitts, Jr. 1984a. Rate constants for the gas phase reactions of NO3 radicals with a series of organics in air at $298 \pm 1^{\circ} \mathrm{K} 1$. J. Phys. Chem. 88: $1210-1215$.

Atkinson, R. , S. M. Aschmann, A. M. Winer, and J. N. Pitts, Jr. 1984b. Kinetics of the gas phase reactions of NO3 radicals with a series of dialkenes, trialkenes, cycloalkenes, and monoterpenes at $295 \pm 1^{\circ} \mathrm{K}$. Environ. Sci. Technol. 18: 370-375.

Atkinson, R. , S. M. Aschmann, and A. M. Winer . 1987. Kinetics of the reactions of NO3 radicals with a series of aromatic compounds. Environ. Sci. Technol. 21: 1123-1126.

Badger, G. M. and T. M. Spotswood . 1960. The formation of aromatic hydrocarbons at high temperatures. Part IX. The pyrolysis of toluene, ethylbenzene, propylbenzene, and butylbenzene. J. Chem. Soc. 4420-4444.

Badger, G. M. , J. K. Donnelly, and T. M. Spotswood . 1966. The formation of aromatic hydrocarbons at high temperatures. Part XXVII. The pyrolysis of isoprene. Austr. J. Chem. 19: 1023-1044.

Bahadir, M. , S. Gab , J. Schmitzer , and F. Korte . 1978. Degradation of CC12F2; formation of CO2 upon adsorption on Mecca sand.

Chemosphere 941-942.

Baxter, R. M. and J. H. Carey . 1982. Reactions of singlet oxygen in humic waters. Freshwat. Biol. 12: 285-292.

Behymer, T. D. and R. A. Hites . 1988. Photolysis of polycyclic aromatic hydrocarbons adsorbed on fly ash. Environ. Sci. Technol. 22:

1311-1319.

Bellus, D. 1979. Physical quenchers of molecular oxygen. Advan. Photochem. 11: 105-205.

Berenbaum, M. R. and R. A. Larson . 1988. Flux of singlet oxygen from leaves of phototoxic plants. Experientia 44: $1030-1032$.

Bielski, B. H. J. 1978. Reevaluation of the spectral and kinetic properties of HO2. and of $-\mathrm{O} 2-$ free radicals. Photochem. Photobiol. 28: 645-649.

Bielski, B. H. J. 1983. Evaluation of the reactivities of HO2/O2 - with compounds of biological interest. In Cohen, G. and R. A. Greenwald , Eds.

Oxy Radicals and Their Scavenger Systems. Vol. 1, Molecular aspects. (Elsevier, Amsterdam), pp. 1-7.

Bielski, B. H. J. and Shiue, G. G. 1979. Reaction rates of superoxide radicals with the essential amino acids. In Oxygen Free Radicals and Tissue Damage, CIBA foundation symposium 65. Excerpta Medica, Amsterdam, pp. 43-56.

Bielski, B. H. J. , D. E. Cabelli , R. L. Arudi, and A. B. Ross . 1985. Reactivity of HO2/O2 -x radicals in aqueous solution. J. Chem. Phys. Ref. Data 14: 1041-1100.

Bolland, J. L. 1949. Kinetics of olefin oxidation. Quart. Rev. 3: 1-21.

Bonneau, R. , R. Pottier, O. Bagno, and J. Joussot-Dubien . 1975. pH dependence of singlet oxygen production in aqueous solutions using thiazine dyes as photosensitizers. Photochem. Photobiol. 21: 159-163.

Bothe, E. , Schuchmann, M. N. , D. Schulte-Frohlinde, and C. von Sonntag . 1978. HOO elimination from a-hydroxyalkylperoxyl radicals in aqueous solution. Photochem. Photobiol. 28: 639-644.

Boyd, S. A. and M. M. Mortland . 1985. Dioxin radical formation and polymerization on Cu (II)-smectite. Nature 316: 532-535.

Braun, A. M. , F. H. Frimmel , and J. Hoigné . 1986. Singlet oxygen analysis in irradiated surface waters. Internat. J. Environ. Anal. Chem. 27: 137-149.

Burton, G. W. and K. U. Ingold . 1984. ^-Carotene: an unusual type of lipid antioxidant. Science 224: 569-573.

Callen, D. F. and R. A. Larson . 1978. Toxic and genetic effects of fuel oil hydroperoxides in Saccharomyces cerevisiae. J. Toxicol. Environ. Health 4: 913-917.

Calvert, J. G. , A. Lazrus , G. L. Kok, B. G. Heikes , J. G. Walega , J. Lind , and C. A. Cantrell . 1985. Chemical mechanisms of acid generation in the troposphere. Nature 317: 27-35.

Cantrell, C. A. , D. H. Stedman, and G. J. Wendell . 1984. Measurement of atmospheric peroxy radicals by chemical amplification. Anal. Chem. 56: 1496-1502.

Carter, W. P. L. and R. Atkinson . 1985. Atmospheric chemistry of alkanes. J. Atmos. Chem. 3: 377-405.

Carter, W. P. L. , K. R. Darnall , A. C. Lloyd , A. M. Winer, and J. N. Pitts, Jr. 1976. Evidence for alkoxy radical isomerization in photooxidations of C4-C6 alkanes under simulated atmospheric conditions. Chem. Phys. Lett. 42: 22-27.

Chan, W. F. and R. A. Larson . 1991. Formation of mutagens from the aqueous reactions of ozone and anilines. Water Res. 25: $1529-1538$.

Chou, P.-T. and A. U. Khan . 1983. L-ascorbic acid quenching of singlet delta molecular oxygen in aqueous media: generalized antioxidant property of vitamin C. Biochem. Biophys. Res. Commun. 115: 932-937.

Choudhry, G. G. , K. Olie, and O. Hutzinger . 1982. In Chlorinated dioxins and related compounds. O. Hutzinger, R. W. Frei , E. Merian , and F. Pocchiari, Eds. (Pergamon Press, New York).

Cloos, P. , A. Moreale , C. Broers, and C. Badot . 1979. Adsorption and oxidation of aniline and p-chloroaniline by montmorillonite. Clay Min. 14: 307-321.

Cloos, P. , C. Badot , and A. Herbillon . 1981. Interlayer formation of humin in smectites. Nature 289: 391-393.

Cooper, W. J. and D. R. S. Lean . 1989. Hydrogen peroxide concentration in a northern lake: photochemical formation and diel variability. Environ. Sci. Technol. 23: 1425-1428.

Cooper, W. J. and R. G. Zika . 1983. Photochemical formation of hydrogen peroxide in surface and ground waters exposed to sunlight. Science 222: 711-712.

Cooper, W. J. , E. S. Saltzman , and R. G. Zika . 1987. The contribution of rainwater to variability in surface ocean hydrogen peroxide. J. Geophys. Res. (Oceanogr.) 92: 2970-2980.

Cooper, W. J., R. G. Zika, R. G. Petasne, and J. M. Plane . 1988. Photochemical formation of H2O2 in natural waters exposed to sunlight. Environ. Sci. Technol. 22: 1156-1160.

Cope, V. W. and D. R. Kalkwarf . 1987. Photooxidation of selected polycyclic aromatic hydrocarbons and pyrenequinones coated on glass surfaces. Environ. Sci. Technol. 21: 643-648.

Cox, R. A. and G. S. Tyndall . 1980. Rate constants for the reactions of $\mathrm{CH} 302$ with $\mathrm{HO} 2$, NO and $\mathrm{NO} 2$ using molecular modulation spectrometry. J. Chem. Soc. Faraday Trans. II 76: 153-163.

Cvetanovic, R. J. 1976. Chemical kinetic studies of atmospheric interest. Paper presented at 12th Sympos. on Free Radicals, Laguna Beach, CA. Darnall, K. R. and J. N. Pitts, Jr. 1970. Peroxyacetyl nitrate, a novel reagent for oxidation of organic compounds. J. Chem. Soc. Chem. Commun. 1305-1306.

Dlugi, R. and H. Güsten . 1983. The catalytic and photocatalytic activity of coal fly ashes. Atmos. Environ. 17, $1765-1771$.

Dorfman, L. M. and G. E. Adams . 1973. Reactivity of the hydroxyl radical in aqueous solutions. Report NSRDS-NBS 46. National Bureau of Standards, Washington, DC. 
Dragun, J. and C. S. Helling . 1985. Physicochemical and structural relationships of organic chemicals undergoing soil-and clay-catalyzed freeradical oxidation. Soil Sci. 139: 100-111.

Draper, W. M. and D. G. Crosby . 1976. Measurement of photochemical oxidants in agricultural field water. Paper presented at 172nd Natl. Mtg., Amer. Chem. Soc., 1, San Francisco, CA.

Draper, W. M. and D. G. Crosby . 1983. The photochemical generation of hydrogen peroxide in natural waters. Arch. Environ. Contam. Toxicol. 12: 121-126.

Drew, R. M. , J. A. Kerr , and J. Olive . 1985. Relative rate constants of the gas phase decomposition of the s-butoxy radical. Internat. J. Chem. Kinet. 17: 167-176.

Duchstein, H.-J. and G. Wurm . 1984. Juglonbildung, eine Indikatorreaktion für molekularen aktivieren Sauerstoff in Singlettzustand. Arch. Pharm. 317: 809-812.

Eiceman, G. A. , R. E. Clement , and F. W. Karasek . 1979. Analysis of fly ash from municipal incinerators for trace organic compounds. Anal. Chem. 51: 2343-2350.

Eklund, G. , J. R. Pedersen , and B. Stromberg . 1986. Phenol and $\mathrm{HCl}$ at $550^{\circ} \mathrm{C}$ yield a large variety of chlorinated toxic compounds. Nature 320 : 155-156.

Eriksen, T. E. , J. Lind, and G. Merenyi . 1985. On the acid-base equilibrium of the carbonate radical. Radiat. Phys. Chem. 26: 197-199.

Faust, B. C. and J. Hoigné . 1987. Sensitized photooxidation of phenols by fulvic acid in natural waters. Environ. Sci. Technol. 21: 957-964.

Faust, B. C. and J. Hoigné . 1990. Photolysis of Fe(III)-hydroxy complexes as sources of OH radicals in clouds, fog, and rain. Atmos. Environ. 23: 235-240.

Finlayson-Pitts, B. J. and J. N. Pitts, Jr. 1986. Atmospheric chemistry: fundamentals and experimental techniques. (New York, NY: WileyInterscience).

Foote, C. S. 1976. Photosensitized oxidation and singlet oxygen: consequences in biological systems. In Free Radicals in Biology, Vol. 2, W. A. Pryor, Ed., (New York, NY: Academic Press), pp. 85-133.

Foote, C. S. 1991. Definition of type I and type II photosensitized oxidation. Photochem. Photobiol. 54: 659.

Foote, C. S. and S. Wexler . 1964. Olefin oxidations with excited singlet molecular oxygen. J. Amer. Chem. Soc. 86: 3879-3880.

Fox, M. A. and S. Olive . 1979. Photooxidation of anthracene on atmospheric particulate matter. Science 205: 582-583.

Freiberg, J. E. and S. E. Schwartz . 1981. Oxidation of S02 in aqueous droplets: mass-transport limitation in laboratory studies and in the ambient atmosphere. Atmos. Environ. 15: 1145-1154.

Fridovich, I. 1974. Superoxide dismutases. Advan. Enzymol. 41: 35-97.

Frimmel, F. H. , H. Bauer, J. Putzien, P. Murasecco, and A. M. Braun . 1987. Laser flash photolysis of dissolved aquatic humic material and the sensitized production of singlet oxygen. Environ. Sci. Technol. 21: 541-545.

Furukawa, T. and G. W. Brindley . 1973. Adsorption and oxidation of benzidine and aniline by montmorillonite and hectorite. Clays Clay Min. 21 : 279-288.

Gardiner, W. C. , Jr. 1984. Combustion Chemistry. (New York, NY: Springer Verlag).

Gohre, K. and G. C. Miller . 1983. Singlet oxygen generation on soil surfaces. J. Agric. Food Chem. 31: 1104-1108.

Gohre, K. and G. C. Miller . 1985. Photochemical generation of singlet oxygen on non-transition-metal oxide surfaces. J. Chem. Soc. Faraday Trans. 7, 81: 793-800.

Gohre, K. , R. Scholl , and G. C. Miller . 1986. Singlet oxygen reactions on irradiated soil surfaces. Environ. Sci. Technol. 20: 934-938.

Gollnick, K. and G. O. Schenk . 1967. In Hamer, J. , Ed. 1,4-Cycloaddition Reactions: Diels-Alder Reaction in Heterocyclic Synthesis. (New York, NY: Academic Press), pp. 255-300.

Govindaraj, N. , M. M. Mortland, and S. A. Boyd . 1987. Single electron transfer mechanism of oxidative dechlorination of 4-chloroanisole on copper(II)-smectite. Environ. Sci. Technol. 21: 1119-1123.

Gsponer, H. E. , C. M. Previtali , and N. A. Garcia . 1987. Kinetics of the photosensitized oxidation of polychlorophenols in alkaline aqueous solution. Toxicol. Environ. Chem. 16: 23-37.

Gunz, D. and M. R. Hoffmann . 1990. Atmospheric chemistry of peroxides: a review. Atmos. Environ. 24A: 1601-1633.

Haag, W. and J. Hoigné . 1986. Singlet oxygen in surface waters. 3. Photochemical formation and steady-state concentration in various types of waters. Environ. Sci. Technol. 20: 341-348.

Haag, W. , J. Hoigné , E. Gassmann and A. M. Braun . 1984. Singlet oxygen in surface waters. Part 1. Furfuryl alcohol as a trapping agent. Chemosphere 13: 631-640.

Haagen-Smit, A. J. 1952. Chemistry and physiology of Los Angeles smog. Industr. Eng. Chem. 44: 1342-1346.

Hamberg, M. and B. Gotthammar . 1973. A new reaction of unsaturated fatty acid hydroperoxides: formation of II-hydroxy-12,13-epoxy-9octadecenoic acid from 13-hydroperoxy-9,ll-octadecadienoic acid. Lipids 8: 737-744.

Hanst, P. L. and B. W. Gay, Jr. 1983. Atmospheric oxidation of hydrocarbons: formation of hydroperoxides and peroxyacids. Atmos. Environ. 17: 2259-2265.

Hauser, E. A. 1955. Silicic Science. (Princeton, NJ: Van Nostrand).

Hawthorne, S. B. , D. J. Miller, R. M. Barkley, and M. S. Krieger . 1988. Identification of methoxylated phenols as candidate tracers for atmospheric wood smoke pollution. Environ. Sci. Technol. 22: 1191-1196.

Hites, R. A. 1976. Sources of polycyclic aromatic hydrocarbons in the aquatic environment. In F. T. Weiss, Ed. Sources, Effects, and Sinks of Hydrocarbons in the Aquatic Environment. (Washington, DC: Amer. Inst. Biol. Sci.), pp. 325-332.

Hoffman, R. V. , G. A. Eiceman, Y.-T. Long, M. C. Collins, and M. Q. Liu . 1990. Mechanism of chlorination of aromatic compounds adsorbed on the surface of fly ash from municipal incinerators. Environ. Sci. Technol. 24: 1635-1641.

Hofzumahaus, A. , H.-P. Dorn , J. Callies , U. Platt , and D. H. Ehhalt . 1991. Tropospheric hydroxyl radical concentration measurements by laser long-path absorption spectroscopy. Atmos. Environ. 25A: 2017-2022.

Hoigné, J. 1983. Reactions of ozone and inorganic radicals in natural waters. Presented at NATO-ARI workshop, Photochemistry of Natural Waters, Woods Hole, MA. Abstracts, p. 77.

Hoigné, J. 1984. Kinetics of reactions of aqueous ozone and of its decomposition products. Paper presented at Conference on Gas-Liquid Chemistry of Natural Waters, Brookhaven, NY. Abstracts, pp. 11-13 to 13-16.

Hon, D. N.-S. , S. T. Chang, and W. C. Feist . 1982. Participation of singlet oxygen in the photodegradation of wood surfaces. Wood Sci. Technol. 16: 193-201.

Hoshino, M. , H. Akimoto, and M. Okuda . 1978. Photochemical oxidation of benzene, toluene, and ethylbenzene initiated by $\mathrm{OH}$ radicals in the gas phase. Bull. Chem. Soc. Japan 51: 718-724.

Howard, J. A. and J. C. Scaiano . 1984. Oxyl-, Peroxyl und verwandte Radikale. In Landoldt-Bornstein, Neue Serie II, H. Fischer , Ed. (Berlin: Springer), pp. 5-431.

Junk, G. A. and C. S. Ford . 1980. A review of organic emissions from selected combustion processes. Chemosphere 9: 187-230.

Katz, M. , C. Chan, H. Tosine, and T. Sakuma . 1979. Relative rates of photochemical and biological oxidation (in vitro) of polycyclic aromatic hydrocarbons. In P. W. Jones and P. Leber, Eds. Polynuclear Aromatic Hydrocarbons. (Ann Arbor, MI: Ann Arbor Sci. Pub.), pp. 171-189. Kautsky, H. and H. de Bruin . 1931. Die Aufklärung der Photoluminescenztilgung fluorescerender Systeme durch Sauerstoff: die Bildung aktiver, diffussionsfähiger Sauerstoffmoleküle durch Sensibilisierung. Naturwissenschaften 19: 1043-1058.

Khalil, G.-E. and M. Kasha . 1978. Oxygen-interaction luminescence spectroscopy. Photochem. Photobiol. 28: 435-443.

Kok, G. L. 1980. Measurements of hydrogen peroxide in rainwater. Atmos. Environ. 14: 653-656. 
Korfmacher, W. A. , D. F. S. Natusch, D. R. Taylor, G. Mamantov, and E. L. Wehry . 1980. Oxidative transformation of polycyclic aromatic hydrocarbons adsorbed on coal fly ash. Science 207: 763-765.

Kormann, C. , D. W. Bahnemann , and M. R. Hoffmann . 1988. Photocatalytic production of $\mathrm{H} 2 \mathrm{O} 2$ and organic peroxides in aqueous suspensions of TiO2, ZnO, and desert sand. Environ. Sci. Technol. 22: 798-806.

Kung, K.-H. and M. B. McBride . 1988a. Electron transfer processes between hausmannite (Mn304) and hydroquinone. Clays Clay Min. 36: 297-302.

Kung, K.-H. and M. B. McBride . 1988b. Electron transfer processes between hydroquinone and iron oxides. Clays Clay Min. 36: 306-309. Laha, S. , and R. G. Luthy . 1990. Oxidation of aniline and other primary aromatic amines by manganese dioxide. Environ. Sci. Technol. 24:363-373.

Lamb, F. A. , P. N. Cote , B. Slutsky, and B. M. Vittimberga . 1974. Oxidation-reduction of 9-(p-methoxyphenyl)-9-fluorenylacetaldehyde on activated alumina. J. Org. Chem. 39: 2796-2797.

Larson, R. A. 1988. The antioxidants of higher plants. Phytochemistry 27: 969-978.

Larson, R. A. and J. M. Hufnal, Jr. 1980. Oxidative polymerization of dissolved phenols by soluble and insoluble inorganic species. Limnol. Oceanogr. 25: 505-512.

Larson, R. A. and R. G. Zepp . 1988. Reactivity of the carbonate radical with aniline derivatives. Environ. Toxicol. Chem. 7: 265-274.

Larson, R. A. , L. L. Hunt, and D. W. Blankenship . 1977. Formation of toxic products from a \#2 fuel oil by photooxidation. Environ. Sci. Technol. 11: 492-496.

Larson, R. A. , T. L. Bott , L. L. Hunt , and K. Rogenmuser . 1979. Photooxidation products of a fuel oil and their antimicrobial activity. Environ.

Sci. Technol. 13: 965-969.

Larson, R. A. , H.-L. Ju , V. L. Snoeyink, M. A. Recktenwalt , and P. A. Dowd . 1988. Some intermediates in the wet air oxidation of phenanthrene adsorbed on powdered activated carbon. Water Res. 22: 337-342.

Laughlin, R. G. W. , T. Gallo, and H. Robey . 1983. Wet air oxidation for hazardous waste control. J. Hazard. Mater. 8: 1-9.

Lehmann, R. G. , H. H. Cheng, and J. B. Harsh . 1987. Oxidation of phenolic acids by soil iron and manganese oxides. Soil Sci. Soc. Amer. J. 51: 352-356.

Lichtenthaler, R. G. , W. R. Haag, and T. Mill . 1989. Photooxidation of probe compounds sensitized by crude oils in toluene and as an oil film on water. Environ. Sci. Technol. 23: 39-45.

Logan, J. A. , M. J. Prather , S. C. Wofsy , and M. B. McElroy . 1981. Tropospheric chemistry: a global perspective. J. Geophys. Res. 86 : 7210-7254.

Loll, M. J. and J. M. Bollag . 1985. Characterization of a citrate-buffer soil extract with oxidative coupling activity. Soil Biol. Biochem. 17: 115-117. Lorenz, K. , D. Rhasa, R. Zellner , and B. Fritz . 1985. Laser photolysis-LIF kinetic studies of the reactions of CH3G and CH2CHO with O2 between 300 and 500K. Ber. Bunsenges. Phys. Chem. 89: 341-342.

Martin, L. R. and D. E. Damschen . 1981. Aqueous oxidation of sulfur dioxide by hydrogen peroxide at low pH. Atmos. Environ. 15: 1615-1621.

Matsuura, T. and K. Omura . 1966. The hydroxylation of phenols by the photolysis of hydrogen peroxide in aqueous media. J. Chem. Soc. Chem.

Commun. 127-128.

Mayo, F. R. 1958. The oxidation of unsaturated compounds. 7. The oxidation of aliphatic unsaturated compounds. J. Amer. Chem. Soc. 80:

2497-2500.

McBride, M. B. 1987. Adsorption and oxidation of phenolic compounds by iron and manganese oxides. Soil Sci. Soc. Amer. J. 51: $1466-1472$.

McBride, M. B. 1989. Oxidation of dihydroxybenzenes in aerated aqueous suspensions of birnessite. Clays Clay Min. 37: $341-347$.

McBride, M. B. , F. J. Sikora, and L. G. Wesselink . 1988. Complexation and catalyzed oxidative polymerization of catechol by aluminum in acidic solution. Soil Sci. Soc. Amer. J. 52: 985-992.

McFarland, D. , D. Kley , J. W. Drummond , A. L. Schmellekopf , and R. H. Winkler . 1979. Nitric oxide measurements in the equatorial Pacific region. Geophys. Res. Lett. 6: 605-608.

McKeen, S. A. , M. Trainer , E. Y. Hsie , R. K. Tallamraju , and S. C. Liu . 1990. On the indirect determination of atmospheric hydroxyl radical concentrations from reactive hydrocarbon measurements. J. Geophys. Res. 95: 7493-7500.

Merkel, P. B. and D. R. Kearns . 1972. Radiationless decay of singlet molecular oxygen in solution. An environmental and theoretical study of electronic-to-vibrational energy transfer. J. Amer. Chem. Soc. 94: 7244-7253.

Mihelcic, D. , M. Helten , H. Fark, P. Müsgen , H. W. Pätz, M. Trainer, D. Kempa, and D. H. Ehhalt . 1982. Tropospheric airborne measurements of $\mathrm{NO} 2$ and $\mathrm{RO} 2$ using the technique of matrix isolation and electron spin resonance. 2nd Sympos. on Composition of the Nonurban Troposphere, Williamsburg, VA. Abstracts, p. 327-329.

Mihelcic, D. , D. H. Ehhalt, G. Kulessa, J. Klomfass, M. Trainer, A. Schmidt, and H. Rohrs . 1978. Measurements of free radicals in the atmosphere by matrix isolation and electron paramagnetic resonance. Pure Appl. Geophys. 116: 530-536.

Mill, T. , D. Hendry , and D. Richardson . 1980. Free-radical oxidants in natural waters. Science 207: 886-887.

Miller, J. A. and G. A. Fisk . 1987. Combustion chemistry. Chem. Eng. News. (Aug. 31). pp. 22-46.

Miller, J. A. , R. J. Kee, and C. K. Westbrook. 1990. Chemical kinetics and combustion modeling. Ann. Rev. Phys. Chem. 41: 345-387.

Millero, F. J. 1987. Estimate of the life time of superoxide in water. Geochim. Cosmochim. Acta 51: 351-353.

Moffett, J. W. and R. G. Zika . 1987. Reaction kinetics of hydrogen peroxide with copper and iron in seawater. Environ. Sci. Technol. 21: 804-810.

Momzikoff, A. , R. Santus, and M. Giraud . 1983. A study of the photosensitizing properties of seawater. Mar. Chem. 11: 1-14.

Mopper, K. and X. Zhou . 1990. Hydroxyl radical photoproduction in the sea and its potential impact on marine processes. Science 250: 661-664. Moreale, A. , P. Cloos , and C. Badot . 1985. Differential behavior of Fe (III) and Cu (II) montmorillonite with aniline. I. Suspensions with constant solid:liquid ratio. Clay Min. 20: 29-37.

Morris, E. D., Jr. and H. Niki . 1974. Reaction of the nitrate radical with acetaldehyde and propylene. J. Phys. Chem. 78: 1337-1338.

Mortland, M. M. and S. A. Boyd . 1989. Polymerization and dechlorination of chloroethenes on Cu (II)-smectite via radical-cation intermediates. Environ. Sci. Technol. 23: 223-227.

Mortland, M. M. and L. J. Halloran . 1976. Polymerization of aromatic molecules on smectite. Soil Sci. Soc. Amer. J. 40: 367-370.

Mowrer, J. and J. Nordin . 1987. Characterization of halogenated organic acids in flue gases from municipal incinerators. Chemosphere 16:

1181-1192.

Mukai, K. , K. Daifuku , K. Ozabe , T. Tanigaki, and K. Inoue . 1991. Structure-activity relationship in the quenching of singlet oxygen by tocopherol (vitamin E) derivatives and related phenols. Finding of linear correlation between the rates of quenching of singlet oxygen and scavenging of peroxyl and phenoxy radicals in solution. J. Org. Chem. 56: 4188-4192.

Munger, J. W. , D. J. Jacob, and M. R. Hoffmann . 1984. The occurrence of bisulfite-aldehyde addition products in fog-and cloudwater. J. Atmos. Chem. 1: 335-350.

Nestrick, T. J. , L. L. Lamparski , and W. B. Crummett . 1987. Thermolytic surface-reaction of benzene and iron (III) chloride to form chlorinated dibenzo-p-dioxins and dibenzofurns. Chemosphere 16: 777-790.

Neta, P. and S. Steenken . 1981. Phenoxyl radicals: formation, detection, and redox properties in aqueous solutions. In M. A. J. Rodgers and E. L. Powers, Eds. Oxygen and Oxy-Radicals in Chemistry and Biology. (New York, NY: Academic Press), pp. 83-88.

Niehaus, W. G. Jr. 1978. A proposed role of superoxide anion as a biological nucleophile in the deesterification of phospholipids. Bioorg. Chem. 7: 77-84.

Niki, H. , P. D. Maker, C. M. Savage, and L. P. Breitenbach . 1980. FTIR studies of the Cl atom initiated oxidation of formaldehyde: detection of a new metastable species in the presence of NO2. Chem. Phys. Lett. 72: 71-73. 
Ogata, Y. , K. Tomizawa, and Y. Yamashita . 1980. Photoinduced oxidation of benzoic acid with aqueous hydrogen peroxide. J. Chem. Soc. Perkin Trans. II: 616-619.

Olszyna, K. J. , J. F. Meagher, and E. M. Bailey . 1988. Gas-phase, cloud and rainwater measurements of hydrogen peroxide at a high-elevation site. Atmos. Environ. 22: 1699-1706.

Pfoertner, K. and D. Böse . 1970. Die photosensibilisierte Oxydation einwertiger Phenole zu Chinonen. Helv. Chim. Acta 53: $1555-1566$. Pickering, W. F. 1966. Heterogeneous oxidation reactions. Rev. Pure Appl. Chem. 16: 185-208.

Pillai, P. , C. S. Helling, and J. Dragun . 1982. Soil-catalyzed oxidation of aniline. Chemosphere 11: 299-317.

Pinnavaia, T. J. 1983. Intercalated clay catalysts. Science 220: 365-371.

Pitts, J. N., Jr. , D. M. Lokensgard , P. S. Ripley, K. A. van Cauwenberghe , L. van Vaeck, S. D. Shaffer , A. J. Thill , and W. L. Belser, Jr. 1980. "Atmospheric" epoxidation of benzo[a]pyrene by ozone: formation of the metabolite benzo[a]pyrene-4,5-oxide. Science 210: 147-149.

Pitts, J. N., Jr. , H. R. Paur , B. Zielinska , J. A. Sweetman, A. M. Winer , T. Ramdahl , and V. Mejia . 1986. Factors influencing the reactivity of poycyclic aromatic hydrocarbons adsorbed on model substrates and in ambient POM with ambient levels of ozone. Chemosphere 15: 675-685. Platt, U. , G. LeBras, G. Poulet, J. P. Burrows, and G. Moortgat . 1990. Peroxy radicals from night-time reaction of NO3 with organic compounds. Nature 348: 147-149.

Pohlman, A. A. and T. Mill . 1983. Peroxy radical interaction with soil constituents. Soil Sci. Soc. Amer. J. 47: 922-927.

Posner, G. H. 1983. Organic reactions at alumina surfaces. Angew. Chem. Int. Ed. Engl. 17: 487-496.

Prinn, R. , D. Cunnold, R. Rasmussen , P. Simmonds, F. Alyea , A. Crawford , P. Fraser , and R. Rosen . 1987. Atmospheric trends in methylchloroform and the global average for the hydroxyl radical. Science 238: 945-950.

Rabani, J. , W. A. Mulac, and M. S. Matheson . 1965. The pulse radiolysis of aqueous tetranitromethane. I. Rate constants and the extinction coefficient of eaq. J. Phys. Chem. 69: 53-62.

Rånby, B. and J. F. Rabek . 1975. Photodegradation, photo-oxidation and photostabilization of polymers. Wiley, London.

Rao, R. S. and E. Hayon . 1975. Redox potential of free radicals. IV. Superoxide and hydroperoxy radicals $\bullet$ O2 - and HOO. J. Phys. Chem. 79 : 397-402.

Rodgers, M. A. and P. T. Snowden . 1982. Lifetime of O2 $(1 \delta \mathrm{g})$ in liquid water as determined by time-resolved infrared luminescence measurements. J. Amer. Chem. Soc. 104: 5541-5543.

Russell, G. A. 1957. Deuterium-isotope effects in the autoxidation of aralkyl hydrocarbons. Mechanism of the interaction of peroxy radicals. J. Amer. Chem. Soc. 79: 3871-3877.

Saito, I. , M. Imuta , and T. Matsuura . 1972. Photoinduced reactions. LIX. Reactivity of singlet oxygen toward methoxybenzenes. Tetrahedron 28: 5307-5311.

Saito, I. , T. Matsuura, M. Nakagawa, and T. Hino . 1977. Peroxidic intermediates in photosensitized oxygenation of tryptophan derivatives. Acc. Chem. Res. 10: 346-352.

Sakugari, H. , G.-I. Furusawa, K. Ueno, and K. Tokamura . 1982. Generation of singlet oxygen on irradiation of contact charge-transfer pairs of 1,2,3,4-tetramethylnaphthalene with oxygen. Chem. Lett. 1213-1216.

Sakugawa, H. , I. R. Kaplan, W. Tsai , and Y. Cohen . 1990. Atmospheric hydrogen peroxide. Environ. Sci. Technol. 24: 1452-1462.

Sawnhey, B. L. , R. K. Kozloski , P. J. Isaacson , and M. P. N. Gent . 1984. Polymerization of 2,6-dimethoxyphenol on smectite surfaces. Clays Clay Min. 32: 108-114.

Sawyer, D. T. and E. J. Nanni, Jr. 1981. Redox chemistry of dioxygen species and their chemical reactivity. In M. A. J. Rodgers and E. L. Powers , Eds. Oxygen and Oxy-Radicals in Chemistry and Biology. (New York, NY: Academic Press), pp. 15-44.

Schofield, P. J. , B. J. Ralph, and J. H. Green . 1964. Mechanisms of hydroxylation of aromatics on silica surfaces. J. Phys. Chem. 68: 472-476. Schumacher, J. N. , C. R. Green , F. W. Best, and M. P. Newell . 1977. Smoke composition. An extensive investigation of the water-soluble portion of cigarette smoke. J. Agric. Food Chem. 25: 310-320.

Scully, F. E. and J. Hoigné . 1987. Rate constants for reactions of singlet oxygen with phenols and other compounds in water. Chemosphere 16: 681-694.

Shaub, W. M. and W. Tsang . 1983. Dioxin formation in incinerators. Environ. Sci. Technol. 17: 721-730.

Shindo, H. and P. M. Huang . 1985. Catalytic polymerization of hydroquinone by primary minerals. Soil Sci. 139: 505-511.

Singh, H. B. and L. J. Salas . 1983. Peroxyacetyl nitrate in the free troposphere. Nature 302: 326-328.

Smotkin, E. S. , F. T. Moy, and W. Z. Plachy . 1991. Dioxygen solubility in aqueous phosphatidylcholine dispersions. Biochim. Biophys. Acta 1061: 33-38.

Solar, S. , W. Solar and N. Getoff . 1986. Resolved multisite OH-attack on aqueous aniline studied by pulse radiolysis. Radiat. Phys. Chem. 28: 229-234.

Solomon, D. H. , B. C. Loft, and J. D. Swift . 1968. Reactions catalyzed by minerals. 4. The mechanism of the benzidine blue reaction. Clay Min. 1: 389-397.

Soma, Y. , and M. Soma . 1983. Formation of hydroxydibenzofurans from chloro-phenols adsorbed on Fe-ion exchanged montmorillonite. Chemosphere 18: 1895-1902.

Spencer, W. F. , J. D. Adams, R. E. Hess , T. D. Shoup , and R. C. Spear . 1980. Conversion of parathion to paraoxon on soil dusts and clay minerals as affected by ozone and UV light. Agric. Food Chem. 28: 366-371.

Stone, A. T. 1987. Reductive dissolution of manganese (III/IV) oxides by substituted phenols. Environ. Sci. Technol. 21: 979-988.

Stone, A. T. and J. J. Morgan . 1984. Reduction and dissolution of manganese(III) and manganese(IV) oxides by organics. 1. Reaction with hydroquinone. Environ. Sci. Technol. 18: 450-456.

Sunda, W. G. , S. A. Huntsman, and G. R. Harvey . 1983. Photoreduction of manganese oxides in seawater and its geochemical and biological implications. Nature 301: 234-236.

Swartz, H. M. and N. J. F. Dodd . 1981. The role of ascorbic acid on radical reactions in vivo . In M. A. J. Rodgers and E. L. Powers, Eds.

Oxygen and Oxy-Radicals in Chemistry and Biology. (New York, NY: Academic Press), pp. 161-168.

Taylor, W. I. and A. R. Battersby . 1967. Oxidative Coupling of Phenols. (New York: NY: Marcel Dekker).

Temple, P. J. and O. C. Taylor . 1983. World-wide ambient measurements of peroxyacetyl nitrate (PAN) and implications for plant injury. Atmos. Environ. 17: 1583-1587.

Theng, B. K. G. 1974. The Chemistry of Clay-Organic Reactions. (New York, NY: John Wiley \& Sons).

Thomas, M. J. and C. S. Foote . 1978. Chemistry of singlet oxygen. XXVI. Photooxygenation of phenols. Photochem. Photobiol. 27: 683-693.

Tratnyek, P. G. and J. Hoigné . 1991. Oxidation of substituted phenols in the environment: a QSAR analysis of rate constants for reaction with singlet oxygen. Environ. Sci. Technol. 25: 1596-1604.

True, M. B. and O. C. Zafiriou . 1987. Reaction of Br2" produced by flash photolysis of sea water with components of the dissolved carbonate system. In Zika, R. G. and Cooper, W. J. , Eds. Aquatic Photochemistry. Amer. Chem. Soc. Sympos. Ser. 327: 106-115.

Ulrich, H.-J. and A. T. Stone . 1989. Oxidation of chlorophenols adsorbed to manganese oxide surfaces. Environ. Sci. Technol. 23: $421-428$.

Vaghijiani, G. L. and A. R. Ravishankara . 1991. New measurement of the rate coefficient for the reaction of OH with methane. Nature 350: 406-409.

Van Cauwenberghe, K. , L. Van Vaeck, and J. N. Pitts, Jr. 1979. Chemical transformations of organic pollutants during aerosol sampling. Advan. Mass Spectrom. 8: 1499-1520.

von Sonntag, C. 1987. The Chemical Basis of Radiation Biology. (London: Taylor and Francis).

Voudrias, E. A. and M. Reinhard . 1986. Abiotic organic reactions at mineral surfaces: a review. In J. A. Davis and K. F. Hayes , Eds.,

Geochemical processes at mineral surfaces. Amer. Chem. Soc. Sympos. Ser. 323: 462-486. 
Waite, T. D. , I. C. Wrigley, and R. Szymczak . 1988. Photoassisted dissolution of a colloidal manganese oxide in the presence of fulvic acid. Environ. Sci. Technol. 22: 778-785.

Waldman, J. M. , J. W. Munger , D. J. Jacob , R. C. Flanagan , J. J. Morgan , and M. R. Hoffmann . 1982. Chemical composition of acid fog. Science 218: 677-680.

Walling, C. 1975. Fenton's reagent revisited. Acc. Chem. Res. 12: 125-131.

Wang, T. S. C. , M. C. Wang , Y. L. Ferng, and P. M. Huang . 1983. Catalytic synthesis of humic substances by natural clays, silts, and soils. Soil Sci. 135: 350-360.

Weschler, C. J. , M. L. Mandich, and T. E. Graedel . 1986. Speciation, photosensitivity, and reactions of transition metal ions in atmospheric droplets. J. Geophys. Res. 91: 5189-5204.

Wilkinson, F. and J. G. Brummer . 1981. Rate constants for the decay and reactions of the lowest electronically excited singlet state of molecular oxygen in solution. J. Phys. Chem. Ref. Data 10: 809-999.

Wilshire, J. and D. T. Sawyer . 1979. Redox chemistry of dioxygen species. Acc. Chem. Res. 12: 105-110.

Yasuhara, A. and M. Morita . 1988. Formation of chlorinated aromatic hydrocarbons by thermal decomposition of vinylidene chloride polymer. Environ. Sci. Technol. 22: 646-650.

Ye, M. and R. H. Schuler . 1990. Determination of oxidation products in radiolysis of halophenols with pulse radiolysis, HPLC, and ion chromatography. J. Liq. Chromatogr. 13: 3369-3387.

Yokley, R. A. , A. A. Garrison , E. L. Wehrly , and G. Mamantov . 1986. Photochemical transformation of pyrene and benzo[a]pyrene vapordeposited on eight coal stack ashes. Environ. Sci. Technol. 20: 86-90.

Yoshizumi, K. , K. Aoki , I. Nouchi , T. Okita , T. Kobayashi , S. Kamukara, and M. Tajima . 1984. Measurements of the concentration in rainwater and of the Henry's law constant of hydrogen peroxide. Atmos. Environ. 18: 395-401.

Zafiriou, O. C. , J. Joussot-Dubien , R. G. Zepp, and R. G. Zika . 1984. Photochemistry of natural waters. Environ. Sci. Technol. 18: 358A-371A. Zafiriou, O. C. , M. B. True, and E. Hayon . 1987. Consequences of $\mathrm{OH}$ radical reaction in sea water: formation and decay of $\mathrm{Br} 2-\mathrm{ion}$ radical. In Zika, R. G. and Cooper, W. J. , eds. Aquatic photochemistry. Amer. Chem. Soc. Sympos. Ser. 327: 89-105.

Zepp, R. G. , N. L. Wolfe , G. L. Baughmann, and R. C. Hollis . 1977. Singlet oxygen in natural waters. Nature 267: 421-423.

Zepp, R. G. , A. M. Braun , J. Hoigné , and J. A. Leenheer . 1987a. Photoproduction of hydrated electrons from natural organic solutes in aquatic environments. Environ. Sci. Technol. 21: 485-490.

Zepp, R. G. , J. Hoigné , and H. Bader . 1987b. Nitrate-induced photooxidation of trace organic chemicals in water. Environ. Sci. Technol. 21: 443-450.

Zepp, R. G. , Y. I. Skurlatov, and J. T. Pierce . 1987c. Algal-induced decay and formation of hydrogen peroxide in water: its possible role in oxidation of anilines by algae. In Zika, R. G. and Cooper, W. J. , Eds. Aquatic photochemistry, Amer. Chem. Soc. Sympos. Ser. 327: $215-224$. Zhou, X. and K. Mopper . 1990. Determination of photochemically produced hydroxyl radicals in seawater and freshwater. Mar. Chem. $30: 71-88$. Zika, R. , E. Saltzman , W. L. Chameides, and D. D. Davis . 1982. H2O2 levels in rainwater collected in south Florida and the Bahama Islands. J. Geophys. Res. 87: 5015-5017.

\section{Reactions With Disinfectants}

Alben, K. 1980. Gas chromatographic-mass spectrometric analysis of chlorination effects on commercial coal-tar leachate. Anal. Chem. 52, 1825-1828.

Amy, G. L. , P. A. Chadlik, P. H. King , and W. J. Cooper . 1984. Chlorine utilization during trihalomethane formation in the presence of ammonia and bromide. Environ. Sci. Technol. 18: 781-786.

Andreozzi, R. , A. Insola , V. Caprio, and M. G. D'Amore . 1991. Ozonation of pyridine in aqueous solution: mechanistic and kinetic aspects. Water Res. 25: 655-659.

Austin, J. M. , T. Groenewald , and M. Spiro . 1980. Heterogeneous catalysis in solution. Part 18. The catalysis by carbons of oxidation-reduction reactions. J. Chem. Soc. Dalton Trans 854-859.

AWWA (American Water Works Association) . 1989. Standard methods for the examination of water and wastewater. 16th ed. American Public Health Association, Washington, DC.

Babenzian, H. D. , A. Schwartz, and W. Schwartz . 1963. Über Chlorschwund im Trinkwasser. II. Einfluss von Bakterien und von organischen Verbindungen auf den Chlorschwund. Zentralbl. Bakteriol. Parasitenkr. Infektionskr. Abt. I 185: 398-415.

Bailey, P. S. 1956. The ozonolysis of phenanthrene in methanol. J. Amer. Chem. Soc. 78: 3811-3816.

Bailey, P. S. 1958. The reactions of ozone with organic compounds. Chem. Rev. 58: 925-1010.

Bailey, P. S. 1982. Ozonation in Organic Chemistry. Vol. 2. (New York, NY: Academic Press).

Bailey, P. S. , P. Kolsaker, B. Sinha, J. B. Ashton, F. Dobinson, and J. E. Batterbee . 1964. Competing reactions in the ozonation of anthracene. J. Org. Chem. 29: 1400-1409.

Bailey, P. S. , T. P. Carter, Jr. , and L. M. Southwick . 1972. Ozonation of amines. VI. Primary amines. J. Org. Chem. 37: $2997-3004$.

Barnhart, E. L. and G. R. Campbell . 1972. Effect of chlorination on selected organic chemicals. EPA Report EPA-12020 EXG PB $160-211$.

Bellar, T. L. , J. J. Lichtenberg , and R. C. Kroner . 1974. The occurrence of organohalides in chlorinated drinking water. J. Amer. Water Works Assoc. 66: 703-706.

Bickel, A. F. and H. R. Gersman . 1959. Autoxidation of hindered phenols in alkaline media. Part 1. J. Chem. Soc. 2711-2716.

Boehm, H. P. , G. Mair, T. Stoehr, A. R. de Rincon, and B. Terczi . 1984. Carbon as catalyst in oxidation reactions and hydrogen halide elimination reactions. Fuel 63, 1061-1063.

Bowen, E. J. and W. M. Cheung. 1932. The photodecomposition of chlorine dioxide solutions. J. Chem. Soc. 1200-1208.

Boyce, S. D. and J. F. Hornig . 1983. Reaction pathways of trihalomethane formation from the halogenation of dihydroxyaromatic model compounds for humic acid. Environ. Sci. Technol. 17: 202-211.

Brueggeman, E. , J. E. Wajon, C. W. R. Wade, and E. P. Burrows . 1982. Analysis of unquenched mixtures of chlorine dioxide and phenols by reversed-phase high-performance liquid chromatography. J. Chromatogr. 237: 484-488.

Buchbauer, G. , S. Freudenreich, C. Hampl, E. Haslinger, and W. Robien . 1984. Zur Reaktion von Camphen mit unterchloriger Saure.

Synthesen in der Isocamphenreihe, 23. Mitt. Monatsh. Chem. 115, 509-517.

Biihler, R. E. , J. Staehelin , and J. Hoigné . 1984. Ozone decomposition in water studied by pulse radiolysis. 1. HO2/O2 - and HO3/O3' as intermediates. J. Phys. Chem. 88: 2560-2564.

Bunn, W. W. , B. B. Haas, E. R. Deane, and R. D. Kleopfer . 1975. Formation of trihalomethanes by chlorination of surface waters. Environ. Lett. 10: 205-213.

Burleson, G. R. and T. M. Chambers . 1982. Effect of ozonation on the mutagenicity of carcinogens in aqueous solution. Environ. Mutagenesis 4: 469-476.

Burleson, G. R. , M. J. Caulfield, and M. Pollard . 1979. Ozonation of mutagenic and carcinogenic polyaromatic amines and polyaromatic hydrocarbons in water. Cancer Res. 39: 2149-2154.

Burleson, J. L. , G. R. Peyton, and W. H. Glaze . 1978. Chlorinated tyrosine in municipal waste treatment plant products after superchlorination.

Bull. Environ. Contam. Toxicol. 19: 724-728. 
Burttschell, R. H. , A. A. Rosen , F. M. Middleton, and M. B. Ettinger . 1959. Chlorine derivatives of phenol causing taste and odor. J. Amer. Water Works Assoc. 51: 205-213.

Butkovic, V. , L. Klasinc, M. Orhanovic , J. Turk, and H. Gusten . 1983. Reaction rates of polynuclear aromatic hydrocarbons with ozone in water. Environ. Sci. Technol. 17: 546-548.

Carlson, R. M. and R. Caple . 1977. Chemical-biological implications of using chlorine and ozone for disinfection. US EPA Report EPA/600/3-77/066.

Carlson, R. M. and R. Caple . 1978. Organochemical implications of water chlorination. In R. L. Jolley, ed. Water Chlorination: Environmental Impact and Health Effects. Vol. 1. (Ann Arbor, MI: Ann Arbor Sci. Pub.), pp. 65-75.

Carlson, R. M. and S. Lin . 1985. Characterization of the products from the reaction of hydroxybenzoic and hydroxycinnamic acids with aqueous solutions of chlorine, chlorine dioxide, and chloramine. In Water Chlorination: Chemistry, Environmental Impact and Health Effects. Vol. 5. R. L. Jolley, R. J. Bull , W. P. Davis , S. Katz, M. H. Roberts, Jr. , and V. A. Jacobs, Eds., (Chelsea, MI: Lewis Pub.), pp. 835-842.

Carlson, R. M. , R. Caple, A. R. Oyler, K. J. Welch, D. L. Bodenner, and R. Liukonnen . 1978. Aqueous chlorination products of polynuclear aromatic hydrocarbons. In Water Chlorination: Environmental Impact and Health Effects. Vol. 2. R. L. Jolley, H. Gorchev, and D. H. Hamilton, Jr. , Eds. (Ann Arbor, Ml: Ann Arbor Sci. Pub.), pp. 59-65.

Caulfield, M. J. , G. R. Burleson, and M. Pollard . 1979. Ozonation of mutagenic and carcinogenic alkylating agents, pesticides, aflatoxin B1, and benzidine in water. Cancer Res. 39: 2155-2159.

Cavanagh, J. E. , H. S. Weinberg , A. Gold , R. Sangalah, D. Marbury, W. H. Glaze , T. W. Collette , S. D. Richardson, and A. D. Thruston Jr. 1992. Ozonation byproducts: identification of bromohydrins from the ozonation of natural waters with enhanced bromide levels. Environ. Sci. Technol. 26, 1658-1662.

Cerkinsky, S. N. and N. Trahtman . 1972. The present status of research on the disinfection of drinking water in the USSR. Bull. World Health Org. 46, 277-283.

Chan, W. F. and R. A. Larson . 1992. Formation of mutagens from the aqueous reactions of ozone and anilines. Water Res. 25, $1529-1538$. Chen, A. S. -C., R. A. Larson, and V. L. Snoeyink . 1982. Reactions of chlorine dioxide with hydrocarbons: effects of activated carbon. Environ. Sci. Technol. 16: 268-273.

Chen, P. N. , G. A. Junk, and H. J. Svec . 1979. Reactions of organic pollutants. 1. Ozonation of acenaphthylene and acenaphthene. Environ. Sci. Technol. 13: 451-454.

Christman, R. F. , J. D. Johnson, J. R. Haas , F. K. Pfaender, W. T. Liao, D. L. Norwood, and H. J. Alexander . 1978. Natural and model aquatic humics: reaction with chlorine. In Water Chlorination: Environmental Impact and Health Effects. Vol. 2. R. L. Jolley , H. Gorchev , and D. H. Hamilton, Jr. , Eds. (Ann Arbor, Ml: Ann Arbor Sci. Pub.), pp. 15-28.

Christman, R. F. , D. L. Norwood, D. S. Millington, and J. D. Johnson . 1983. Identity and yields of major halogenated products of aquatic fulvic acid chlorination. Environ. Sci. Technol. 17: 625-628.

Chrostowski, P. C. , A. M. Dietrich , and I. H. Suffet . 1983. Ozone and oxygen induced oxidative coupling of aqueous phenolics. Water Res. 17: 1627-1633.

Coleman, W. E. , J. W. Munch, P. A. Hodakievic , F. C. Kopfler , J. R. Meier , R. P. Streicher, and H. Zimmer . 1988. GC/MS identification of mutagens in aqueous chlorinated humic acid and drinking waters following HPLC fractionation of strong acid extracts. In Larson, R. A. , Ed. Biohazards of Drinking Water Treatment. (Chelsea, MI: Lewis Pub.), pp. 107-121.

Conyers, B. , and F. E. Scully, Jr. 1993. N-Chloroaldimines. 3. Chlorination of phenylalanine in model solutions and in a wastewater. Environ. Sci. Technol. 27: 261-266.

Cotruvo, J. A. , V. F. Simmon, and R. J. Spanggord . 1977. Investigation of mutagenic effects of products of ozonation reactions in water. Ann. N. Y. Acad. Sci. 298: 124-140.

Crane, A. M. , S. J. Erickson , and C. E. Hawkins . 1980. Contribution of marine algae to trihalomethane production in chlorinated estuarine water. Estuar. Coast. Mar. Sci. 11: 239-249.

Das, B. S. , S. G. Reid , J. L. Betts, and K. Patrick . 1969. Tetrachloro-o-benzoquinone as a component in bleached kraft chlorination effluent toxic to young salmon. J. Fish. Res. Bd. Canada 26: 3055-3067.

De la Mare, P. B. D. , A. D. Ketley, and C. A. Vernon . 1954. The kinetics and mechanisms of aromatic halogen substitution. I. Acid-catalyzed chlorination by aqueous solutions of hypochlorous acid. J. Chem. Soc. 1290-1297.

De Leer, E. W. B. and C. Erkelens . 1988. Pathways for the production of organochlorine compounds in the chlorination of humic materials. In Larson, R. A. , Ed. Biohazards of Drinking Water Treatment. (Chelsea, MI: Lewis Pub.), pp. 97-106.

De Leer, E. W. B. , J. S. Sinninghe Damsté, C. Erkelens, and L. de Galan . 1985. Identification of intermediates leading to chloroform and C-4 diacids in the chlorination of humic acid. Environ. Sci. Technol. 19: 512-522.

De Leer, E. W. B. , T. Baggerman, C. Erkelens, and L. de Galan 1987. The production of cyano compounds on chlorination of humic acid. A comparison between terrestrial and aquatic material. Sci. Total Environ. 62: 329-334.

Dence, C. and K. Sarkanen . 1960. A proposed mechanism for the chlorination of softwood lignin. Tappi 43: 87-96.

Dennis, W. H., Jr. , L. A. Hull , and D. H. Rosenblatt . 1967. Oxidation of amines. IV. Oxidative fragmentation. J. Org. Chem. 32: $3783-3787$.

Dennis, W. H., Jr. , V. P. Olivieri , and C. W. Krusé . 1978. Reaction of uracil with hypochlorous acid. Biochem. Biophys. Res. Commun. 83:

168-171.

Dennis, W. H., Jr. , V. P. Olivieri , and C. W. Krusé . 1979. The reaction of nucleotides with aqueous hypochlorous acid. Water Res. 13: $357-362$.

DeRosa, M. and J. L. T. Alonso . 1978. Studies of the mechanism of chlorination of indoles. Detection of N-chloroindole and 3-chloro-3H-indole as intermediates. J. Org. Chem. 43: 2639-2643.

Donnet, J.-B. 1982. Structure and reactivity of carbons; from carbon black to carbon composites. Carbon 20: 266-282.

Dore, M. , B. Langlais, and B. Legube . 1978. Ozonation des phénols et des acides phenoxyacetiques. Water Res. 12:413-425.

Duguet, J.-P. , A. Bruchet, B. Dussert, and J. Mallevialle . 1988. Formation of aromatic polymers during the ozonation or enzymatic oxidation of waters containing phenolic compounds. In Larson, R. A. , Ed. Biohazards of Drinking Water Treatment. (Chelsea, MI: Lewis Pub.), pp. 171-184. Eisenhauer, H. R. 1968. The ozonisation of phenolic wastes. J. Water Pollut. Contr. Fed. 40: 1887-1899.

Eklund, G. , B. Josefsson and A. Bjørseth . 1978. Determination of chlorinated and brominated lipophilic compounds in spent bleach liquors from a sulphite pulp mill. Glass capillary column gas chromatography-mass spectrometry-computer analysis and identification. J. Chromatogr. 150: 161-169.

Ellis, A. J. and F. G. Soper . 1954. Studies of N-halogeno compounds. VI. The kinetics of chlorination of tertiary amines. J. Chem. Soc. 1750-1755.

Erickson, M. and C. W. Dence . 1976. Phenolic and chlorophenolic oligomers in chlorinated pine kraft pulp and in bleach plant effluents. Svensk Papperstidn. 10: 316-322.

Everly, C. R. and J. G. Traynham . 1979. Formation and rearrangement of ipso intermediates in aromatic free-radical chlorination reactions. J. Org. Chem. 44: 1784-1787.

Fair, G. M. , J. C. Morris , S. L. Chang , I. Weil , and R. P. Burden . 1948. The behavior of chlorine as a water disinfectant. J. Amer. Water Works Assoc. 40: 1051-1061.

Farhataziz and A. B. Ross . 1977. Selected specific rates of reactions of transients from water in aqueous solution. III. Hydroxyl radical and perhydroxyl radical and their radical ions. NSRDS-NBS Publication \#59. US Dept, of Commerce, Washington, DC.

Fischer, A. and G. N. Henderson . 1979. Ipso chlorination of 4-alkylphenols. Formation of 4-alkyl-4-chlorocyclohexa-2,5-dienones. Can. J. Chem. 57: 552-557.

Fonouni, H. E. , S. Krishnan, D. G. Kuhn , and G. A. Hamilton . 1983. Mechanisms of epoxidations and chlorinations of hydrocarbons by inorganic hypochlorite in the presence of a phase-transfer catalyst. J. Amer. Chem. Soc. 105: 7672-7676. 
Forni, L. , D. Bahnemann, and E. J. Hart . 1982. Mechanism of the hydroxide ion initiated decomposition of ozone in aqueous solution. J. Phys. Chem. 86: 255-259.

Freitag, D. , L. Scheunert , W. Klein , and F. Korte . 1984. Long-term fate of 4-chloroaniline-14C in soil and plants under outdoor conditions. A contribution to terrestrial ecotoxicology of chemicals. J. Agric. Food Chem. 32, 203-207.

Friedman, A. H. and S. Morgulis . 1936. The oxidation of amino acids with sodium hypobromite. J. Amer. Chem. Soc. 58: 909-913.

Fujii, M. and M. Ukita . 1957. Mechanism of wheat protein coloring by chlorine dioxide. Nippon Nogei Kagaku Kaishi 31: 101-109.

Gaffney, P. E. 1977. Chlorobiphenyls and PCBs: formation during chlorination. J. Water Pollut. Contr. Fed. 49: 401-404.

Gess, J. M. 1971. Reactions of creosol with aqueous chlorine. Ph.D. Thesis, State Univ. Coll. Forestry (Syracuse, NY), 1971. Diss. Abstr. B31: 5258.

Ghanbari, H. A. , W. B. Wheeler, and J. R. Kirk . 1983. Reactions of aqueous chlorine and chlorine dioxide with lipids: chlorine incorporation. J.

Food Sci. 47: 482-485.

Gibson, T. M. , J. Haley, M. Righton , and C. D. Watts . 1986. Chlorination of fatty acids during water treatment disinfection: reactivity and product identification. Environ. Technol. Lett. 7: 365-372.

Giger, W. , M. Reinhard, C. Schaffner, and F. Zurcher . 1976. Analyses of organic constituents in water by high-resolution gas chromatography in combination with specific detection and computer-assisted mass spectrometry. In L. H. Keith, Ed. Identification and Analysis of Organic Pollutants in Water. (Ann Arbor, Ml: Ann Arbor Sci. Pub.), pp. 433-452.

Gilbert, E. 1976. über den Abbau von organischen Schadstoffen in Wasser durch Ozon. Vom Wasser 43: 275-290.

Gilbert, E. 1978. Reactions of ozone with organic compounds in dilute aqueous solution: identification of their oxidation products. In R. G. Rice and J. A. Cotruvo, Eds. Ozone-Chlorine Dioxide Oxidation Products of Organic Materials. (Cleveland, OH: Ozone Press Intl.), pp. $227-242$. Glaze, W. H. 1987. Drinking-water treatment with ozone. Environ. Sci. Technol. 21: 224-230.

Glaze, W. H. , J. E. Henderson IV , and G. Smith . 1978. Analysis of new chlorinated organic compounds formed by chlorination of municipal wastewater. In R. L. Jolley, Ed. Water Chlorination: Environmental Impact and Health Effects. Vol. 1. (Ann Arbor, MI: Ann Arbor Sci. Pub.), pp. 139-159.

Glaze, W. H. , M. Koga , E. C. Ruth, and D. Cancilla . 1988. Application of closed loop stripping and XAD resin adsorption for the determination of ozone byproducts from natural water. In Larson, R. A. , Ed. Biohazards of Drinking Water Treatment. (Chelsea, MI: Lewis Pub.), pp. 201-210. Gordon, G. , R. G. Kieffer, and D. H. Rosenblatt . 1972. The chemistry of chlorine dioxide. Progr. Inorg. Chem. 15: $201-286$.

Gould, J. P. and W. J. Weber Jr. 1976. Oxidation of phenols by ozone. J. Water Pollut. Contr. Fed. 48: 47-60.

Guilmet, E. and B. Meunier . 1980. A new catalytic route for the epoxidation of styrene with sodium hypochlorite activated by transition metal complexes. Tetrahedron Lett. 21: 4449-4450.

Gurol, M. D. and S. Nekoulnalni . 1984. Kinetic behavior of ozone in aqueous solutions of substituted phenols. Industr. Eng. Chem. Fundamentals 23: $54-60$.

Guthrie, J. P. and J. Cossar . 1986. The chlorination of acetone: a complete kinetic analysis. Can. J. Chem. 64: $1250-1266$.

Guthrie, J. P. , J. Cossar, and J. Lu . 1991. Dihydroxyacids from the chlorination of ketones: an unexpected process. Can. J. Chem. 69:

1904-1908.

Haag, W. R. and J. Hoigné . 1983. Ozonation of bromide-containing waters: kinet ics of formation of hypobromous acid and bromate. Environ.

Sci. Technol. 17: 261-267.

Haenen, G. R. M. M. and A. Bast . 1991. Scavenging of hypochlorous acid by lipoic acid. Biochem. Pharmacol. 42: $2244-2246$.

Hanna, J. V. , W. D. Johnson, R. A. Quezada, M. A. Wilson, and L. Xiao-Qiao . 1991. Characterization of aqueous humic substances before and after chlorination. Environ. Sci. Technol. 25: 1160-1164.

Hauchman, F. S. , C. I. Noss, and V. P. Olivieri . 1986. Chlorine dioxide reactivity with nucleic acids. Water Res. 20: 357-361.

Hauser, C. R. and M. L. Hauser . 1930. Researches on chloramines. I. Ortho-chlorobenzalchlorimine and anisalchlorimine. J. Amer. Chem. Soc. 52: 2050-2054.

Hayatsu, H. , S. K. Pan, and E. T. Ukita . 1971. Reaction of sodium hypochlorite with nucleic acids and their constituents. Chem. Pharm. Bull. 19: 2189-2192.

Helz, G. R. , R. Y. Hsu , and R. M. Block . 1978. Bromoform production by oxidative biocides in marine waters. In R. G. Rice and J. A. Cotruvo, Eds. Ozone-Chlorine Dioxide Oxidation Products of Organic Materials. (Cleveland, OH: Ozone Press Intl.), pp. 68-76.

Hemming, J. , B. Holmbom, M. Reunanen, and L. Kronberg . 1986. Determination of the strong mutagen 3-chloro-4-(dichloromethyl)-5-hydroxy2(5H)-furanone in chlorinated drinking and humic waters. Chemosphere 15: 549-556.

Hirose, Y. , T. Okitsu and S. Kanno . 1982. Formation of trihalomethanes by reaction of halogenated phenols or halogenated anilines with sodium hypochlorite. Chemosphere 11: 81-87.

Hodgen, H. W. and R. S. Ingols . 1954. Direct colorimetric method for the determination of chlorine dioxide in water. Anal. Chem. 26: 1224-1226. Hoehn, R. C. , C. W. Randall , F. A. Bell, Jr. , and P. T. B. Shaffer . 1977. Trihalomethanes and viruses in a water supply. J. Environ. Eng. Div.,Amer. Soc. Chem. Eng. 103: 803-814.

Hoehn, R. C. . R. P. Goode , C. W. Randall, and P. T. B. Shaffer . 1978. Chlorination and treatment for minimizing trihalomethanes in drinking water. In Water Chlorination: Environmental Impact and Health Effects. Vol. 2. R. L. Jolley, H. Gorchev, and D. H. Hamilton, Jr. , Eds. (Ann Arbor, MI: Ann Arbor Sci. Pub.), pp. 519-535.

Hoigné, J. 1982. Mechanisms, rates, and selectivities of oxidations of organic compounds initiated by ozonation of water. In Handbook of Ozone Technology and Applications. R. G. Rice and A. Netzer, Eds. (Ann Arbor, MI: Ann Arbor Sci. Pub.), pp. 341-379.

Hoigné, J. and H. Bader . 1975. Ozonation of water: role of hydroxyl radicals as oxidizing intermediates. Science 190: $782-783$.

Hoigné, J. and H. Bader . 1979. Ozonation of water: "oxidation-competition values" of different types of waters used in Switzerland. Ozone Sci.

Eng. 1: 357-372.

Hoigné, J. and H. Bader . 1982. Kinetik typischer Reaktionen von Chlordioxid mit Wasserinhaltsstoffen. Vom Wasser 59: $253-267$.

Hoigné, J. and H. Bader . 1983a. Rate constants of reactions of ozone with organic and inorganic compounds in water. I. Non-dissociating organic compounds. Water Res. 17: 173-183.

Hoigné, J. and H. Bader . 1983b. Rate constants of reactions of ozone with organic and inorganic compounds in water. II. Dissociating organic compounds. Water Res. 17: 185-194.

Horth, H. , M. Fielding, H. A. James, M. J. Thomas, T. Gibson, and P. Wilcox. 1990. Production of organic chemicals and mutagens during chlorination of amino acids in water. In Water Chlorination: Chemistry, Environmental Impact and Health Effects. Vol. 6. R. L. Jolley , L. W. Condie , J. D. Johnson, S. Katz , R. A. Minear, J. S. Mattice, and V. A. Jacobs, Eds. (Chelsea, MI: Lewis Pub.), pp. $107-124$.

Houben, J. and T. Weyl . 1962. Methoden der organischen Chemie ("Houben-Weyl"). 4. Aufl., B. 5, p. 793. Thieme Verlag, Stuttgart.

Hoyano, Y. , V. Bacon, R. E. Simmons , W. E. Pereira, B. Halpern, and A. M. Duffield . 1973. Chlorination studies. IV. The reaction of aqueous hypochlorous acid with pyrimidine and purine bases. Biochem. Biophys. Res. Commun. 53: 1195-1199.

Hrudey, S. E. , A. Gac, and S. A. Daignault . 1988. Potent odor-causing chemicals arising from drinking water disinfection. Water Sci. Technol. 20: $55-61$.

Hwang, S.-C. , R. A. Larson, and V. L. Snoeyink . 1990. Reactions of free chlorine with substituted anilines in aqueous solution and on granular activated carbon. Water Res. 24: 427-432.

Ingols, R. S. , H. A. Wyckoff , T. W. Kethley, H. W. Hodgen , E. L. Fincher , J. C. Hildebrand, and J. E. Mandel . 1953. Bacterial studies of chlorine. Industr. Eng. Chem. 45: 996-1000.

Jackson, D. E. , R. A. Larson, and V. L. Snoeyink . 1987. Reactions of chlorine and chlorine dioxide with resorcinol in aqueous solution and adsorbed on granular activated carbon. Water Res. 231: 849-857. 
Jenkins, R. L. , J. E. Haskins , L. G. Carmona , and R. B. Baird . 1978. Chlorination of benzidine and other aromatic amines in aqueous environments. Arch. Environ. Contam. Toxicol. 1: 301-315.

Johnsen, S. and I. S. Gribbestad . 1988. Influence of humic substances on the formation of chlorinated polycyclic aromatic hydrocarbons during chlorination of polycyclic aromatic hydrocarbon polluted water. Environ. Sci. Technol. 22: 978-981.

Johnson, J. D. , D. L. Norwood, and R. F. Christman . 1982. Reaction products of aquatic humic substances with chlorine. Environ. Health Perspect. 46: 63-71.

Jurs, R. H. 1966. Die Wirkung des Ozons auf wassergelöste Stoffe. Fortschr. Wasserchem. 4: 40-64.

Keith, L. H. , A. W. Garrison , F. R. Allen , M. H. Carter , T. L. Floyd , J. D. Pope , and A. D. Thruston Jr. 1976. Identification of organic

compounds in drinking water from thirteen U.S. cities. In L. H. Keith, Ed. Identification and Analysis of Organic Pollutants in Water. (Ann Arbor MI: Ann Arbor Sci. Pub.), pp. 329-373.

Killops, S. D. 1986. Volatile ozonation products of aqueous humic material. Water Res. 20: 153-165.

Knox, W. E. , P. K. Stumpf, D. E. Green, and V. H. Auerbach . 1948. The inhibition of sulfhydryl enzymes as the basis of the bactericidal action of chlorine. J. Bacteriol. 55: 451-458.

Kolar, J. J. and B. O. Lindgren . 1982. Oxidation of styrene by chlorine dioxide and by chlorite in aqueous solutions. Acta Chem. Scand. B36: 599-605.

Kopperman, H. L. , R. C. Hallcher , A. Riehl , R. M. Carlson , and R. Caple . 1976. Aqueous chlorination of $\alpha$-terpineol. Tetrahedron 32 : 1621-1626.

Kovacic, P. , M. Lowery , and K. W. Field . 1970. Chemistry of N-bromamines and N-chloramines. Chem. Rev. 70: 639-665.

Kringstad, K. P. , P. O. Ljungquist, F. De Sousa, and L. M. Strömberg . 1981. Identification and mutagenic properties of some chlorinated aliphatic compounds in the spent liquor from kraft pulp chlorination. Environ. Sci. Technol. 15: 562-566.

Kronberg, L. , B. Holmbom , M. Reunanen , and L. Tikkanen . 1988. Identification and quantification of the Ames mutagenic compound 3-chloro4-(dichloromethyl)-5-hydroxy-2(5H)-furanone and of its geometric isomer (E)-2-chloro-3-(dichloromethyl)-4-oxobutenoic acid in chlorine-treated humic water and drinking water extracts. Environ. Sci. Technol. 22: 1097-1103.

Kuo, P. P. K. , E. S. Chian , and B. J. Chang . 1977. Identification of end products resulting from ozonation and chlorination of organic compounds commonly found in water. Environ. Sci. Technol. 11: 1177-1181.

Långvik, V.-A. , O. Hormi , L. Tikkanen , and B. Holmbom . 1991. Formation of the mutagen 3-chloro-4-(dichloromethyl)-5-hydroxy-2(5H)-furanone and related compounds by chlorination of phenolic compounds. Chemosphere 22, 547-555.

Larson, R. A. , Ed. 1988. Biohazards of Drinking Water Treatment. (Chelsea, MI: Lewis Pub.).

Larson, R. A. and K. A. Marley . 1988. Sunlight photochlorination and dark chlorination of monoterpenes. Sci. Total Environ. 77: $245-252$.

Larson, R. A. and A. L. Rockwell . 1979. Chloroform and chlorophenol production by decarboxylation of natural acids during aqueous chlorination. Environ. Sci. Technol. 13: 325-329.

Larson, R. A. and R. G. Zepp . 1988. Reactivity of the carbonate radical with aniline derivatives. Environ. Toxicol. Chem. 1: $265-274$.

Lawrence, J. , H. Tosine , F. I. Onuska, and H. E. Comba . 1980. The ozonation of natural waters: product identification. Ozone Sci. Eng. 2:

$55-64$.

Leach, J. M. and A. N. Thakore . 1977. Compounds toxic to fish in pulp mill waste streams. Progr. Water Technol. 9: $787-798$.

Lee, G. F. and J. C. Morris . 1962. Kinetics of chlorination of phenol: chlorophenolic tastes and odors. Internat. J. Air Water Pollut. 6: 419-431.

Legube, B. , S. Guyon, H. Sugimitsu, and M. Doré . 1986. Ozonation du naphthalene en milieu aqueux. I. Consommation d'ozone et produits de reaction. Water Res. 20: 197-208.

LeRoux, Y. , J. C. Ginisty, and C. Nofre . 1969. Degradation comparee de la xan thine sous l'effet de l'oxygene singulet excitee et du radical libre hydroxyle. Compt. Rend. Acad. Sci. Paris 269C: 744-747.

Lin, S. and R. M. Carlson . 1984. Susceptibility of environmentally important heterocycles to chemical disinfection: reactions with aqueous chlorine, chlorine dioxide, and chloramine. Environ. Sci. Technol. 18: 743-748.

Lin, S. , R. J. Liukkonen, R. E. Thorn, J. G.M. Bastian, T. Lukasewycz, and R. M. Carlson . 1984. Increased chloroform production from model compounds of aquatic humus and mixtures of chlorine dioxide/chlorine. Environ. Sci. Technol. 18: 932-935.

Lindgren, B. O. 1971. Chlorine dioxide and chlorite oxidations of phenols related to lignin. Svensk Papperstidn. 74: 57-63.

Lindgren, B. O. , C. M. Svahn, and G. Widmark . 1965. Chlorine dioxide oxidation of cyclohexene. Acta Chem. Scand. $19:$ 7-13.

Lindgren, B. O. and T. Nilsson . 1973. Preparation of carboxylic acids from aldehydes (including hydroxylated benzaldehydes) by oxidation with chlorite. Acta Chem. Scand. 27: 888-890.

Lindgren, B. O. and T. Nilsson . 1974. Oxidation of lignin model compounds with chlorine dioxide and chlorite. Reactions with stilbenes. Acta Chem. Scand. 28: 847-852.

Lindgren, B. O. and T. Nilsson . 1975. Chlorate formation during the reaction of chlorine dioxide with lignin model compounds. Svensk Papperstidn. 78: 66-68.

Lindstrom, K. and F. Osterberg . 1986. Chlorinated carboxylic acids in softwood kraft pulp spent bleach liquors. Environ. Sci. Technol. 20: 133-138.

Lykins, B. W. , W. Koffskey, and R. G. Miller . 1986. Chemical products and toxicologic effects of disinfection. J. Amer. Water Works Assoc. 78: 66-75.

Macalady, D. L. , J. H. Carpenter, and C. A. Moore . 1977. Sunlight-induced bromate formation in chlorinated seawater. Science 195:

1335-1337.

Marley, K. A. , R. A. Larson, P. L. Stapleton, W. J. Garrison, and C. L. Klodnycky . 1987. Ozonolysis of naphthalene derivatives in water and in kerosene films. Ozone Sci. Eng. 9: 23-36.

Masschelein, W. J. 1979. Chlorine dioxide: chemistry and environmental impact of oxychlorine compounds. (Ann Arbor, Ml: Ann Arbor Science). Matheson, N. R. and T. J. Travis . 1985. Differential effects of oxidizing agents on human plasma a!-antiproteinase inhibitor and human neutrophil myeloperoxidase. J. Biochem. 24, 1941-1945.

Matsui, M. , H. Nakazumi , K. Kamiya , C. Yatome , K. Shibata, and H. Muramatsu . 1989. Ozonolysis of uracils in water. Chem. Lett. $723-724$. Matsushima, Y. 1951. Studies on amino-hexoses. I. A new method for preparing crystalline D-arabinose. Bull. Chem. Soc. Japan 24: 7-20.

Mauger, R. P. and F. G. Soper . 1946. Acid catalysis in the formation of chloramides from hypochlorous acid. N-chlorination by hypochlorite ions and by acyl hypochlorite. J. Chem. Soc. 71-75.

McCreary, J. J. , V. L. Snoeyink, and R. A. Larson . 1982. Comparison of the reaction of aqueous free chlorine with phenolic acids in solution and adsorbed on granular activated carbon. Environ. Sci. Technol. 16: 339-344.

McKague, A. B. and K. P. Kringstad . 1988. Some lipophilic compounds formed in the chlorination of pulp lignin and humic acids. In Larson, R. A. , Ed. Biohazards of Drinking Water Treatment. (Chelsea, MI: Lewis Pub.), pp. 123-131.

McKague, A. B. , E. G. H. Lee, and G. R. Douglas . 1981. Chloroacetones: mutagenic constituents of bleached kraft chlorination effluent. Mutat. Res. 91: 301-306.

McKague, A. B. , F. de Sousa, L. M. Stromberg, and K. P. Kringstad . 1987. Formation of 2,2,4,5-tetrachlorocyclopentene-1,3-dione in the chlorination of kraft lignin, kraft pulp, tetrachlorocatechol and tetrachloro-o-benzoquinone. Holzforschung 41: 191-193.

McKague, A. B. , M. C. Kolar, and K. P. Kringstad . 1989. Nature and properties of some chlorinated, lipophilic, organic compounds in spent liquors from pulp bleaching. 2. Environ. Sci. Technol. 23: 1126-1129.

McKinney, J. D. , R. R. Maurer, J. R. Hass, and R. O. Thomas . 1976. Possible factors in the drinking water of laboratory rats causing reproductive failure. In L. H. Keith , Ed. Identification and Analysis of Organic Pollutants in Water. (Ann Arbor, MI: Ann Arbor Sci. Pub.), pp. 417-432. 
Meier, J. R. , H. P. Ringhand, W. E. Coleman , K. M. Schenk , J. W. Munch , R. P. Streicher , W. H. Kaylor, and F. C. Kopfler . 1986. Mutagenic by-products from chlorination of humic acid. Environ. Health Perspect. 69: 101-107.

Menzel, D. B. 1971. Oxidation of biologically active reducing substances by ozone. Arch. Environ. Health 23: 149-153.

Merenyi, G. , J. Lind, and X. Shen . 1988. Electron transfer from indoles, phenol, and sulfite (SO3 2-) to chlorine dioxide (ClO2 ·). J · Phys. Chem. 92: 134-137.

Miller, J. W. and P. C. Uden . 1983. Characterization of nonvolatile aqueous chlorination products of humic substances. Environ. Sci. Technol. 17: 150-156.

Minear, R. A. and J. Bird . 1980. Trihalomethanes: impact of bromide ion concentration on yield, species distribution, rate of formation and influence of other variables. In Water Chlorination: Environmental Impact and Health Effects. Vol. 3. R. L. Jolley , Ed. (Ann Arbor, MI: Ann Arbor Sci. Pub.), pp. 151-160.

Molina, M. J. , T. Ishiwata, and L. T. Molina . 1980. Production of OH from photolysis of $\mathrm{HOCl}$ at 307-309 nm. J. Phys. Chem. 84: 821-826.

Morris, J. C. 1967. Kinetics of reactions between aqueous chlorine and nitrogen compounds. In S. D. Faust and J. V. Hunter , Eds. Principles and Applications of Water Chemistry. (New York, NY: John Wiley \& Sons), pp. 22-53.

Morris, J. C. and B. Baum . 1978. Precursors and mechanisms of haloform formation in the chlorination of water supplies. In Water Chlorination: Environmental Impact and Health Effects. Vol. 2. R. L. Jolley, H. Gorchev, and D. H. Hamilton, Jr. , Eds. (Ann Arbor, MI: Ann Arbor Sci. Pub.), pp. 29-48.

Morton, A. A. 1946. The Chemistry of Heterocyclic Compounds. McGraw-Hill, New York.

Mudd, J. B. , R. Leavitt, A. Ongun, and T. T. McManus . 1969. Reaction of ozone with amino acids and proteins. Atmos. Environ. 3: 669-682. Namba, K. and S. Nakayama . 1982. Hydrogen peroxide-catalyzed ozonation of refractory organics. 1. Hydroxyl radical formation. Bull. Chem. Soc. Japan 55: 3339-3340.

NAS (US National Academy of Sciences) . 1980. Drinking Water and Health. Vol. 2. (Washington, DC: National Academy Press).

Naudet, M. and P. Desnuelle . 1950. Sur la formation des acides dihydroxy et epoxy-steariques su cours du traitement de l'acide chlorhydroxystearique par divers agents alcalins. Bull. Soc. Chim. France 845-848.

Nickelsen, M. G. , A. Nweke , F. E. Scully, Jr. , and H. P. Ringhand . 1991. Reactions of aqueous chlorine in vitro in stomach fluid from the rat: chlorination of tyrosine. Chem. Res. Toxicol. 4: 94-101.

Norwood, D. L. , J. D. Johnson, R. F. Christman , J. R. Hass, and M. J. Bo-benreith . 1980. Reactions of chlorine with selected aromatic models of humic material. Environ. Sci. Technol. 14: 187-190.

Norwood, D. L. , R. F. Christman , and P. G. Hatcher . 1987. Structural characterization of aquatic humic material. 2. Phenolic content and its relationship to chlorination mechanism in an isolated aquatic fulvic acid. Environ. Sci. Technol. 21: 791-798.

Noss, C. I. , F. S. Hauchman, and V. P. Olivieri . 1986. Chlorine dioxide reactivity with proteins. Water Res. 20: 351-356.

Nowell, L. H. and D. G. Crosby . 1985. Photodegradation of water pollutants in chlorinated water. In Water Chlorination: Chemistry, Environmental Impact, and Health Effects. Vol. 5. R. L. Jolley, R. J. Bull, W. P. Davis, S. Katz , M. H. Roberts, Jr. , and V. A. Jacobs , Eds., (Chelsea, MI: Lewis Pub.), pp. 1055-1062.

Nwaukwa, S. O. and P. M. Keehn . 1982. The oxidation of alcohols and ethers using calcium hypochlorite. Tetrahedron Lett. $23:$ 35-38.

Nweke, A. and F. E. Scully, Jr. 1989. Stable N-chloroaldimines and other products of the chlorination of isoleucine in model solutions and in a wastewater. Environ. Sci. Technol. 23, 989-994.

Ogata, Y. , Y. Suzuki, and K. Takagi . 1979. Photolytic oxidation of aliphatic acids by aqueous sodium hypochlorite. J. Chem. Soc. Perkin Trans. II 1715-1719.

Oliver, B. G. 1978. Chlorinated non-volatile organics produced by the reaction of chlorine with humic materials. Can. Res. 11: 21-22.

Oliver, B. G. 1983. Dihaloacetonitriles in drinking water: algae and fulvic acid as precursors. Environ. Sci. Technol. $17:$ 80-83.

Oliver, B. G. and J. H. Carey . 1977. Photochemical production of chlorinated organics in aqueous solutions containing chlorine. Environ. Sci. Technol. 11: 893-895.

Oliver, B. G. and J. Lawrence . 1979. Haloforms in drinking water: a study of precursors and precursor removal. J. Amer. Water Works Assoc. 71: 161-164.

Oliver, B. G. and D. B. Shindler . 1980. Triahlomethanes from the chlorination of aquatic algae. Environ. Sci. Technol. 14: $1502-1505$.

Oliver, B. G. and S. A. Visser . 1980. Chloroform production from the chlorination of aquatic humic material: the effect of molecular weight, environment and season. Water Res. 14: 1137-1141.

Onodera, S. , K. Yamada , Y. Yamaji , and S. Ishikura . 1984. Chemical changes of organic compounds in chlorinated water. IX. Formation of polychlorinated phenoxyphenols during the reaction of phenol with hypochlorite in dilute aqueous solution. J. Chromatogr. 288: 91-100. Onodera, S. , T. Muritani , N. Kobatake, and S. Suzuki . 1986. Chemical changes of organic compounds in chlorinated water. XII. Gas chromatographic-mass spectrometric studies of the reactions of methylnaphthalenes with hypochlorite in dilute aqueous solution. J. Chromatogr. 370: 259-274.

Osterberg, F. and K. Lindstrom . 1985. Characterization of the high molecular mass chlorinated matter in spent bleach liquors (SBL). 3. Mass spectrometric interpretation of aromatic degradation products in SBL. Org. Mass Spectrom. 20: 515-524.

Otson, R. , G. L. Polley, and J. L. Robertson . 1986. Chlorinated organics from chlorine used in water treatment. Water Res. 20 : 775-779.

Owusu-Yaw, J. , J. P. Toth , W. B. Wheeler, and C. I. Wei . 1990. Mutagenicity and identification of the reaction products of aqueous chlorine or chlorine dioxide with L-tryptophan. J. Food Sci. 55: 1714-1720.

Oyler, A. R. , D. L. Bodenner, K. J. Welch, R. J. Liukkonen, R. M. Carlson, H. L. Kopperman , and R. Caple . 1978. Determination of aqueous chlorination reaction products of polynuclear aromatic hydrocarbons by reversed phase high performance liquid chromatography - gas chromatography. Anal. Chem. 50: 837-842.

Oyler, A. R. , R. J. Liukkonen, M. T. Lukasewycz , K. E. Heikkila, D. A. Cox , and R. M. Carlson . 1983. Chlorine "disinfection" chemistry of aromatic compounds. Polynuclear aromatic hydrocarbons: rates, products, and mechanisms. Environ. Sci. Technol. 17: 334-342.

Ozawa, T. and T. Kwan . 1984. Electron spin resonance studies on the reactive character of chlorine dioxide (ClO2) radical in aqueous solution. Chem. Pharm. Bull. 32: 1587-1589.

Paluch, K. 1964. The reaction of chlorine dioxide with phenols. II. Hydroquinone, chloro derivatives of hydroquinone, and nitrophenols. Roczniki Chem. 38: 43-46.

Patton, W. , V. Bacon , A. M. Duffield , B. Halpern, Y. Floyano , W. Pereira , and J. Lederberg . 1972. Chlorination studies. I. The reaction of aqueous hypochlorous acid with cytosine. Biochem. Biophys. Res. Commun. 48: 880-884.

Pauling, L. 1960. The Nature of the Chemical Bond. (Ithaca, NY: Cornell Univ. Press).

Pereira, W. E. , Y. Hoyano, R. E. Simmons, V. A. Bacon, and A. M. Duffield . 1973. Chlorination studies. II. The reaction of aqueous hypochlorous acid with $\alpha$-amino acids and dipeptides. Biochim. Biophys. Acta 313: 170-180.

Peters, R. J. B. , E. W. de Leer, and L. de Galan . 1990. Chlorination of cyanoethanoic acid in aqueous medium. Environ. Sci. Technol. 24: 81-86.

Peyton, G. R. , F. Y. Huang , J. L. Burleson, and W. H. Glaze . 1982. Destruction of pollutants in water with ozone in combination with ultraviolet radiation. 1. General principles and oxidation of tetrachloroethylene. Environ. Sci. Technol. 16: 448-453.

Peyton, G. R. , C. S. Gee, M. A. Smith , J. Bandy, and S. W. Maloney . 1988. Byproducts from ozonation and photolytic ozonation of organic pollutants in water: preliminary observations. In Larson, R. A. , Ed. Biohazards of Drinking Water Treatment. (Chelsea, MI: Lewis Pub.), pp. 185-200.

Pryor, W. A. , D. G. Prier, and D. F. Church . 1981. Radical production from the interaction of ozone and PUFA as demonstrated by electron spin resonance spintrapping techniques. Environ. Res. 24: 42-52. 
Pryor, W. A. , D. H. Giamalva, and D. F. Church . 1984. Kinetics of ozonation. 2. Amino acids and model compounds in water and comparisons to rates in nonpolar solvents. J. Amer. Chem. Soc. 106: 7094-7100.

Pyysalo, H. and K. Antervo . 1985. GC profiles of chlorinated terpenes (toxaphene) in some Finnish environmental samples. Chemosphere 14: 1723-1728.

Quimby, B. D. , M. F. Delaney , P. C. Uden , and R. M. Barnes . 1980. Determination of the aqueous chlorination products of humic substances by gas chromatography with microwave emission detection. Anal. Chem. 52: 259-263.

Rav-Acha, C. and E. Choshen . 1987. Aqueous reactions of chlorine dioxide with hydrocarbons. Environ. Sci. Technol. 21: $1069-1074$.

Reckhow, D. A. , P. C. Singer , and R. L. Malcolm . 1990. Chlorination of humic materials: byproduct formation and chemical interpretations.

Environ. Sci. Technol. 24, 1655-1664.

Reinhard, M. , V. Drevenkar, and W. Giger . 1976. Effects of aqueous chlorination on the aromatic fraction of diesel fuel. Analysis by computerassisted gas chromatography-mass spectrometry. J. Chromatogr. 116: 43-51.

Reynolds, G. L. , H. A. Filaderli , A. E. McIntyre, N. J. D. Graham , and R. Perry . 1988. Isolation and identification of reaction products arising from the chlorination of cytosine in aqueous solution. Environ. Sci. Technol. 22: 1425-1429.

Roller, S. D. , V. P. Olivieri, and K. Kawata . 1980. Mode of bacterial inactivation by chlorine dioxide. Water Res. 14: 635-641.

Rook, J. J. 1974. Formation of haloforms during chlorination of natural waters. Water Treat. Exam. 23: 234-243.

Rook, J. J. 1976. Haloforms in drinking water. J. Amer. Water Works Assoc. 68: 168-172.

Rook, J. J. 1977. Chlorination reactions of fulvic acids in natural waters. Environ. Sci. Technol. 11: 478-482.

Rook, J. J. , A. A. Gras, B. G. van der Heidjen, and J. de Wee . 1978. Bromide oxidation and organic substitution in water treatment. J. Environ. Sci. Health 13A: 91-116.

Rosenblatt, D. H. 1975. Chlorine and oxychlorine species reactivity with organic substances. In J. D. Johnson, Ed. Disinfection: Water and Wastewater. (Ann Arbor, Ml: Ann Arbor Sci. Pub.), pp. 249-276.

Rosenblatt, D. H. 1978. Chlorine dioxide: chemical and physical properties. In R. G. Rice and J. A. Cotruvo, Eds. Ozone-Chlorine Dioxide Oxidation Products of Organic Materials. (Cleveland, OH: Ozone Press Intl.), pp. 332-343.

Rosenbusch, K. 1965. Neure Erfahrungen bei der Oxydativ-Enthaarung. Leder 16: 237-248.

Sander, R. , W. Kühn, and H. Sontheimer . 1977. Untersuchungen zur Umsetzung von Chlor mit Huminsubstanzen. Z. Wasser-Abwasser Forsch. 10: 155-158.

Sandford, P. A. , A. J. Nafziger, and A. Jeanes . 1971. Reaction of sodium hypochlorite with amines and amides: a new method for quantitating amino sugars in monomeric form. Anal. Biochem. 42: 422-436.

Sawamura, R. , E. Sakurai , M. Yamamoto, M. Tachikawa, and A. Hasegawa . 1982. The reaction of hypochlorite with glycine. I. Decomposition of glycine and formation of cyanogen chloride. Eisei Kagaku 28: 267-273.

Scully, F. E., Jr. , and W. N. White . 1991. Reactions of chlorine, monochloramine in the GI tract. Environ. Sci. Technol. 25: 820-828.

Scully, F. E., Jr. , G. D. Howell , R. Kravitz , J. T. Jewell , V. Hahn, and M. Speed . 1988. Proteins in natural waters and their relation to the formation of chlorinated organics during water disinfection. Environ. Sci. Technol. 22: 537-542.

Shackelford, W. M. and L. H. Keith . 1976. Frequency of organic compounds identified in water. EPA Report EPA-600/4-76-062.

Shapiro, R. H. , K. J. Kolonko, P. M. Greenstein , R. M. Barkley, and R. E. Sievers . 1978. Ozonation products from caffeine in aqueous solutions. In R. G. Rice and J. A. Cotruvo, Eds. Ozone-Chlorine Dioxide Oxidation Products of Organic Materials. (Cleveland, OH: Ozone Press Intl.), pp. 284-290.

Shimizu, Y. and R. Y. Hsu . 1975. Interaction of chlorine and selected plant phenols in water. Chem. Pharm. Bull. 23: 2179-2181.

Shiriashi, M. , N. H. Pilkington , A. Otsuki , and K. Fuwa . 1985. Occurrence of chlorinated polynuclear aromatic hydrocarbons in tap water.

Environ. Sci. Technol. 19: 585-590.

Sievers, R. E. , R. M. Barkley, G. Z. Eiceman , L. P. Haack, R. H. Shapiro, H. F. Walton, K. J. Kolonko, and I. R. Field . 1977. Environmental trace analysis of organics in water by glass capillary column chromatography and ancillary techniques. J. Chromatogr. 142: 745-754.

Sigleo, A. C. , G. R. Helz, and W. H. Zoller . 1980. Organic-rich colloidal material in estuaries and its alteration by chlorination. Environ. Sci. Technol. 14: 673-679.

Smith, J. G. , S. F. Lee, and A. Netzer . 1975. Chlorination in dilute aqueous systems: 2,4,6-trichlorophenol. Environ. Lett. $10: 47-52$.

Snider, E. H. and F. C. Alley . 1979. Kinetics of the chlorination of biphenyl under conditions of waste treatment processes. Environ. Sci. Technol. 13: 1244-1248.

Snoeyink, V. L. , R. R. Clark , J. J. McCreary, and W. F. McHie . 1981. Organic compounds produced by the aqueous free-chlorine-activated carbon reaction. Environ. Sci. Technol. 15: 188-192.

Somsen, R. A. 1960. Oxidation of some simple organic molecules with aqueous chlorine dioxide. II. Reaction products. TAPPI 43: 157-160.

Soper, F. G. and G. F. Smith . 1926. The halogenation of phenols. J. Chem. Soc. 1582-1591.

Spanggord, R. J. and C. A. Tyson . 1979. N-Formyliminodiacetic acid, a new compound from the reaction of nitrilotriacetic acid and chlorine. Science 204: 1081-1082.

Staehelin, J. and J. Hoigné . 1985. Decomposition of ozone in water in the presence of organic solutes acting as promoters and inhibitors of radical chain reactions. Environ. Sci. Technol. 19: 1206-1213.

Stanbro, W. D. and W. D. Smith . 1979. Kinetics and mechanism of the decomposition of N-chloroalanine in aqueous solution. Environ. Sci.

Technol. 13: 446-451.

Stevens, A. A. 1982. Reaction products of chlorine dioxide. Environ. Health Per - spect. 46: 101-110.

Stevens, A. A. , C. J. Slocum, D. R. Seeger, and G. G. Robeck . 1976. Chlorination of organics in drinking water. In R. L. Jolley , Ed. Water Chlorination: Environmental Impact and Health Effects. Vol. 1. (Ann Arbor, MI: Ann Arbor Sci. Pub.), pp. 77-104.

Stevens, A. A. , D. R. Seeger, and C. J. Slocum . 1978. Products of chlorine dioxide treatment of organic materials in water. In R. G. Rice and J. A. Cotruvo , Eds. Ozone-Chlorine Dioxide Oxidation Products of Organic Materials. (Cleveland, OH: Ozone Press Intl.), pp. 383-399.

Stoward, P. J. 1975. A histochemical study of the apparent deamination of proteins by sodium hypochlorite. Histochemistry 45: $213-226$.

Streeter, H. W. 1929. Chlorophenol tastes and odors in water supplies of Ohio River cities. Publ. Health Rep. 44: $2149-2156$.

Streicher, R. P. , H. Zimmer, J. P. Bercz, and W. E. Coleman. 1986. The interactions of aqueous solutions of chlorine with citric acid. A source of mutagens. Anal. Lett. 19: 681-696.

Sturrock, M. G. , E. L. Cline, K. R. Robinson, and K. A. Zercher . 1960. Pyridine carboxylic acids. US Patent 2964529.

Sturrock, M. G. , E. L. Cline, and K. R. Robinson . 1963. The ozonation of phenan-threne with water as a participating solvent. J. Org. Chem. 28: 2340-2343.

Stuthridge, T. R. , A. L. Wilkins , A. G. Longdon, K. L. Mackie, and P. N. Mac-farlane . 1990. Identification of novel chlorinated monoterpenes formed during kraft pulp bleaching of Pinus radiata. Environ. Sci. Technol. 24: 903-908.

Suffet, I. H. , L. Brenner, and B. Silver . 1976. Identification of 1,1,1-trichloroacetone (1,1,1-trichloropropanone) in two drinking waters: a known precursor in the haloform reaction. Environ. Sci. Technol. 10: 1273-1275.

Symons, J. M. , T. A. Bellar, J. K. Carswell, J. Demarco, K. L. Kropp, G. G. Robeck, D. R. Seeger , C. J. Slocum, B. L. Smith , and A. A. Stevens . 1975. National organics reconaissance survey for halogenated organics. J. Amer. Water Works Assoc. 67: $634-647$.

Tan, H. , A. C. Sen , W. B. Wheeler, J. A. Cornell, and C. I. Wei . 1987. A kinetic study of the reaction of aqueous chlorine and chlorine dioxide with amino acids, peptides, and proteins. J. Food Sci. 52: 1706-1711.

Taube, H. and H. Dodgen . 1949. Application of radioactive chlorine to the study of the mechanisms of reactions involving changes in the oxidation state of chlorine. J. Amer. Chem. Soc. 71: 3330-3336. 
Taylor, W. I. and A. R. Battersby . 1967. Oxidative Coupling of Phenols. (New York, NY: Marcel Dekker).

Taymaz, K. , D. T. Williams, and F. M. Benoit . 1979. Chlorine dioxide oxidation of aromatic hydrocarbons commonly found in water. Bull. Environ. Contam. Toxicol. 23: 398-404.

Thakore, A. N. and A. C. Oehlschlager . 1977. Structures of toxic constituents in kraft mill caustic extraction effluents from $13 \mathrm{C}$ and!H nuclear magnetic resonance. Can. J. Chem. 55: 3298-3303.

Thibaud, H. , J. DeLaat, N. Merlet , and M. Dore . 1987. Formation de chloropicrine en milieu aqueux: influence des nitrites sur la formation de precurseurs par oxydation de composes organiques. Water Res. 21: 813-821.

Thielemann, H. 1972a. Über die Einwirkung von Chlordioxid auf einige polycyklis-che aromatischen Kohlenwasserstoffe. Mikrochim. Acta 575-577.

Thielemann, H. 1972b. Effect of chlorine dioxide on 1-and 2-naphthol containing test solutions. Mikrochim. Acta 669-671.

Trehy, M. L. and T. I. Bieber . 1981. Detection, identification, and quantitative analysis of dihaloacetonitriles in chlorinated natural waters. In L. H. Keith, Ed. Advances in the Identification and Analysis of Organic Pollutants in Water. Vol. 2. (Ann Arbor, Ml: Ann Arbor Sci. Pub.), pp. 941-975.

Trehy, M. L. , R. A. Yost, and C. J. Miles . 1988. Amino acids as model compounds for halogenated by-products formed on chlorination of natural waters. In Larson, R. A. , Ed. Biohazards of Drinking Water Treatment. (Chelsea, MI: Lewis Pub.), pp. 133-140.

Uhler, A. D. and J. C. Means . 1985. Reaction of dissolved chlorine with surficial sediment: oxidant demand and production of trihalomethanes. Environ. Sci. Technol. 19: 340-344.

Van Buren, J. B. and C. W. Dence . 1970. Chlorination behavior of pine kraft lignin. TAPPI 53: 2246-2253.

van Steenderen, R. A. , W. E. Scott, and D. I. Welch . 1988. Microcystis aeruginosa as an organohalogen precursor. Water SA 14: 59-62.

Verweij, H. , K. Christianse, and J. van Steveninck . 1982. Different pathways of tyrosine oxidation by ozone. Chemosphere 11: 721-725.

Voudrias, E. A. , R. A. Larson, and V. L. Snoeyink . 1985a. Effects of activated carbon on the reactions of free chlorine with phenols. Environ.

Sci. Technol. 19: 441-449.

Voudrias, E. A. , R. A. Larson, and V. L. Snoeyink . 1985b. Effects of activated carbon on the reactions of combined chlorine with phenols. Water Res. 19: 909-915.

Wachter, J. K. and J. B. Andelman . 1984. Organohalide formation on chlorination of algal extracellular products. Environ. Sci. Technol. 18: 811-817.

Wei, C.-I. , D. L. Cook, and J. R. Kirk . 1985. Use of chlorine compounds in the food industry. Food Technol. 39: $107-115$.

Weil, I. W. and J. C. Morris . 1974. Dynamics of breakpoint chlorination. In A. J. Rubin , Ed., Chemistry of Water Treatment, Supply, and

Distribution. (Ann Arbor, MI: Ann Arbor Sci. Pub.), pp. 297-332.

Whistler, R. L. and R. Schweiger . 1957. Oxidation of amylopectin with hypochlorite at different hydrogen ion concentrations. J. Amer. Chem. Soc. 79: 6460-6464.

White, G. C. 1972. Handbook of Chlorination. (New York: NY: Van Nostrand Reinhold).

White, J. F. , M. C. Taylor, and G. P. Vincent . 1942. The chemistry of chlorites. Industr. Eng. Chem. 34: 782-792.

Xie, Y. and D. A. Reckhow . 1992. Formation of ketoacids in ozonated drinking water. Ozone Sci. Eng. 14: 269-275.

Yagi, N. and Y. Itokawa . 1979. Cleavage of thiamine by chlorine in tap water. J. Nutr. Sci. Vitaminol. 25: 281-287.

Yamada, H. and I. Somiya . 1989. The ozonation of natural water: identification of carbonyl products and their behavior. Ozone Sci. Eng. 20: 125-141.

Yamamoto, Y. , E. Niki , H. Shiokawa, and Y. Kamiya . 1979. Ozonation of organic compounds. 2. Ozonation of phenol in water. J. Org. Chem. 44: 2137-2142.

Zika, R. G. , C. A. Moore , L. T. Gidel , and W. J. Cooper . 1985. Sunlight-induced photodecomposition of chlorine dioxide. In Water chlorination: chemistry, environmental impact, and health effects, Vol. 5, R. L. Jolley , R. J. Bull, W. P. Davis, S. Katz, M. H. Roberts, Jr. , and V. A. Jacobs, Eds., (Chelsea, MI: Lewis Pub.), pp. 1041-1053.

\section{Environmental Photochemistry}

Acher, A. M. and I. Rosenthal . 1977. Dye-sensitized photooxidation - a new approach to the treatment of organic matter in sewage effluents. Water Res. 11, 557-562.

Anjaneyulu, A. S. and U. V. Mallavadhani . 1988. Photosensitised reactions of aniline. Indian J. Chem. 27B, 154-155.

Arnold, D. R. 1968. The photocycloaddition of carbonyl compounds to unsaturated systems: the synthesis of oxetanes. Advan. Photochem. 6 , 301-423.

Asthana, A. , R. A. Larson, K. A. Marley, and R. W. Tuveson . 1992. Mechanisms of citral phototoxicity. Photochem. Photobiol. 56, $211-222$. Bailey, G. W. and S. W. Karickhoff . 1973. Ultraviolet-visible spectroscopy in the characterization of clay mineral surfaces. Anal. Lett. 6, 43-49. Baker, K. S. and R. C. Smith . 1982. Bio-optical classification and model of natural waters. Limnol. Oceanogr. $27,500-509$.

Bakke, J. 1970. The photocyclization of 2-(o-nitrophenyl)-ethanol to N-hydroxyindole. Acta Chem. Scand. 24, 2650-2651.

Balzani, V. and V. Carassiti . 1970. Photochemistry of coordination compounds. Academic Press, London.

Banerjee, S. , H. C. Sikka, R. Gray, and C. M. Kelly . 1978. Photodegradation of 3,3-dichlorobenzidine. Environ. Sci. Technol. 12, $1425-1427$.

Berenbaum, M. and R. A. Larson . 1988. Flux of singlet oxygen from leaves of phototoxic plants. Experientia 44, $1030-1032$.

Berends, W. and J. Posthuma . 1962. Energy transfer in aqueous solution. J. Phys. Chem. 66, 2547-2550.

Bertino, D. J. and R. G. Zepp . 1991. Effects of solar radiation on manganese dioxide reactions with selected organic compounds. Environ. Sci.

Technol. 25, 1267-1273.

Bollag, J.-M. , S. Y. Liu, and R. D. Minard . 1982. Enzymatic oligomerization of vanillic acid. Soil Biol. Biochem. 14: 157-163.

Boule, P. , C. Guyon, A. Tissot, and J. Lemaire . 1987. Specific phototransformation of xenobiotic compounds: chlorobenzenes and halophenols. In Zika, R. G. and Cooper, W. J. , eds. Aquatic photochemistry. Amer. Chem. Soc. Sympos. Ser. 327, 10-26.

Bunce, N. J. and J. C. Gallagher . 1982. Photolysis of aryl chlorides with dienes and with aromatic amines. J. Org. Chem. 47, $1955-1958$.

Burkhard, N. and J. A. Guth . 1976. Photodegradation of atrazine, atraton and ametryne in aqueous solution with acetone as a photosensitizer.

Pestic. Sci. 7, 65-71.

Butz, R. G. , C. C. Yu, and Y. H. Atallah . 1982. Photolysis of hexachlorocyclopen-tadiene in water. Ecotoxicol. Environ. Safety 6, $347-357$.

Calkins, J. 1975. Measurements of the penetration of solar UV-B into various natural waters. In Impacts of climatic change on the biosphere. CIAP Monograph \#5, U.S. Dept, of Transportation, Washington, DC. pp. 2-267.

Carey, J. H. , J. Lawrence, and H. M. Tosine . 1976. Photodechlorination of PCBs in the presence of titanium dioxide in aqueous suspensions. Bull. Environ. Con-tam. Toxicol. 16, 697-701.

Castro, C. E. and N. O. Belser . 1981. Photohydrolysis of methyl bromide and chloropicrin. J. Agric. Food Chem. 29, $1005-1008$.

Castro, C. E. , S. Mayorga, and N. O. Belser . 1987. Photohydrolysis of 1,2-dibromo-3-chloropropane. J. Agric. Food Chem. 35, 865-870.

Chan, H. W.-S. 1977. Photo-sensitized oxidation of unsaturated fatty acid methyl esters. The identification of different pathways. J. Amer. Oil Chem. Soc. 54:100-104.

Chandrasekaran, K. and J. K. Thomas . 1985. Photophysical and photochemical properties of pyrene-doped TiO2 particle suspensions in water. J. Colloid Interf. Sci. 106, 532-537.

Chaudhary, S. K. , R. H. Mitchell , P. R. West, and M. J. Ashwood-Smith . 1985. Photodechlorination of methoxychlor induced by hydroquinone: rearrangement and conjugate formation. Chemosphere 14: 27-40. 
Chesta C. A. , J. J. Cosa, and C. M. Previtali . 1986. The N,N-dimethylaniline-photosensitized dechlorination of chlorobenzenes. J. Photochem. $32,203-215$.

Chesta, C. A. , J. J. Cosa, and C. M. Previtali . 1988. Photoinduced electron transfer from N,N-dimethylaniline to chlorobenzene. The decomposition rate constant of the radical anion of chlorobenzene. J. Photochem. Photobiol. A45, 9-15.

Chien, J. C. W. 1965. On the possible initiation of photooxidation by charge-transfer excitation. J. Phys. Chem. 69, 4317-4325.

Chou, S.-F. J. , R. A. Griffin, M.-I.M. Chou, and R. A. Larson . 1987. Photodegradation products of hexachlorocyclopentadiene (C-56) in aqueous solution. Environ. Toxicol. Chem., 6, 371-376.

Choudry, G. G. and O. Hutzinger . 1984. Acetone-sensitized and nonsensitized pho-tolyses of tetra-, penta-, and hexachlorobenzenes in acetonitrile-water mixtures: Photoisomerization and formation of several products including polychloro-biphenyls. Environ. Sci. Technol. 18, 235-241.

Conrad, R. , W. Seiler , G. Bunse, and H. Giehl . 1982. Carbon monoxide in sea water (Atlantic Ocean). J. Geophys. Res. 87, 8839-8852. Crosby, D. G. 1983. Atmospheric reactions of pesticides. In J. Miyamoto and P. C. Kearney, eds., Pesticide chemistry: human welfare and the environment. Perga-mon Press, NY, pp. 327-332.

Crosby, D. G. and H. O. Tutass . 1966. Photodecomposition of 2,4-dichlorophenoxyacetic acid. J. Agric. Food Chem. 14, 596-599.

Crosby, D. G. and A. S. Wong . 1973. Photodecomposition of 2,4,5-trichlorophenoxyacetic acid (2,4,5-T) in water. J. Agric. Food Chem. 21, 1052-1054.

Cunningham, K. M., M. C. Goldberg , and E. R. Weiner . 1985. The aqueous photolysis of ethylene glycol adsorbed on goethite. Photochem. Photobiol. 41, 409-416.

Cunningham, K. M., M. C. Goldberg, and E. R. Weiner . 1988. Mechanisms for aqueous photolysis of adsorbed benzoate, oxalate, and succinate on iron oxyhy-droxide (goethite) surfaces. Environ. Sci. Technol. 22, 1090-1097.

DeBoer, C. D. and R. H. Schlessinger . 1968. The multiplicity of the photochemically reactive state of 1,2-diphenylcyclobutene. J. Amer. Chem. Soc. 90, 803-804.

Dopp, D. 1975. Reactions of aromatic nitro compounds via excited triplet states. Topics Curr. Chem. 55, $49-85$.

Draper, R. B. and D. G. Crosby . 1987. Catalyzed photodegradation of the herbicides molinate and thiobencarb. In Zika, R. G. and Cooper, W. J. , eds. Aquatic photochemistry, Amer. Chem. Soc. Sympos. Ser. 327, 240-247.

Dulin, D. , H. Drossman, and T. Mill . 1986. Products and quantum yields for photolysis of chloroaromatics in water. Environ. Sci. Technol. 20, 12-11.

Eisenberg, T. N. , E. J. Middlebrook, and V. D. Adams . 1987. Sensitized photooxidation for wastewater disinfection and detoxification. Water Sci. Technol. 19, 1255-1258.

Epling, G. A. , W. McVicar, and A. Kumar . 1987. Accelerated debromination of biphenyls by photolysis with sodium borohydride. Chemosphere 16, 1013-1020.

Epling, G. A. , E. M. Florio , A. J. Bourque, X.H. Qian, and J. D. Stuart . 1988. Borohydride, micellar, and exciplex-enhanced dechlorination of chlorobiphenyls. Environ. Sci. Technol. 22, 952-956.

Faust, B. C. and M. R. Hoffmann . 1986. Photoinduced reductive dissolution of a-Fe2O3 by bisulfite. Environ. Sci. Technol. $20,943-948$.

Faust, B. C. and J. Hoigné . 1990. Photolysis of Fe (III)-hydroxy complexes as sources of OH radicals in clouds, fog, and rain. Atmos. Environ. 23, 235-240.

Ferek, R. J. and M. O. Andrae . 1984. Photochemical production of carbonyl sulphide in marine surface waters. Nature 307, $148-150$.

Finden, D. A. S. , E. Tipping , G.H.M. Jaworski , and C. S. Reynolds . 1984. Light-induced reduction of natural iron (III) oxide and its relevance to phytoplankton. Nature 309, 783-784.

Foote, C. S. , S. Wexler , E. J. Corey, and W. C. Taylor . 1964. Olefin oxidations with singlet oxygen. J. Amer. Chem. Soc. 86, 3879-3881.

Fujihara, M. , Y. Satoh, and T. Osa. 1981. Heterogeneous photocatalytic oxidation of aromatic compounds on Ti02. Nature 293, 206-208.

Giannotti, C. , S. LeGreneur and O. Watts . 1983. Photo-oxidation of alkanes by metal oxide semiconductors. Tetrahedron Lett. $24,5071-5072$.

Gjessing, E. T. 1966. Enhancement of colour and chemical oxygen demand in a dammed-up lake. Vattenhygien 4, 181-183.

Gjessing, E. T. 1970. Reduction of aquatic humus in streams. Vatten 1, 14-23.

Haag, W. R. and J. Hoigné . 1985. Photosensitized oxidation in natural water via $\bullet O H$ radicals. Chemosphere $14,1659-1671$.

Hansen, H. P. 1975. Photochemical degradation of petroleum hydrocarbon surface films. Mar. Chem. 3, 183-195.

Harbour, J. R. , J. Tromp, and M. L. Hair . 1985. Photogeneration of H202 in aqueous Ti02 dispersions. Can. J. Chem. 63, $204-208$.

Hautala, R. 1978. Surfactant effect on pesticide photochemistry in water and soil. EPA Report EPA-600/3-78-060.

Hebert, V. R. and G. C. Miller . 1989. Depth dependence of direct and indirect photolysis on the soil surfaces. J. Agric. Food Chem. 37, 913-918.

Heelis, P. F. 1982. The photophysical and photochemical properties of flavins. Chem. Soc. Rev. 11, 15-39.

Hirsch, M. and O. Hutzinger . 1989. Naturally occurring proteins from pond water sensitize hexachlorobenzene photolysis. Environ. Sci. Technol. 23, 1306-1307.

Hwang, H.-M. , R. E. Hodson , and R. F. Lee . 1986. Degradation of phenol and chlorophenols by sunlight and microbes in estuarine water. Environ. Sci. Technol. 20, 1002-1007.

Hwang, H.-M. , R. E. Hodson, and R. F. Lee . 1987a. Photolysis of phenol and chlorophenols in estuarine water. In Zika, R. G. and Cooper, W. J. , eds. Aquatic photochemistry, Amer. Chem. Soc. Sympos. Ser. 327, $27-43$.

Hwang, H.-M. , R. E. Hodson, and R. F. Lee . 1987b. Degradation of aniline and chloroanilines by sunlight and microbes in estuarine water. Water Res. 21, 309-316.

Ishimitsu, S. , S. Fujimoto, and A. Ohara . 1985. The photochemical decomposition and hydroxylation of phenylalanine in the presence of riboflavin. Chem. Pharm. Bull. 33:1552-1556.

Joshi, P. C. 1985. Comparison of the DNA-damaging property of photosensitised riboflavin via singlet oxygen and superoxide radical (O2 -) mechanisms. Toxicol. Lett. 26:211-217.

Khalil, G.-E. , and M. Kasha . 1978. Oxygen-interaction luminescence spectroscopy. Photochem. Photobiol. 28:435-443.

Kirk, J. T. O. 1977. Attenuation of light in natural waters. Austr. J. Mar. Freshwat. Res. 28, 497-508.

Knight, R. J. and R. N. Sylva . 1975. Spectrophotometric investigation of iron (III) hydrolysis in light and heavy water at $25^{\circ} \mathrm{C}$. J. Inorg. Nucl. Chem. 37, 779-783.

Kormann, C. , D. W. Bahnemann , and M. R. Hoffmann . 1988. Photocatalytic production of $\mathrm{H} 202$ and organic peroxides in aqueous suspensions of TiO2, ZnO, and desert sand. Environ. Sci. Technol. 22, 798-806.

Kotzias, D. , H. Parlar and F. Korte . 1982. Photoreaktivitat organischer Chemika-lien in wassrigen Systemen in Gegenwart von Nitraten und Nitriten. Naturwis-senschaften 69, 444.

Kropp, P. J. 1984. Photobehavior of alkyl halides in solution: radical, carbocation, and carbene intermediates. Acc. Chem. Res. 17, $131-137$. Landymore, A. F. and N. J. Antia . 1978. White-light promoted degradation of leucopterin and related pteridines dissolved in seawater, with evidence for involvement of complexation from major divalent cations of seawater. Mar. Chem. 6, 309-325.

Langford, C. M. , M. Wingham, and V. S. Sastri . 1973. Ligand photooxidation in copper (II) complexes of nitrilotriacetic acid. Implications for natural waters. Environ. Sci. Technol. 7, 820-822.

Larson, R. A. and L. L. Hunt . 1978. Photooxidation of a refined petroleum oil: inhibition by $\beta$-carotene and role of singlet oxygen. Photochem. Photobiol. 28, 553-555.

Larson, R. A. and S. A. Rounds . 1987. Photochemistry in aqueous surface layers: 1-naphthol. In Zika, R. G. and Cooper, W. J. , eds. Aquatic photochemistry, Amer. Chem. Soc. Sympos. Ser. 327, 206-214. 
Larson, R. A. , L. L. Hunt, and D. W. Blankenship . 1977. Formation of toxic products from a \#2 fuel oil by photooxidation. Environ. Sci. Technol. 11, 492-496.

Larson, R. A. , T. L. Bott , L. L. Hunt, and K. Rogenmuser . 1979. Photooxidation products of a fuel oil and their antimicrobial activity. Environ. Sci. Technol. 13, 965-969.

Larson, R. A. , D. D. Ellis , H.-L. Ju , and K. A. Marley . 1989. Flavin-sensitized photodecomposition of anilines and phenols. Environ. Toxicol. Chem. 8, 1165-1170.

Larson, R. A. , P. L. Stackhouse, and T. O. Crowley . 1992a. Tetraacetylriboflavin, a potentially useful photosensitizing agent for water treatment. Environ. Sci. Technol. 26, 1792-1798.

Larson, R. A. , M. B. Schlauch, and K. A. Marley . 1992b. Ferric ion promoted photodecomposition of triazines. J. Agric. Food Chem. 39, 2057-2062.

Leermakers, P. A. and M. T. Thomas . 1965. Electronic spectra and photochemistry of adsorbed organic molecules. I. Spectra of ketones on silica gel. J. Amer. Chem. Soc. 87, 1620-1622.

Leifer, A. 1988. The kinetics of environmental aquatic photochemistry: theory and practice. American Chemical Society, Washington, DC.

Lelieveld, J. and P. J. Crutzen . 1991. The role of clouds in tropospheric photochemistry. J. Atmos. Chem. 12, 229-267.

Lichtenthaler, R. G. , W. R. Haag, and T. Mill . 1989. Photooxidation of probe compounds sensitized by crude oils in toluene and as an oil film on water. Environ. Sci. Technol. 23, 39-45.

Lockhart, H. B. and R. V. Blakely . 1975. Aerobic photodegradation of X (N) chelates of (ethylenedinitrilo)tetraacetic acid (EDTA): implications for natural waters. Environ. Lett. 9, 19-31.

Mabey, W. R. , D. Tse , A. Baraze, and T. Mill . 1983. Photolysis of nitroaromatics in aquatic systems. I. 2,4,6-Trinitrotoluene. Chemosphere 12, 3-16.

Mansour, M. and H. Parlar . 1978. Gas chromatographic determination of several cyclodiene insecticides in the presence of polychlorinated biphenyls by photoisomerization reaction. J. Agric. Food Chem. 26, 483-485.

Masuda, Y. and M. Kuratsune . 1966. Photochemical oxidation of benzo[a]pyrene. Air Water Pollut. Int. J. 10, 805-811.

Matthews, R. W. 1983. Near-U. V.-light-induced competititve hydroxyl radical reactions in aqueous slurries of titanium dioxide. J. Chem. Soc. Chem. Commun. 177-179.

Matthews, R. W. 1986. Photo-oxidation of organic material in aqueous suspensions of titanium dioxide. Water Res. 20, 569-578.

Miille, M. J. and D. G. Crosby . 1983. Pentachlorophenol and 3,4-dichloroaniline as models for photochemical reactions in seawater. Mar. Chem. $14,111-120$.

Miles, C. J. and P. L. Brezonik . 1981. Oxygen consumption in humic-colored waters by a photochemical ferrous-ferric catalytic cycle. Environ.

Sci. Technol. 15, 1089-1095.

Mill, T. , W. R. Mabey , B. Y. Lan, and A. Baraze . 1981. Photolysis of polycyclic aromatic hydrocarbons in water. Chemosphere 10, $1281-1290$. Miller, G. C. and R. G. Zepp . 1979. Effects of suspended sediments on the photolysis rates of dissolved pollutants. Water Res. 13, 453-459.

Miller, G. C. and R. G. Zepp . 1983. Extrapolating photolysis rates from the laboratory to the environment. Residue Rev. 85, 89-110.

Miller, G. C. , M. J. Miille, D. G. Crosby, S. Sontum , and R. G. Zepp . 1979. Photosolvolysis of 3,4-dichloroaniline in water. Evidence for an aryl cation intermediate. Tetrahedron 35, 1797-1800.

Moore, T. and R. M. Pagni . 1987. Unusual photochemistry of 4-chlorobiphenyl in water. J. Org. Chem. 52, 770-773.

Mopper, K. and R. G. Zika . 1987. Natural photosensitizers in sea water: riboflavin and its breakdown products. In Zika, R. G. and Cooper, W. J. eds. Aquatic photochemistry, Amer. Chem. Soc. Sympos. Ser. 327, 174-190.

Morita, M. , M. Mukunoki , F. Okubo, and S. Tadakora . 1976. Lipid-oxidation catalyses by substances in water on lipid-water interface. J. Amer. Oil Chem. Soc. 53, 489-490.

Morrison, H.A. 1969. The photochemistry of the nitro and nitroso groups. In Feuer, H. , ed., The chemistry of the nitro and nitroso groups. Part I. New York: Inter science.

Moser, J. and M. Grätzel . 1982. Photochemistry with colloidal semiconductors. Laser studies of halide oxidation in colloidal dispersions of TiO2 and a-Fe2O3 . Helv. Chim. Acta 65, 1436-1444.

Nicholls, C. H. and P. A. Leermakers . 1971. Photochemical and spectroscopic properties of organic molecules in adsorbed or other perturbing polar environments. Adv. Photochem. 8, 315-336.

Oelkrug, D. , W. Flemming , R. Fülleman , R. Günther , W. Honnen , G. Krabliche, M. Schäfer , and S. Uhl . 1986. Photochemistry on surfaces. Pure AppL Chem. 58, 1207-1218.

Ollis, D. F. , E. Pelizzetti, and N. Serpone . 1991. Photocatalyzed destruction of water contaminants. Environ. Sci. Technol. 25, 1522-1529. Omura, K. and T. Matsuura . 1971. Photolysis of halogenophenols in aqueous alkali and in aqueous cyanide. Tetrahedron 27, 3101-3109.

Onodera, K. , H. Sakuragi, and K. Tokumaru . 1980. Effect of light wavelength of photooxygenation of hexamethylbenzene. Tetrahedron Lett. 21 , 2831-2832. Orvis, J. , J. Weiss, and R. M. Pagni . 1991. Further studies on the photoisomerization and hydrolysis of chlorobiphenyls in water. Common ion effect in the photohydrolysis of 4-chlorobiphenyl. J. Org. Chem. 56, 1851-1857.

Pasternak, M. and A. Morduchowitz . 1983. Photochemical oxidation and dimerization of alkylbenzenes. Selective reactions of the alkyl side groups. Tetrahedron Lett. 24, 4275-4278.

Payne, J. R. and C. R. Phillips . 1985. Photochemistry of petroleum in water. Environ. Sci. Technol. 19, 569-579.

Peake, E. , B. L. Baker, and G. W. Hodgson . 1972. The contribution of amino acids, hydrocarbons, and chlorins to the Beaufort Sea by the Mackenzie River system. Geochim. Cosmochim. Acta 36, 867-883.

Rabek, J. F. 1968. Photosensitized processes in polymer chemistry: a review. Photochem. Photobiol. 7, 5-57.

Rejto, M. , S. Saltzman , A. J. Acher, and L. Muszkat . 1983. Identification of sensitized photoooxidation products of s-triazine herbicides in water. J. Agric. Food Chem. 31, 138-142.

Rizzuto, F. , J. D. Spikes, and G. D. Coker . 1986. The lumiflavin-sensitized photooxidation of substituted phenylalanines and tyrosines.

Photobiochem. Photobiophys. 10:149-162.

Rodgers, M. A. and P. T. Snowden . 1982. Lifetime of $02\left({ }^{\star} \mathrm{Ag}\right)$ in liquid water as determined by time-resolved infrared luminescence measurements. J. Amer. Chem. Soc. 104, 5541-5543.

Ross, R. D. , and D. G. Crosby . 1975. The photooxidation of aldrin in water. Chemosphere. 5: 277-282.

Ross, R. D. , and D. G. Crosby . 1985. Photooxidant activity in natural waters. Environ. Toxicol Chem. 4, 773-778.

Ruzo, L. O., M. J. Zabik, and R. D. Schuetz . 1974. Photochemistry of bioactive compounds. Photochemical processes of polychlorinated biphenyls. J. Amer. Chem. Soc. 96, 3809-3813.

Sancier, K. M. and H. Wise . 1981. Photoassisted oxidation of organic material catalyzed by sand. Atmos. Environ. 15, 639-640.

Schmitzer, J. , S. Gab , M. Bahadir, and F. Korte . 1980. Photomineralisierung chlorierter Alkane, Alkene und Aromaten an Kieselgel. Z. Naturforsch. 35b, 182-186.

Schwack, W. 1988. Photoinduced additions of pesticides to biomolecules. 2. Model reactions of DDT and methoxychlor with methyl oleate. J. Agric. Food Chem. 36, 645-648.

Scott, A. I. 1964. Interpretation of the ultraviolet spectra of natural products. Pergamon, Oxford.

Scully, F. E. and J. Hoigné . 1987. Rate constants for reactions of singlet oxygen with phenols and other compounds in water. Chemosphere 16, 681-694.

Sigman, M. E. , S. P. Zingg , R. M. Pagni , and J. H. Burns . 1991. Photochemistry of anthracene in water. Tetrahedron Lett. 41, 5737-5740. Simmons, M. S. and R. G. Zepp . 1986. Influence of humic substances on photolysis of nitroaromatic compounds in aqueous systems. Water Res. 20, 899-904. 
Smith, E. C. and D. E. Metzler . 1963. The photochemical degradation of riboflavin. J. Amer. Chem. Soc. 85, 3285-3288.

Spencer, W. F., J. D. Adams , T. D. Shoup, R. E. Hess, and R. D. Spear . 1980. Conversion of parathion to paraoxon on soil dusts and clay minerals as affected by ozone and ultraviolet light. J. Agric. Food Chem. 28, 366-371.

Srisankar, E. V. and L. K. Patterson . 1979. Reactions of ozone with fatty acid monolayers: a model system for disruption of lipid molecular assemblies by ozone. Arch. Environ. Health 34, 346-349.

Stearns, R. H. 1916. Decolorization of water by storage. J. New Engl. Water Works Assoc. 30, $20-27$.

Sunda, W. G. , S. A. Huntsman, and G. R. Harvey . 1983. Photoreduction of manganese oxides in seawater and its geochemical and biological implications. Nature 301, 234-236.

Suzuki, J. , T. Sato , and S. Suzuki . 1985. Hydroxynitrobiphenyls produced by photochemical reaction of biphenyl in aqueous nitrate solution and their mutagenicities. Chem. Pharm. Bull. 33, 2507-2515.

Suzuki, J. , T. Hayagino, and S. Suzuki . 1987. Formation of 1-nitropyrene by photolysis of pyrene in water containing nitrite ion. Chemosphere $16,859-867$.

Suzuki, J. , T. Watanabe , K. Sato and S. Suzuki . 1988. Roles of oxygen in photochemical reaction of naphthols in aqueous nitrite solution and mutagen formation, Chem. Pharm. Bull. 36, 4567-4575.

Takahashi, N. , N. Mikami , H. Yamada, and J. Miyamoto . 1985. Photodegradation of the pyrethroid insecticide fenpropathrin in water, on soil and on plant foliage. Pestic. Sci. 16, 119-131.

Takahashi, N. , N. Ito , N. Mikami , T. Matsuda, and J. Miyamoto . 1988. Identification of reactive oxygen species generated by irradiation of aqueous humic acid solution. J. Pestic. Sci. 13, 429-435.

Trott, T. , R. W. Henwood, and C. H. Langford . 1972. Sunlight photochemistry of ferric nitriloacetate complexes. Environ. Sci. Technol. 6, 367-368.

Turro, N. J. 1978. Modern molecular photochemistry. Benjamin-Cummings, Menlo Park, CA.

Tuveson, R. W. , R. A. Larson, K. A. Marley, G.R. Wang, and M. R. Berenbaum . 1989. Sanguinarine, a phototoxic H2O2-producing alkaloid. Photochem. Photobiol. 50, 733-738.

Tyner, C. E. 1990. Application of solar thermal technology to the destruction of hazardous wastes. Solar Energy Mater. 21, 113-129.

Wagner, I. , H. Strehlow, and G. Busse . 1980. Flash photolysis of nitrate ions in aqueous solution. Z. Phys. Chem. 123, 1-33.

Waite, T. D. 1985. Photoredox chemistry of colloidal metal oxides. In J. A. Davis and K. F. Hayes, eds., Geochemical processes at mineral surfaces. ACS Sympos. Ser. \#323, pp. 426-445.

Waite, T. D. , I. C. Wrigley, and R. Szymczak . 1988. Photoassisted dissolution of a colloidal manganese oxide in the presence of fulvic acid. Environ. Sci. Technol. 22, 778-785.

Wang, W. H. , R. Beyerle-Pfnur, and J. P. Lay . 1988. Photoreaction of salicylic acid in aquatic systems. Chemosphere 17, $1197-1204$.

Wei, K. , J. Mani , and J. N. Pitts Jr. 1967. The formation of polyenic dialdehydes in the photooxidation of pure liquid benzene. J. Amer. Chem.

Soc. 89, 4225-4227.

Weiner, E. R. and M. C. Goldberg . 1985. Aquatic photochemistry: selected topics from current research. Toxicol. Environ. Chem. 9, 327-339. Wheeler, J. 1972. Some effects of solar levels of ultra-violet radiation on lipids in artificial sea water. J. Geophys. Res. 77, $5302-5306$.

White, G. L. and R. H. Heflich . 1985. Mutagenic activation of 2-aminofluorene by fluorescent light. Teratogen. Carcinogen. Mutagen. 5, 63-73.

Wong, A. S. and D. G. Crosby . 1979. Photodecomposition of pentachlorophenol in water. J. Agric. Food Chem. 29, 125-130.

Zadelis, D. and M. S. Simmons . 1983. Effects of particulates on the photodecomposition of polynuclear aromatic hydrocarbons in aquatic systems. In M. Cooke and A. J. Dennis, eds. Polynuclear aromatic hydrocarbons: formation, metabolism, and measurement. Battelle Press, Columbus, OH. pp. 1279-1291.

Zafiriou, O. C. 1983. Natural water photochemistry. In J. P. Riley and R. Chester, eds. Chemical oceanography, Vol. 8, pp. 339-379, Academic Press, London.

Zafiriou, O. C. , J. Joussot-Dubien , R. G. Zep, and R. G. Zika . 1984. Photochemistry of natural waters. Environ. Sci. Technol. 18: 358A-371A. Zepp, R. G. 1982. Experimental approaches to environmental photochemistry. In O. Hutzinger, ed. Handbook of environmental chemistry. Springer Verlag, Berlin. Vol. 2B, pp. 19-41.

Zepp, R. G. 1988. Factors affecting the photochemial treatment of hazardous waste. Environ. Sci. Technol. 22, $256-257$.

Zepp, R. G. and D. M. Cline . 1977. Rates of direct photolysis in the aqueous environment. Environ. Sci. Technol. 11, $359-366$.

Zepp, R. G. and P. F. Schlotzhauer . 1979. Photoreactivity of selected aromatic hydrocarbons in water. In P. W. Jones and P. Leber, eds. Polynuclear aromatic hydrocarbons. Ann Arbor Sci. Pub., Ann Arbor, MI. pp. 141-158.

Zepp, R. G. and P. F. Schlotzhauer . 1983. Influence of algae on photolysis rates of chemicals in water. Environ. Sci. Technol. $17,462-468$.

Zepp, R. G. , N. L. Wolfe, J. A. Gordon, and R. C. Fincher . 1976. Light-induced transformations of methoxychlor in aquatic systems. J. Agric. Food Chem. 24, 727-733.

Zepp, R. G. , N. L. Wolfe, G. L. Baughmann, and R. C. Hollis . 1977. Singlet oxygen in natural waters. Nature 267, 421-423.

Zepp, R. G. , N. L. Wolfe, G. L. Baughman, P. F. Schlotzhauer, and J. N. Macallister . 1979. Dynamics of processes influencing the behavior of hexachlorocyclopen-tadiene in the aquatic environment. Abstr. Papers, 178th Mtg. Amer. Chem. Soc., ENVR-042.

Zepp, R. G. , G. L. Baughman, and P. F. Schlotzhauer . 1981a. Comparison of photochemical behavior of various humic substances in water. 1. Sunlight induced reactions of aquatic pollutants photosensitized by humic substances. Chemosphere 10, 109-117.

Zepp, R. G. , G. L. Baughman, and P. F. Schlotzhauer . 1981b. Comparison of photochemical behavior of various humic substances in water. 2. Photosensitized oxygenations. Chemosphere 10, 119-126.

Zepp, R. G. , J. Hoigné , and H. Bader . 1987a. Nitrate-induced photooxidation of trace organic chemicals in water. Environ. Sci. Technol. 21, 443-450.

Zepp, R. G. , Y. I. Skurlatov, and J. T. Pierce . 1987b. Algal-induced decay and formation of hydrogen peroxide in water: its possible role in oxidation of anilines by algae. In Zika, R. G. and Cooper, W. J. , eds. Aquatic photochemistry, Amer. Chem. Soc. Sympos. Ser. 327, $215-224$. Zepp, R. G. , A. M. Braun , J. Hoigné, and J. A. Leenheer . 1987c. Photoproduction of the hydrated electron from natural organic solutes in aquatic environments. Environ. Sci. Technol. 21: 485-490.

\section{Molecular Reactions: The Diels-Alder and other reactions}

Breslow, R. , U. Maitra, and D. Rideout . 1983. Selective Diels-Alder reactions in aqueous solutions and suspensions. Tetrahedron Lett. 24: 1901-1904.

Collet, C. and P. Laszlo . 1991. Clay catalysis of the non-aqueous Diels-Alder reaction and the importance of humidity control. Tetrahedron Lett. 32: 2905-2908.

Dessau, R. M. 1986. Catalysis of Diels-Alder reactions by zeolites. J. Chem. Soc. Chem. Commun. 1167-1168.

Grieco, P. A. , P. Garner, K. Yoshida, and J. C. Huffman . 1983. Aqueous intermolecular Diels-Alder chemistry: novel products derived from substituted benzoquinone-diene carboxylate adducts via tandem Michael reactions. Tetrahedron Lett. 24, 3807-3810.

Inukai, T. and T. Kojima . 1971. Aluminum chloride catalyzed diene condensation. J. Org. Chem. 36: 924-928.

Ipaktschi, J. 1986. Diels-Alder reaction in the presence of zeolite. Z. Naturforsch. 41b: 496-498.

Laszlo, P. and J. Lucchetti . 1984. Catalysis of the Diels-Alder reaction in the presence of clays. Tetrahedron Lett. 25: 1567-1570. 
Laszlo, P. and H. Moison . 1989. Catalysis of Diels-Alder reactions with acrolein as dienophile by iron(III)-doped montmorillonite. Chem. Lett. 1031-1034.

Mingelgrin, U. and S. Salzman . 1979. Surface reactions of parathion on clays. Clays Clay Min. 27, 72-78.

Pakdel, H. , C. Roy , H. Aubin , G. Jean , and S. Coulombe . 1991. Formation of $d l$ - limonene in used tire vacuum pyrolysis oils. Environ. Sci. Technol. 25: 1646-1649.

Philp, R. P. , J. R. Maxwell , and G. Eglinton . 1976. Environmental geochemistry of aquatic sediments. Sci. Progr. (Oxf.) 63: 521-545.

Sieskind, O. and P. Albrecht . 1985. Efficient synthesis of rearranged cholest-13(17)-enes catalysed by montmorillonite clay. Tetrahedron Lett. 26: 2135-2136.

Voudrias, E. A. and M. Reinhard . 1986. Abiotic organic reactions at mineral surfaces: a review. In J. A. Davis and K. F. Hayes , eds., Geochemical processes at mineral surfaces. Amer. Chem. Soc. Sympos. Ser. 323: 462-486. 